Chemical Technology

ANL-01/23

Division

Chemical Technology

Division

Chemical Technology

Division

Chemical Technology

Division

Chemical Technology Division

Chemical Technology

Division

Chemical Technology

Division

Chemical Technology

Division

Chemical Technology

Division

Chemical Technology

Division

Chemical Technology

Division

Chemical Technology

Division

Chemical Technology

Division

Chemical Technology

Division

Chemical Technology

Division

Chemical Technology

Division

Division

\title{
Development of an Improved 2-cm Centrifugal Contactor for Cesium Removal from High-Level Waste
}

by R. A. Leonard

S. B. Aase

H. A. Arafat

C. Conner

J. R. Falkenberg

G. F. Vandegrift

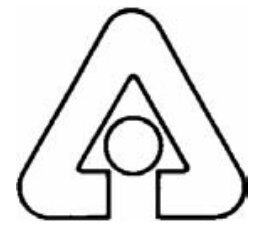

Argonne National Laboratory, Argonne, Illinois 60439

operated by The University of Chicago

for the United States Department of Energy under Contract W-31-109-Eng-38

Chemical Technology

Division

Chemical Technology

Division

Chemical Technology

Division

Chemical Technology

Division 
Argonne National Laboratory, with facilities in the states of Illinois and Idaho, is owned by the United States government, and operated by The University of Chicago under the provisions of a contract with the Department of Energy.

\section{DISCLAIMER}

This report was prepared as an account of work sponsored by an agency of the United States Government. Neither the United States Government nor any agency thereof, nor any of their employees, makes any warranty, express or implied, or assumes any legal liability or responsibility for the accuracy, completeness, or usefulness of any information, apparatus, product, or process disclosed, or represents that its use would not infringe privately owned rights. Reference herein to any specific commercial product, process, or service by trade name, trademark, manufacturer, or otherwise, does not necessarily constitute or imply its endorsement, recommendation, or favoring by the United States Government or any agency thereof. The views and opinions of authors expressed herein do not necessarily state or reflect those of the United States Government or any agency thereof. 
ANL-01/23

ARGONNE NATIONAL LABORATORY

9700 South Cass Avenue

Argonne, IL 60439

DEVELOPMENT OF AN IMPROVED 2-CM CENTRIFUGAL CONTACTOR FOR CESIUM REMOVAL FROM HIGH-LEVEL WASTE

by

R. A. Leonard, S. B. Aase, H. A. Arafat, C. Conner, J. R. Falkenberg, and G. F. Vandegrift

Chemical Technology Division

September 2001 


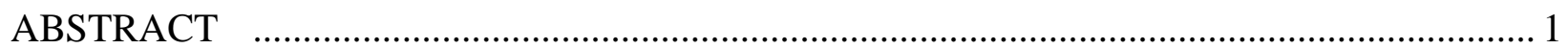

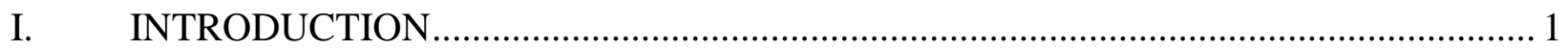

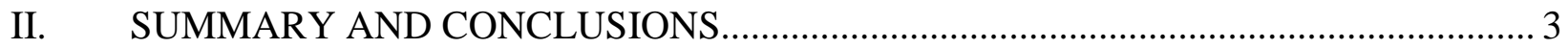

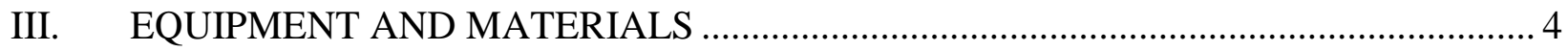

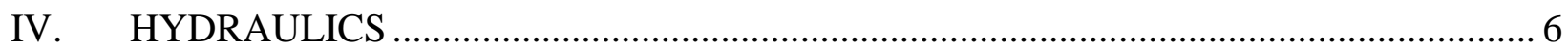

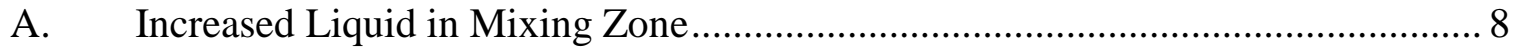

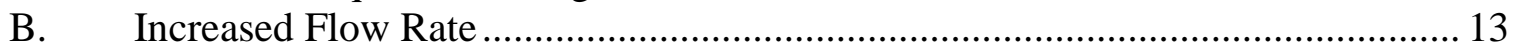

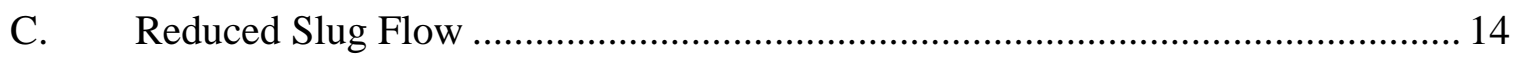

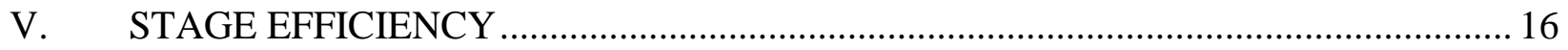

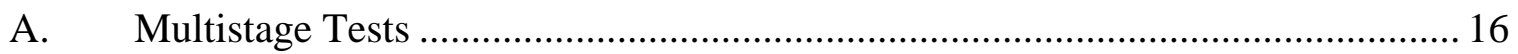

B. Equilibrium Distribution Ratios for Cs ......................................................... 19

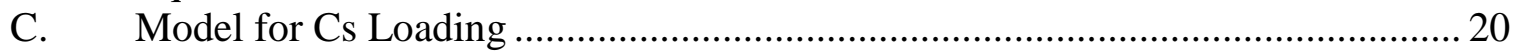

D. Calculation of Stage Efficiency..................................................................... 21

E. Metal Ions in the Aqueous Strip Effluent........................................................... 21

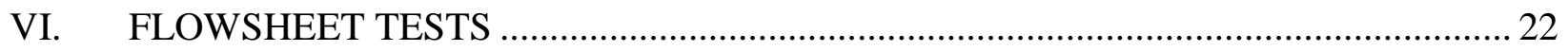

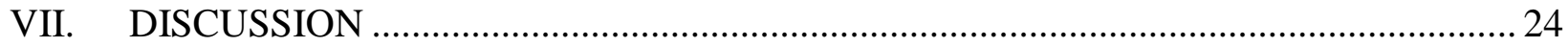

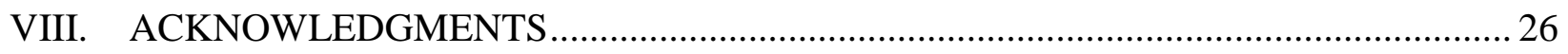

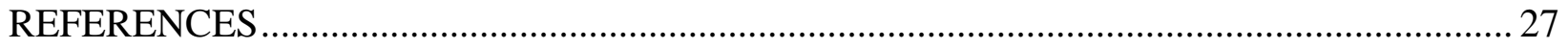

APPENDIX A. FURTHER DETAILS OF HYDRAULIC TESTS USING THE

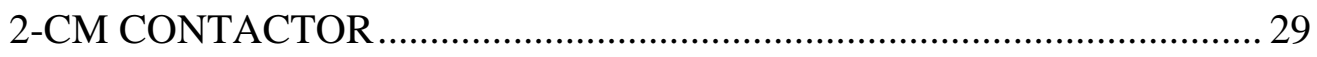

APPENDIX B. FURTHER DETAILS OF THE STAGE EFFICIENCY TESTS .................... 32

APPENDIX C. FURTHER DETAILS OF THE CSSX FLOWSHEET TESTS ...................... 36

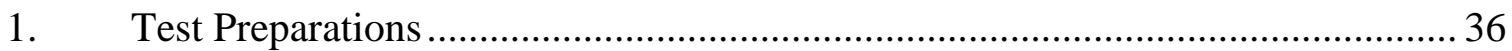

2. $\quad$ Measurements and Observations during the Tests ................................................ 38

3. Measurements and Observations after the Tests ................................................50 


\section{LIST OF FIGURES}

No.

$\underline{\text { Title }}$

$\underline{\text { Page }}$

1. Schematic of Operating Contactor Stage ................................................................ 2

2. Structure of the BOBCalixC6 Extractant ................................................................. 5

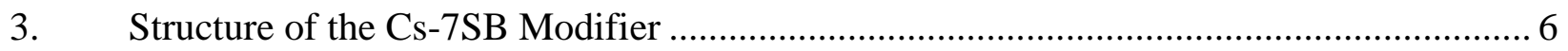

4. Effect of O/A Flow Ratio and Single-stage vs. Multistage Operation on Stage Efficiency for the 2-cm Centrifugal Contactor ..................................................... 7

5. Effect of Water Flow Rate and Contactor Geometry on Liquid Height in Annular Mixing Zone

6. Photo Taken Using Automatic Flash of Water Flowing through Modified 2-cm Contactor at $50 \mathrm{~mL} / \mathrm{min}$

7. Photo Taken Using Available Light of Water Flowing through Modified 2-cm Contactor at $50 \mathrm{~mL} / \mathrm{min}$ 12

8. CSSX Flowsheet with Total Flow Rate in the Extraction Section of $60 \mathrm{~mL} / \mathrm{min}$ 13

9. Wire Rope in Effluent Line. 15

10. Flowsheet for Stage Efficiency Test of the Extraction Section (Test CS20)..... 17

11. Flowsheet for Stage Efficiency Test of the Scrub Section (Test CS21) 17

12. Flowsheet for Stage Efficiency Test of the Strip Section (Test CS22)... 18

13. Aqueous Interstage Line during Test CS20 ......

14. Decontamination Factor vs. Time for CSSX Flowsheet Test with Solvent Recycle (CS25)

15. Concentration Factor vs. Time for CSSX Flowsheet Test with Solvent Recycle (CS25)

16. Stripping Factor vs. Time for CSSX Flowsheet Test with Solvent Recycle (CS25)

17. Electronic Balance Being Used for Measurements of Feed Flow Rates. 37

18. Liquid Level Changes in the Organic Interstage Line from Stage 3 to Stage 4 during CSSX Flowsheet Test CS25. 


\section{LIST OF TABLES}

No.

$\underline{\text { Title }}$

$\underline{\text { Page }}$

1. Composition of Average SRS Simulant 5

2. Cesium Distribution Ratios from Batch-Equilibrium Measurements for Stage Efficiency Tests. 20

3. Stage Efficiency for Multistage Operation. 21

4. Composition of the Aqueous Strip Effluent during Stage Efficiency Test CS22

5. Effect of Water Flow Rate and Contactor Geometry on Liquid Height in the Annular Mixing Zone

6. Results of Two-Phase Flow Tests in Single-Stage 2-cm Contactor. 30

7. Effluent Samples Taken during Stage Efficiency Tests 33

8. Amount of Liquid in Interstage Lines during Stage Efficiency Tests........................... 34

9. Stage Samples Taken after Stage Efficiency Tests 34

10. Feed and Effluent Streams during Stage Efficiency Tests 35

11. $\mathrm{D}_{\mathrm{Cs}}$ Values from Batch-Equilibrium Measurements for Flowsheet Tests 36

12. Aqueous (DW) Raffinate for the CSSX Flowsheet Tests 40

13. Aqueous Strip (EW) Effluent for the CSSX Flowsheet Tests 41

14. Organic Strip (EP) Effluent for the CSSX Flowsheet Tests ..... 42

15. Summary of the Aqueous and Organic Flow Rates for the CSSX Flowsheet Tests 43

16. Summary of the Cesium Concentrations for the CSSX Flowsheet Tests 44

17. Room Temperature during CSSX Flowsheet Tests 45

18. Stage Temperatures during CSSX Flowsheet Test CS24 . 45

19. Stage Temperatures during the CSSX Flowsheet Test CS25 46 


\section{LIST OF TABLES (cont'd.)}

No.

Title

$\underline{\text { Page }}$

20. Liquid Levels in Aqueous Interstage Lines during CSSX Flowsheet Tests .................. 47

21. Liquid Levels in Organic Interstage Lines during CSSX Flowsheet Tests 48

22. Stage Samples Taken after CSSX Flowsheet Test CS23 ......................................... 51

23. Stage Samples Taken after the CSSX Flowsheet Test CS24 ....................................52

24. Stage Samples taken after the CSSX Flowsheet Test CS25 ....................................53

25. Composition of the Aqueous Strip Effluent for the CSSX Flowsheet Tests ...................54

26. Composition of the SRS Simulant for the CSSX Flowsheet Tests ............................... 55 


\title{
DEVELOPMENT OF AN IMPROVED 2-CM CENTRIFUGAL CONTACTOR FOR CESIUM REMOVAL FROM HIGH-LEVEL WASTE
}

\author{
by
}

R. A. Leonard, S. B. Aase, H. A. Arafat, C. Conner, J. R. Falkenberg, and G. F. Vandegrift

\begin{abstract}
To test a caustic-side solvent extraction (CSSX) process for the removal of cesium from Savannah River Site (SRS) high-level waste, an improved minicontactor (2-cm centrifugal contactor) was needed. In particular, the stage efficiency had to be improved from $60 \%$ to greater than $80 \%$ to achieve the SRS process requirements in a 32 -stage minicontactor. To find out how to improve stage efficiency, the hydraulic performance of a single-stage minicontactor was evaluated. On the basis of these tests, we made changes to the contactor that increased the stage efficiency from 60 to $90 \%$. As a result of these changes and a modest level of temperature control, the first fully successful tests of the CSSX flowsheet were completed.
\end{abstract}

\section{INTRODUCTION}

The Argonne centrifugal contactor was developed in the early 1970s for carrying out solvent extraction operations required in the nuclear industry [BERNSTEIN-1973]. A schematic of a contactor, given in Fig. 1, shows where the more-dense phase (typically the aqueous phase) and the less-dense phase (typically the organic phase) enter and exit the unit. Detailed discussion of contactor operation can be found elsewhere [BERNSTEIN-1973, LEONARD-1980]. A typical solvent extraction flowsheet contains multistage extraction/scrub sections that recover selected elements from the waste feed stream and multistage strip/wash sections that separate those elements from each other and the solvent.

In the contactor discussed here, the rotor has a $2-\mathrm{cm}$ diameter (hence the name " $2-\mathrm{cm}$ centrifugal contactor"). The 2-cm contactor was first tested and found to be limited in that it did not work well at organic-to-aqueous (O/A) flow ratios below 0.8 [LEONARD-1980]. However, the small volume of feed needed for flowsheet tests in the 2-cm contactor (typically, 1 to $2 \mathrm{~L}$ instead of the 10 to $20 \mathrm{~L}$ needed for the 4-cm contactor) makes it very attractive when feed is in short supply, hard to obtain, or expensive. This also minimizes the waste generated during laboratory tests. As a result, we developed an improved 2-cm contactor that can work at all O/A flow ratios [LEONARD-1997]. 


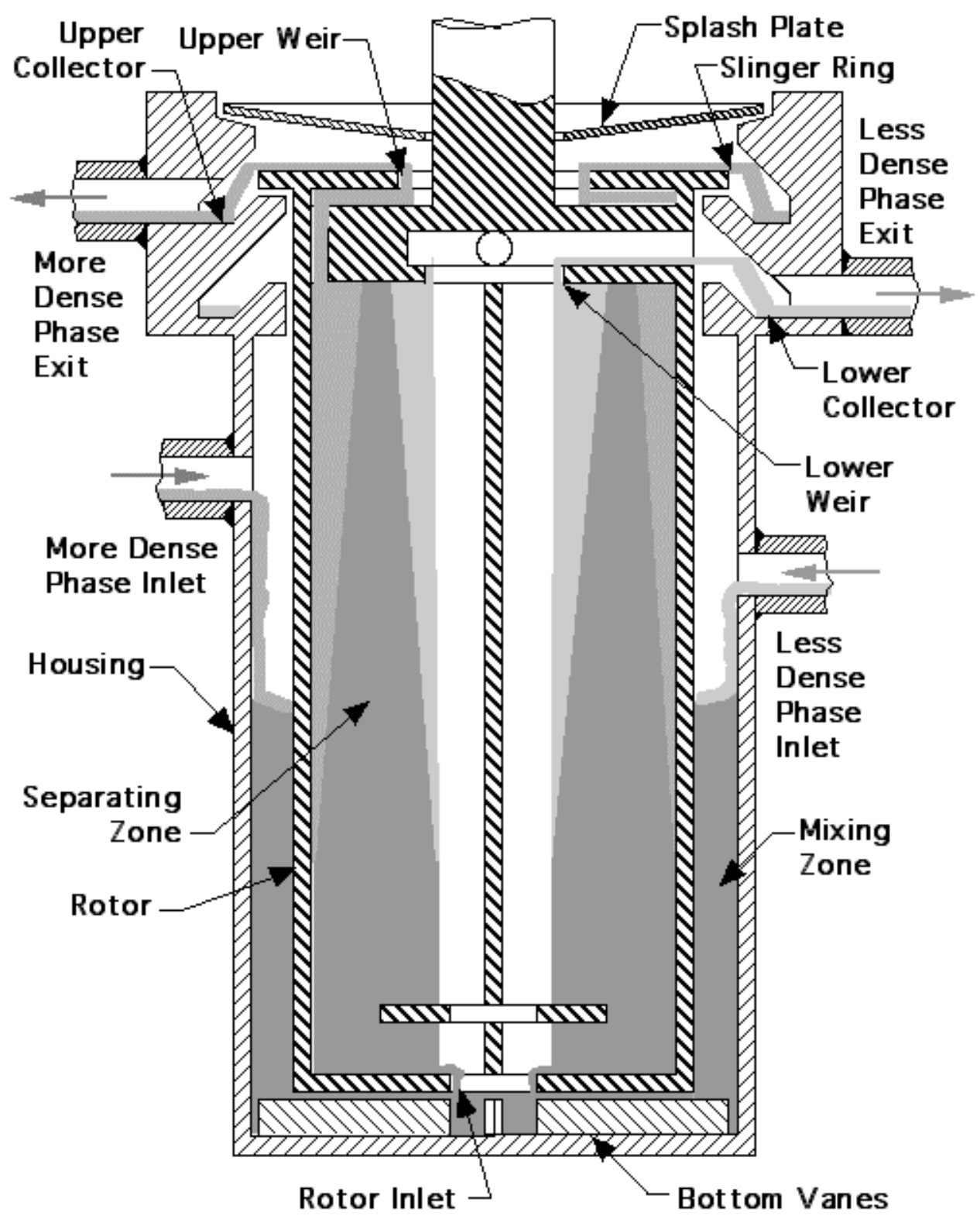

Fig. 1. Schematic of Operating Contactor Stage

Work performed at Argonne National Laboratory (ANL) in FY1998 using a new causticside solvent extraction (CSSX) process showed that cesium can be extracted from simulants representative of the high-level waste at Savannah River Site (SRS) [LEONARD-1999A, 2001A]. This problem is important as SRS has 34 million gallons of high-level waste in 48 tanks that need to be decontaminated [LEVENSON-2000]. As a part of this process, the cesium will be removed from waste containing both supernatant liquid and dissolved salt cake, then vitrified for disposal. After the cesium is removed, the resultant solution will be immobilized in low-level grout. 
The ANL tests showed that, while the process worked, the solvent needed improvement, and the stage efficiency in the 2-cm centrifugal contactor was less than desired. The solvent was subsequently improved at Oak Ridge National Laboratory (ORNL) in FY1999 [BONNESEN2000], and as reported here, we improved contactor hydraulics so that the stage efficiency of the 2 -cm contactor was increased from 60 to $90 \%$. These improvements were verified in 4-stage contactor tests. Then, with the improved ORNL solvent, the higher stage efficiency, and a temperature control plan, we demonstrated that the CSSX flowsheet can remove cesium from a high-level SRS simulant in a 32-stage contactor. In particular, we achieved the two key process goals: (1) the cesium was removed from the waste with decontamination factors greater than 40,000 , and (2) the recovered cesium was concentrated by a factor of 15 in dilute nitric acid.

This work is part of the integrated scope of work supporting the SRS High Level Waste Salt Processing Project (SPP). The work was performed in collaboration with Savannah River Technology Center (SRTC) and ORNL. Personnel at SRTC are performing tests with real waste, including batch solvent extraction and solvent irradiation. At the time the work reported here was done, SRTC personnel were planning for a CSSX flowsheet test with real waste in the 2-cm centrifugal contactor. This test has now been successfully completed [CAMPBELL-2001]. Personnel at ORNL are responsible for solvent development and commercialization. They are also evaluating the effect of heat and irradiation on the solvent so that solvent cleanup methods can be developed. The development of this improved 2-cm contactor is a key part of the solvent extraction effort as it allows the first full tests of the CSSX process.

In the overall SPP work, the CSSX process was being compared with two alternatives that also remove cesium from tank waste. These processes were (1) small tank tetraphenylborate precipitation (STTP), where tetraphenylborate was used to precipitate out the cesium in small tanks, and (2) crystalline silicotitanate ion exchange (CST IX), where crystalline silicotitanate was used to remove the cesium in packed beds [LEVENSON-2000]. In July 2001, the CSSX process was chosen as the basis for the cesium removal component of a plant designed to treat all the SRS tank waste.

\section{SUMMARY AND CONCLUSIONS}

Several changes were made to improve stage efficiency in the 2-cm centrifugal contactor. These changes were to (1) increase the liquid in the mixing zone, (2) maintain the low aqueous flow rates in the stripping section above $2 \mathrm{~mL} / \mathrm{min}$, and (3) minimize slug flow in the interstage lines. These three changes increased stage efficiency in multistage operation of the $2-\mathrm{cm}$ contactor from 60 to $90 \%$.

With this high-efficiency 2-cm contactor and a modest level of temperature control, the proof-of-principle flowsheet tests for the CSSX process were demonstrated with and without solvent recycle. The solvent was cycled four times in the recycle test. In both cases, the key process goals required by SRS were achieved: (1) the cesium was removed from the waste feed with a decontamination factor greater than 40,000, and (2) the recovered cesium was stripped from the solvent and concentrated by a factor of 15. A report giving the results of these tests has 
already been published [LEONARD-2000]. The results from that report are summarized here. In addition, many test details that were not in the earlier report are included here as Appendix C.

On the basis of the success of these proof-of-concept tests, further tests were done at ANL and SRS. In these tests, the solvent was recycled 28 to 42 times in order to investigate long-term effects, especially the buildup of degradation products in the solvent. In March 2001, Argonne National Laboratory did a three-day test with SRS simulant [LEONARD-2001B], and Savannah River Site did a two-day test with real waste from the SRS tanks [CAMPBELL-2001]. Both tests also met process goals.

\section{EQUIPMENT AND MATERIALS}

The equipment used in this work was a 32-stage 2-cm annular centrifugal contactor located in a glovebox at ANL. The contactors, which are manufactured in banks of four stages, were built at ANL (ANL print number CMT-E1265, January 1994). They were modified as discussed below to improve stage efficiency.

Highly alkaline simulant for tank waste (supernate liquid plus dissolved salt cake) was prepared using [PETERSON-2000] and is designated "SRS simulant" or "average SRS simulant." Its composition is given in Table 1 . The simulant was spiked with up to $0.5 \mathrm{mCi} / \mathrm{L}$ of Cs-137. The simulant was the aqueous feed to the extraction section. The scrub feed was 0.05 $\underline{\mathrm{M}} \mathrm{HNO}_{3}$, and the strip feed was $0.001 \mathrm{M} \mathrm{HNO}_{3}$. The SRS simulant and both acid feeds were prepared at ANL. The solvent, which was prepared at ORNL and shipped to ANL, had four components: (1) an extractant, calix[4]arene-bis(tert-octylbenzo-crown-6), designated BOBCalixC6, which is a calixarene crown that is very specific for cesium extraction, (2) a modifier, 1-(2,2,3,3,-tetrafluoropropoxy)-3-(4-sec-butylphenoxy)-2-propanol, also called Cs$7 \mathrm{SB}$, which is an alkyl aryl polyether that keeps the extractant dissolved in the solvent and increases the ability to extract cesium in the extraction section, (3) a suppressant, trioctylamine (TOA), which suppresses effects from organic impurities to ensure that the cesium can be back extracted from the solvent in the strip section, and (4) a diluent, Isopar ${ }^{\circledR} \mathrm{L}$, which is a mixture of branched hydrocarbons. The structure of the BOBCalixC6, which has a molecular weight of $1149.52 \mathrm{~g} / \mathrm{mol}$, is given in Fig. 2. The structure of Cs-7SB, which has a molecular weight of $338.34 \mathrm{~g} / \mathrm{mol}$, is given in Fig. 3. The solvent composition is $0.01 \underline{\mathrm{M}}$ BOBCalixC6, $0.50 \mathrm{M}$ Cs7SB, and $0.001 \underline{\mathrm{M}}$ TOA in Isopar ${ }^{\circledR} \mathrm{L}$ and is designated the "CSSX solvent." 
Table 1. Composition of Average SRS Simulant

\begin{tabular}{|c|c|c|c|}
\hline Component & Conc., mol/L & Component & Conc., $\mathrm{mg} / \mathrm{L}$ \\
\hline $\mathrm{Na}^{+}$ & 5.6 & $\mathrm{Cu}$ & 1.44 \\
\hline $\mathrm{K}^{+}$ & 0.015 & $\mathrm{Cr}$ & 75 \\
\hline $\mathrm{Cs}^{+}$ & $0.00014^{\mathrm{a}}$ & $\mathrm{Ru}$ & 0.82 \\
\hline $\mathrm{OH}^{-}$ & 2.06 & $\mathrm{Pd}$ & 0.41 \\
\hline $\mathrm{NO}_{3}{ }^{-}$ & 2.03 & $\mathrm{Re}$ & 0.21 \\
\hline $\mathrm{NO}_{2}{ }^{-}$ & 0.50 & $\mathrm{Zn}$ & 1.44 \\
\hline $\mathrm{AlO}_{2}{ }^{-}$ & 0.28 & $\mathrm{Sn}$ & 8 \\
\hline $\mathrm{CO}_{3}{ }^{2-}$ & 0.15 & $\mathrm{Hg}$ & 2.4 \\
\hline $\mathrm{SO}_{4}{ }^{2-}$ & 0.14 & $\mathrm{~Pb}$ & 0.05 \\
\hline $\mathrm{Cl}^{-}$ & 0.024 & Ag & 2.1 \\
\hline $\mathrm{F}^{-}$ & 0.028 & Tri-n-butyl phosphate (TBP) & 0.01 \\
\hline $\mathrm{PO}_{4}{ }^{3-}$ & 0.007 & Di-n-butyl phosphate (DBP) & 25 \\
\hline $\mathrm{C}_{2} \mathrm{O}_{4}{ }^{2-}$ & 0.008 & Mono-n-butyl phosphate (MBP) & 25 \\
\hline $\mathrm{SiO}_{3}{ }^{2-}$ & 0.03 & n-Butanol & 2 \\
\hline $\mathrm{MoO}_{4}{ }^{2-}$ & 0.000078 & Formate & 1500 \\
\hline $\mathrm{NH}_{3}$ & 0.001 & Tri-methylamine (TMA) & 10 \\
\hline & & & \\
\hline
\end{tabular}

a This is the total cesium concentration in the average SRS tank waste. In addition, Cs137 was added at a tracer level of $0.5 \mathrm{mCi} / \mathrm{L}$ or less. For the composition of the average SRS tank waste, Cs-137 is $22.6 \%$ of the total cesium.

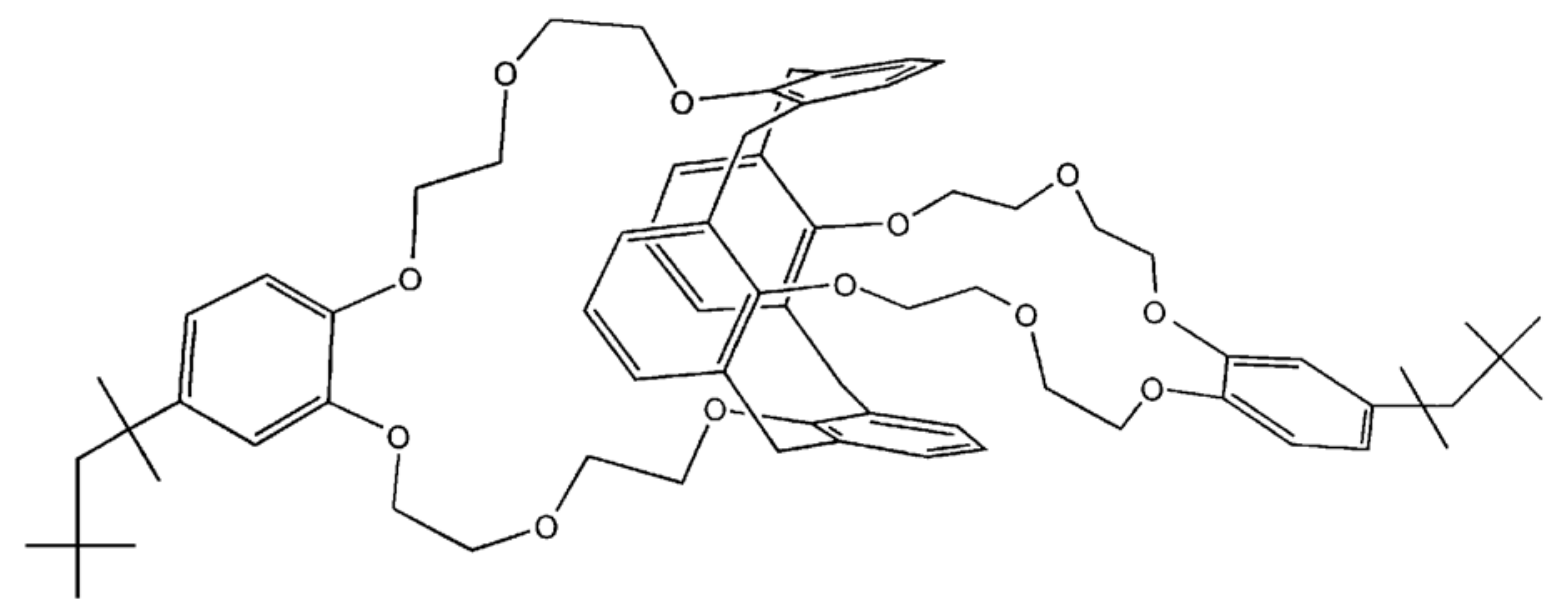

Fig. 2. Structure of BOBCalixC6 Extractant 


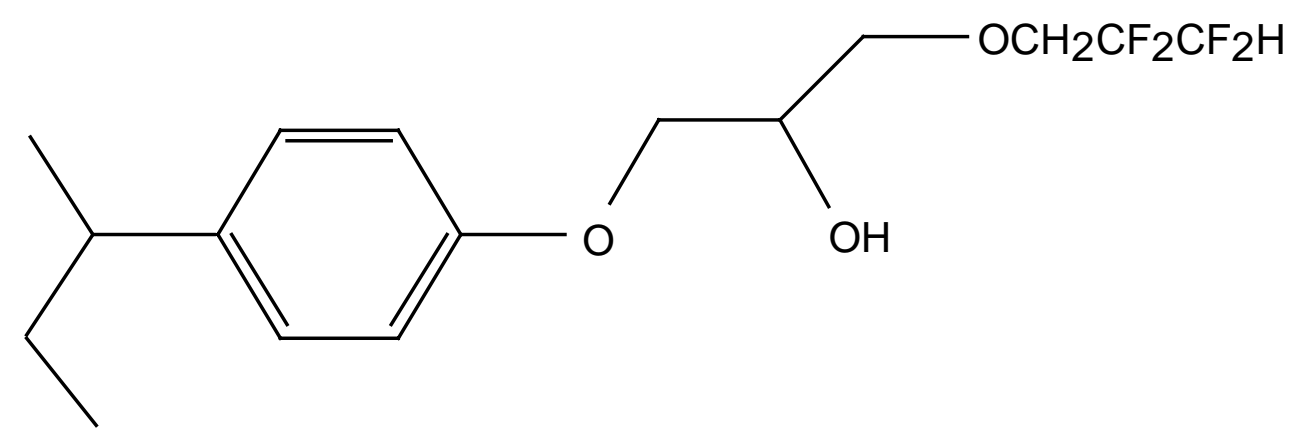

Fig. 3. Structure of Cs-7SB Modifier

In preliminary tests, we used three alkaline solutions that were simpler than the average SRS simulant in Table 1. Alkaline simulant I was very simple, $1 \mathrm{M} \mathrm{NaOH}$, and had a density of $1.081 \mathrm{~g} / \mathrm{L}$. Alkaline simulant II had the same density $(1.258 \mathrm{~g} / \mathrm{L})$ and $\mathrm{NaOH}$ concentration as the average SRS simulant with the minimum number of components. It consisted of $2 \mathrm{M} \mathrm{NaOH}$ and $3.64 \underline{\mathrm{M}} \mathrm{NaNO}_{3}$. Alkaline simulant III had most of the components of the average SRS simulant but was missing the $\mathrm{NaNO}_{3}$ as well as two of the trace organics (TMA and MBP).

\section{HYDRAULICS}

Earlier work suggests that hydraulics affects the stage efficiency of the 2-cm contactor [LEONARD-1999A]. This work, which is summarized in Fig. 4, indicates that stage efficiency depends on (1) O/A flow ratio and (2) single-stage vs. multistage operation. The data for singlestage operation are correlated by

$$
E_{a}=1-0.15 \bullet\left|\log _{10} R\right|
$$

where $E_{a}$ is the fractional stage efficiency, $R$ is the O/A flow ratio, and the correlation coefficients were obtained by a least-squares fit of single-stage data. The data for multistage operation are correlated by

$$
E_{a}=0.80-0.17 \bullet\left|\log _{10} R\right|
$$

where the correlation coefficients were obtained by a least-squares fit of the "original" multistage data in Fig. 4. 


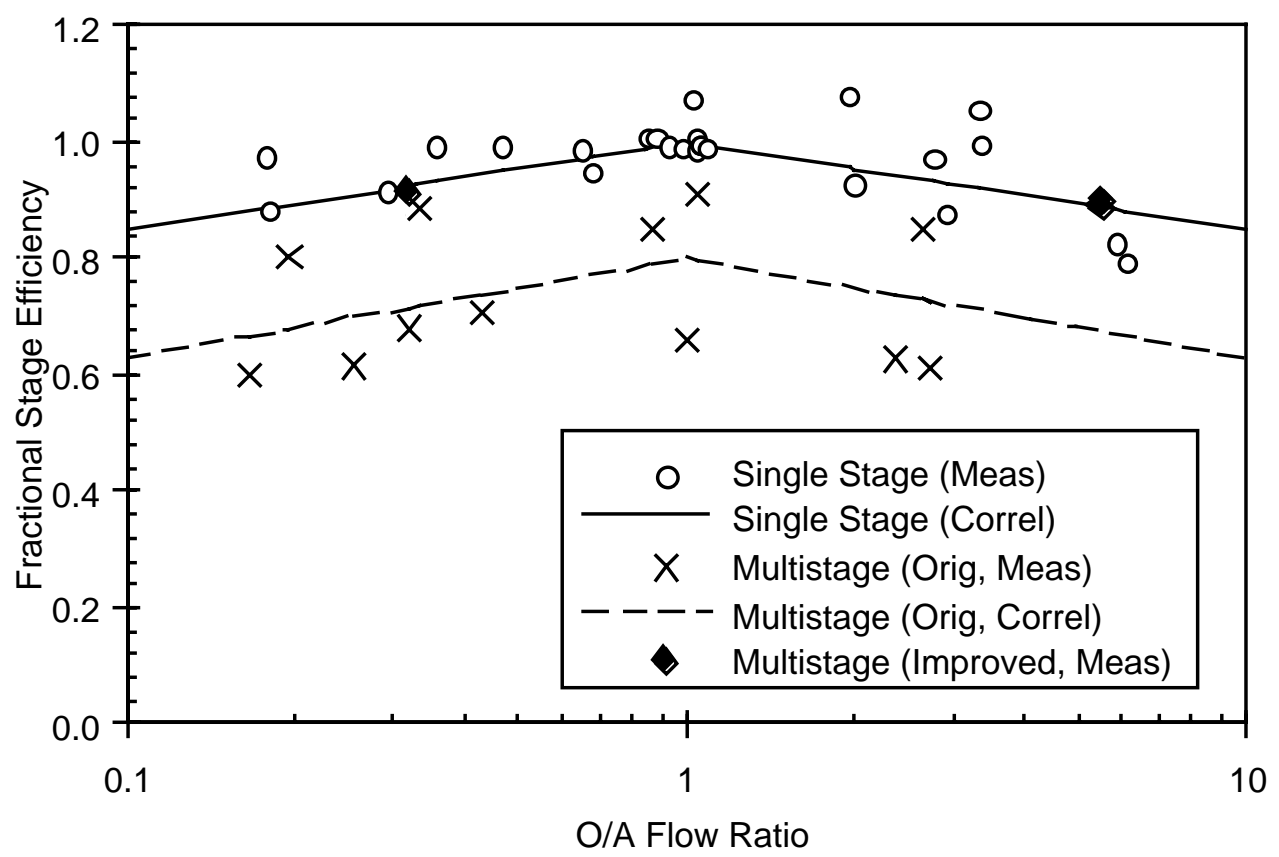

Fig. 4. Effect of O/A Flow Ratio and Single-stage vs. Multistage Operation on Stage Efficiency for the 2-cm Centrifugal Contactor

A well-designed annular centrifugal contactor has sufficient mixing energy per unit volume and residence time in the annular mixing zone to give a mass transfer efficiency of 98 to $100 \%$ in each contactor stage. However, to achieve this high efficiency, the two liquid phases must flow steadily into the mixing zone. This is the case as long as the fluid momentum (inertial forces) controls the liquid flows [LEONARD-1999A]. However, at low flow rates (less than about $100 \mathrm{~mL} / \mathrm{min}$ ), surface tension forces can be greater than the fluid momentum (inertial forces). When this happens, the liquid moves through the interstage line and enters the annular mixing zone as discrete slugs of liquid rather than a continuous liquid flow. When this happens, the actual O/A ratio in the mixing zone fluctuates significantly about the average value for the overall process. As a result, even though the actual stage efficiency is close to $100 \%$, the measured stage efficiency can be significantly lower. As the volume of the slug and the time between slugs increases, the apparent stage efficiency decreases.

For laboratory-scale centrifugal contactors, such as the 2-cm contactor (which has a nominal throughput of $40 \mathrm{~mL} / \mathrm{min}$ ), operation is entirely in the slug-flow regime. This problem is small for single-stage operation since pumps ensure a fairly uniform flow rate to the stage. However, even there, liquid will enter the annular mixing zone as small slugs or droplets when flow rates are sufficiently low, so that surface tension and gravity forces become important. The expected stage efficiency for the 2-cm contactor is 98 to $99 \%$ for continuous flow into the annular mixing zone. As shown in Fig. 4, this value is attained for single-stage operation at an $\mathrm{O} / \mathrm{A}$ flow ratio near 1 . As the $\mathrm{O} / \mathrm{A}$ flow ratio moves away from 1 , either higher or lower, the apparent stage efficiency drops off, reaching $85 \%$ at $\mathrm{O} / \mathrm{A}$ of 10 or 0.1 . The actual stage efficiency probably stays high, however, as a slug of one phase enters, there is relatively less of 
the other phase present. Since the other-phase volume is less, the amount that can be extracted from it is also less.

With multistage operation of the 2-cm contactor, the problem becomes more severe. The momentum of the liquid spun out of the rotor is dissipated in the collector ring. This liquid is then held in the collector ring until gravity can overcome the surface tension. The liquid then exits the collector ring and flows through the interstage line as a slug. These slugs of liquid can have a volume that is on the same order of magnitude as the mixing zone of the 2-cm contactor, i.e., about $2 \mathrm{~mL}$. If the flow rate is $2 \mathrm{~mL} / \mathrm{min}$, then there will be one slug moving through the interstage line every minute. These large slugs during interstage flow give an even lower apparent stage efficiency for the 2-cm contactor during multistage operation. At an O/A flow ratio of 1 , the stage efficiency is about $80 \%$. As the $\mathrm{O} / \mathrm{A}$ flow ratio moves away from 1 , either higher or lower, the apparent stage efficiency drops off, reaching 63\% at O/A of 10 or 0.1 .

Since the CSSX process has to concentrate the recovered cesium by a factor of 15 , the O/A flow ratio in the extraction section must be low (for example, 0.3), while that in the strip section must be high (for example, 4.5). Thus, in both the extraction and strip sections, the contactor is being operated in a region that is far from its maximum stage efficiency. In the CSSX tests done earlier using a 24-stage 2-cm contactor [LEONARD-1999A], the apparent stage efficiency in these sections was around $60 \%$. For the tests reported here, we used a 32stage $2-\mathrm{cm}$ contactor. With 32 stages, we needed to achieve a stage efficiency of $80 \%$ or greater to meet the goals for the CSSX process. Based on our understanding of the hydraulics in the 2$\mathrm{cm}$ contactor, we proposed three changes to increase the apparent stage efficiency to $80 \%$ or greater. First, a change was made to the rotor to increase the liquid in the mixing zone. Second, contactor hydraulics were tested to determine if the contactor could be operated above its nominal throughput of $40 \mathrm{~mL} / \mathrm{min}$ (total flow) for the extraction section. Third, a change was made to the interstage lines to reduce slug flow.

\section{A. Increased Liquid in Mixing Zone}

If more liquid can be retained in the mixing zone, a discrete droplet or slug of liquid entering the annular mixing zone will have less impact on the O/A flow ratio in the mixing zone. This will increase the apparent stage efficiency. The liquid in the mixing zone can be increased by widening the diameter of the inlet at the bottom of the rotor. In the past, this diameter has always been small enough to pump the liquid up to the organic (less-dense-phase) weir. A rotor of this design is said to be "fully pumping." For a fully pumping rotor, the liquid in the annular mixing zone has a certain height that is a function of the liquid flow rate, the annular gap, the number of bottom vanes, the height of the bottom vanes, and the gap between the bottom vanes and the rotor. When the diameter of the rotor inlet exceeds a certain value, the liquid in the separating zone cannot be pumped as high as the organic (less-dense-phase) weir. A rotor of this design is said to be "partially pumping." For a partially pumping rotor, the liquid in the mixing zone not only has its normal height, but also an additional height required to boost the liquid inside the rotor to the top. Thus, by making a rotor partially pumping, more liquid will stay in the mixing zone. 
When the rotor is spinning, the hydrostatic head inside the rotor must balance the difference in centrifugal forces at the organic weir and the rotor inlet. Solving this force balance for the hydrostatic head gives

$$
b=\frac{\omega^{2}}{2 g}\left(r_{o}^{2}-r_{b}^{2}\right)
$$

where $b$ is the hydrostatic head in $\mathrm{m}, \mathrm{g}$ is the gravitational acceleration in $\mathrm{m} / \mathrm{s}^{2}, \mathrm{r}_{\mathrm{b}}$ is the radius of the rotor inlet in $\mathrm{m}, \mathrm{r}_{\mathrm{o}}$ is the radius to the liquid over the lower (organic) weir in $\mathrm{m}$, and $\omega$ is the rotor speed in $\mathrm{rad} / \mathrm{s}$. For the base-case 2 -cm contactor, which has a rotor inlet diameter of 7.92 $\mathrm{mm}(0.312 \mathrm{in}$.), a lower weir diameter of $12.23 \mathrm{~mm}(0.4815 \mathrm{in}$.), and a rotor speed of $377 \mathrm{rad} / \mathrm{s}$ (3600 rpm), the hydrostatic head calculated from Eq. 3 is $157.1 \mathrm{~mm}$ if there is no liquid flow. Since the height of the lower weir above the rotor inlet is $67.3 \mathrm{~mm}$, the base-case 2-cm contactor has a fully pumping rotor. The locations of the lower weir and the rotor inlet are shown in Fig. 1.

On the basis of this information, we increased the rotor inlet diameter to $10.72 \mathrm{~mm}$ (0.422 in.). This dropped the hydrostatic head to $62.8 \mathrm{~mm}$ so that the rotor is now partially pumping and gives an additional $4.5 \mathrm{~mm}$ of liquid height in the mixing zone at no-flow conditions. When the flow rate increases over the lower weir, the liquid surface moves higher over the weir and $r_{o}$ decreases. This causes $b$ to decrease and increases the liquid height in the mixing zone outside the rotor.

A second way to increase liquid height in the annular mixing zone is to increase the gap between the top of the bottom vanes and the bottom of the rotor. This gap, which can be seen in Fig. 1, is typically small. This is a qualitative observation; there is no correlation or model. This method can be used for a fully pumping rotor. A large gap is generally not used because it increases the liquid holdup under the rotor and thus, at least for existing units, increases the gap between the slinger ring on the rotor and the lip of the upper (aqueous) collector ring. As the gap grows larger, aqueous phase splashes through this gap, moving into the lower (organic) collector ring and so into the organic effluent. For the base case in this study, the bottom gap was $1.2 \mathrm{~mm}$ (3/64 in.) with an error of $\pm 0.4 \mathrm{~mm}$ (1/64 in.). The large bottom gap was $2.0 \mathrm{~mm}(5 / 64 \mathrm{in}$.).

Both the larger diameter for the rotor inlet and the larger gap between the rotor and the bottom vanes were tested by flowing water through a single-stage 2 -cm contactor that has a transparent acrylic housing. With this housing, we can measure the increase in liquid height in the mixing zone. In each test, the liquid height in the annular mixing zone was measured in three ways: (1) with a ruler during the test, (2) from a photo taken with a flash, and (3) from a photo taken with available light. These three measurements were averaged, and the results are plotted in Fig. 5. Table 5 in Appendix A gives the data used to create Fig. 5. Typical photos using flash and available light are shown in Figs. 6 and 7, respectively. As shown in Fig. 5, increasing either the bottom gap or the diameter of the rotor inlet causes the liquid height in the annular mixing zone to increase above the base-case values. The effect of increasing the bottom gap is most pronounced at low flow rates. The effect of increasing the rotor inlet has a large effect at all flow rates. When the bottom gap is increased with the larger rotor inlet, there is very little additional effect. At zero flow rate with the base-case bottom gap, the difference in liquid height is $5.5 \mathrm{~mm}$ for the two rotor inlets, slightly higher than the $4.5 \mathrm{~mm}$ calculated from Eq. 3, but within the 
experimental error. When the diameter of the rotor inlet was increased, the liquid height in the mixing zone was increased by about $48 \%$ relative to the base-case height at zero flow. As the flow rate was increased from 0 to $50 \mathrm{~mL} / \mathrm{min}$, the relative liquid height increased to $86 \%$. Note that, for each case in Fig. 5, the annular liquid height increases as the flow rate increases.

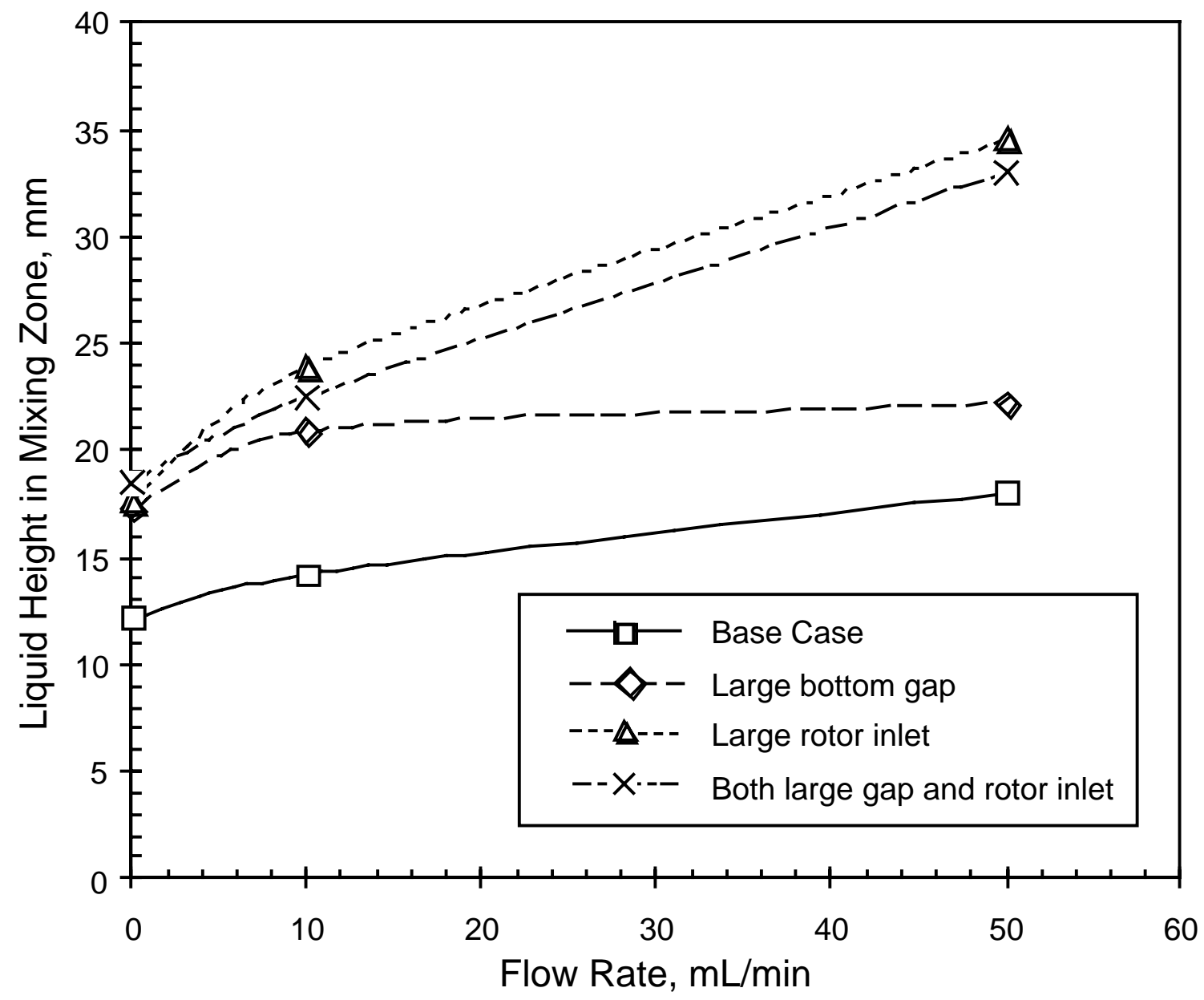

\section{Fig. 5. Effect of Water Flow Rate and Contactor Geometry on Liquid Height in Annular Mixing Zone}

Liquid volumes in the mixing zone were calculated from the liquid heights in Table 5 along with the inside diameter of the housing, $25.40 \mathrm{~mm}$ (1.000 in.), and the outside diameter of the rotor, $22.23 \mathrm{~mm}$ (0.875 in.). For the base case at zero flow, the liquid height is $12.2 \mathrm{~mm}$, which gives an annular value of $1.3 \mathrm{~mL}$. As the flow rate increases to $50 \mathrm{~mL} / \mathrm{min}$, the liquid height increases to $18.0 \mathrm{~mm}$, which gives a liquid volume of $2.1 \mathrm{~mL}$. For the rotor with the large inlet, the volume increases from 2.1 to $4.1 \mathrm{~mL}$ as the flow rate increases from 0 to $50 \mathrm{~mL} / \mathrm{min}$. For both cases, there is an additional $1.6 \mathrm{~mL}$ of liquid in the region under the rotor since the distance from the bottom of the rotor to the bottom of the vanes is $3.21 \mathrm{~mm}$. These calculations assume that the mixing zone is filled with liquid. Figure 6 shows some air trapped in the mixingzone liquid. Thus, these calculations are a first approximation to the liquid in the mixing zone. 


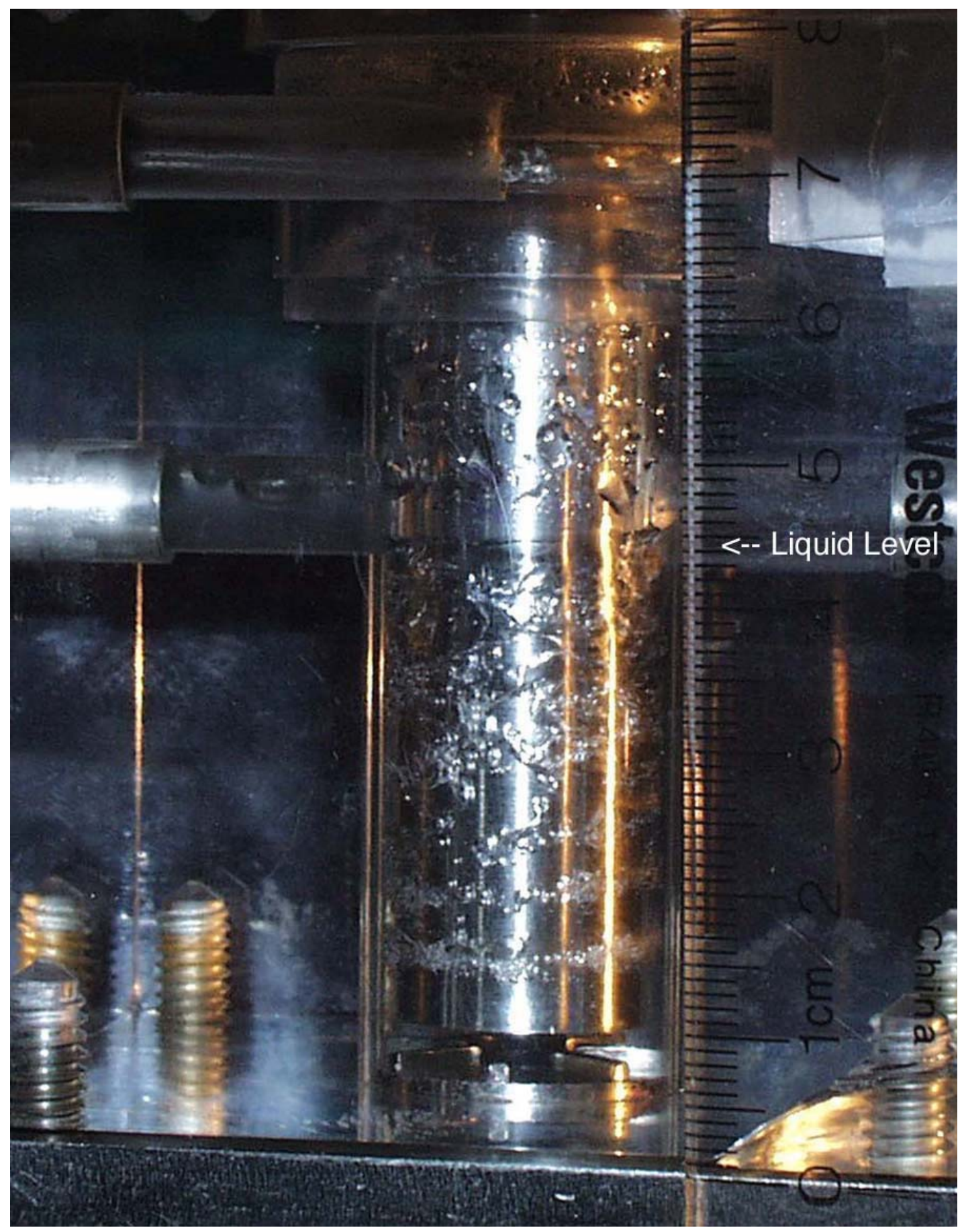

Fig. 6. Photo Taken Using Automatic Flash of Water Flowing through Modified 2-cm Contactor at $50 \mathrm{~mL} / \mathrm{min}$ 


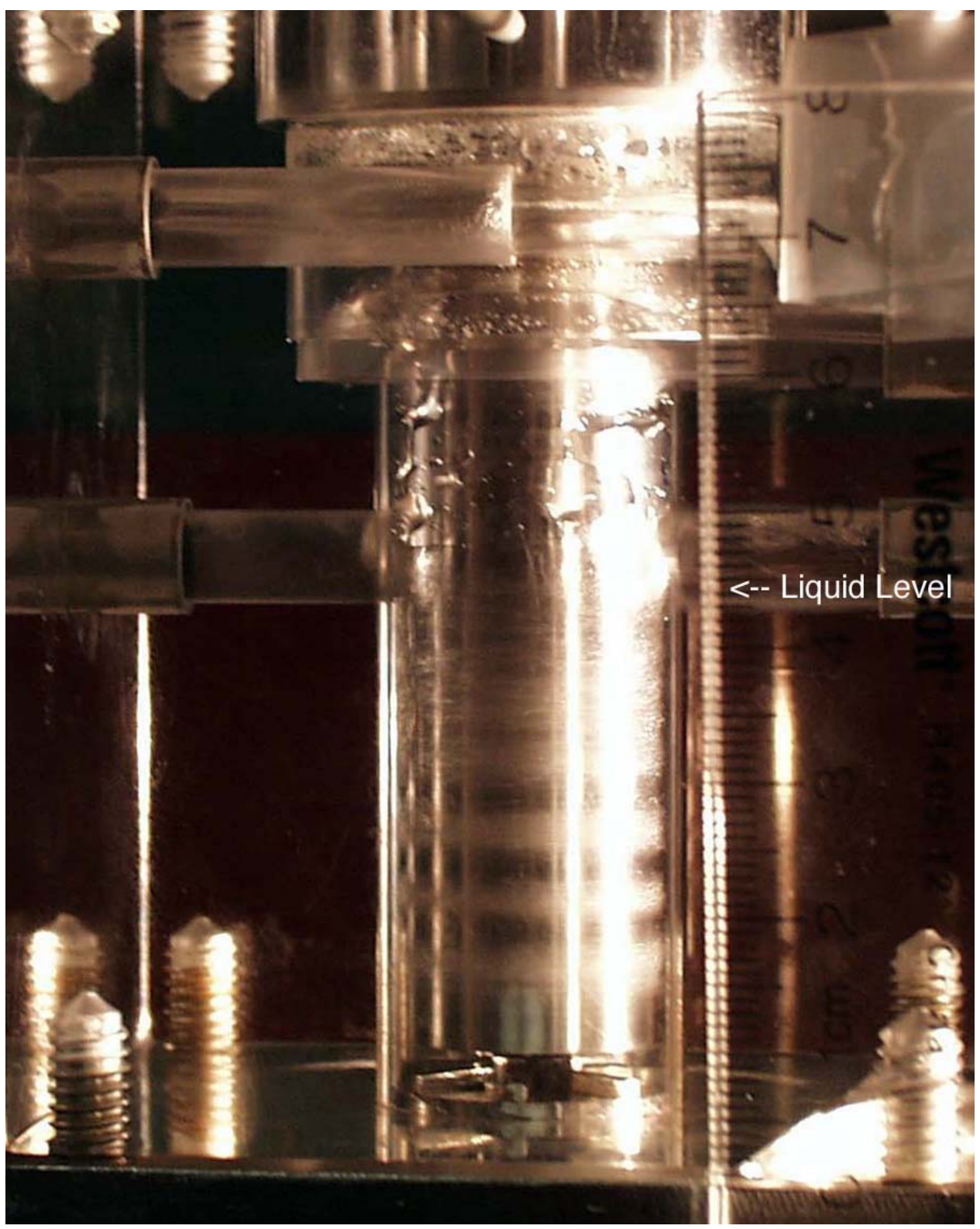

Fig. 7. Photo Taken Using Available Light of Water Flowing through Modified 2-cm Contactor at $50 \mathrm{~mL} / \mathrm{min}$ 


\section{B. Increased Flow Rate}

Earlier work with centrifugal contactors indicates that stage efficiency is improved by increasing the flow rate. These results are summarized in Appendix C of [LEONARD-1999A]. It was observed that, as flow rate increases, the time between slugs of liquid in the interstage lines gets shorter until the flow becomes continuous. The result is improved stage efficiency in multistage operation with increasing flow rates. For single-stage flow in 2-cm contactors, only one condition gave an efficiency less than $80 \%$. That condition occurred at the lowest flow rate, $1.7 \mathrm{~mL} / \mathrm{min}$. At higher flow rates, $3.3 \mathrm{~mL} / \mathrm{min}$ and above, the stage efficiency was always greater than $80 \%$. Based on this data, we want to keep the flow rate of all process streams greater than $2 \mathrm{~mL} / \mathrm{min}$.

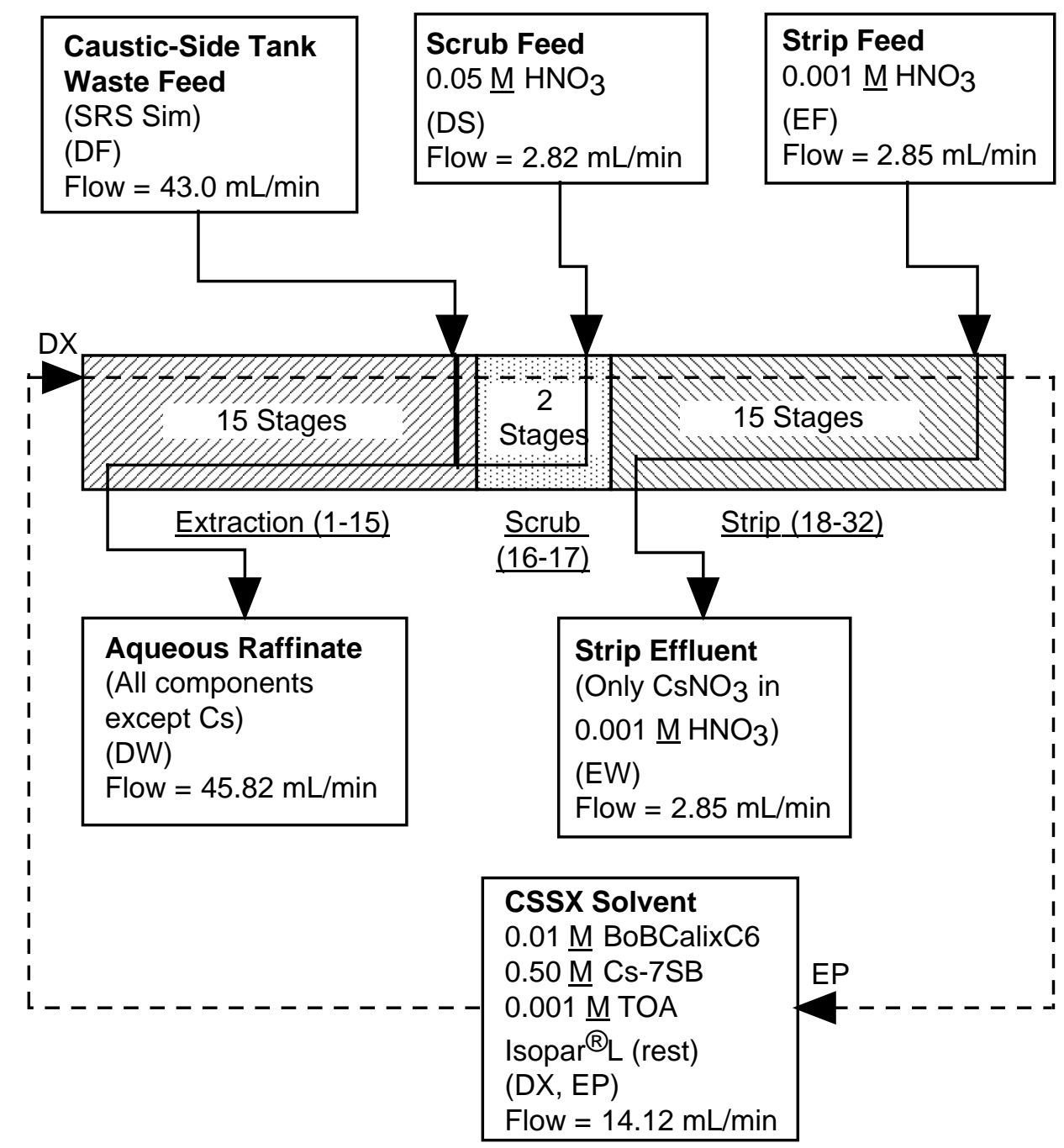

Fig. 8. CSSX Flowsheet with Total Flow Rate in the Extraction Section of $60 \mathrm{~mL} / \mathrm{min}$ 
If we operate at the nominal throughput of the contactor, $40 \mathrm{~mL} / \mathrm{min}$ (both phases), in the extraction section, the aqueous flow rate in the strip section will only be $1.90 \mathrm{~mL} / \mathrm{min}$ and that in the scrub section will be $1.88 \mathrm{~mL} / \mathrm{min}$. If we can operate the contactor at $60 \mathrm{~mL} / \mathrm{min}$ in the extraction section, the aqueous flow rate in the strip section will be $2.85 \mathrm{~mL} / \mathrm{min}$ and that in the scrub section will be $2.82 \mathrm{~mL} / \mathrm{min}$. Thus, we would like to run at a flow rate of $60 \mathrm{~mL} / \mathrm{min}$ in the extraction section of the $2-\mathrm{cm}$ centrifugal contactor so that we can realize a possible increase in stage efficiency. For that operating condition, the CSSX flowsheet would have the rates shown in Fig. 8. To determine if this operation were possible, we carried out hydraulic performance tests in the $2-\mathrm{cm}$ contactor. The results, given in Appendix A, indicate that, while the hydraulic performance in the scrub and strip sections is mixed, the contactor works when operated at the high O/A flow ratios needed for the CSSX flowsheet. In addition, while the hydraulic performance in the extraction section is good for the flow rates and O/A flow ratios needed for the CSSX flowsheet, $60 \mathrm{~mL} / \mathrm{min}$ must be considered the maximum throughput. Based on these tests of the hydraulic performance of the 2-cm contactor, we measured stage efficiency for multistage operation using the feeds and flow rates shown in Fig. 8.

\section{Reduced Slug Flow}

We observed that the flow in the interstage lines of the 2-cm contactor quite often occurs as slugs, that is, there is little or no interstage flow as liquid accumulates in the collector ring. When gravity overcomes surface tension, a large volume of liquid (a liquid slug) moves from the collector ring through the interstage line and into the next stage. This also occurs in the effluent lines but should not be a problem there. The interstage lines are made of perfluoroalkoxy (Teflon PFA or PFA) tubing. The effluent lines are made of either fluorinated ethylene propylene (Teflon FEP or FEP) or PFA tubing. These Teflon lines are used to prevent any interaction between the solvent and the tubing. The PFA and FEP tubes are fairly clear so that interstage flow can be observed. As the aqueous phase does not wet the Teflon tubing, slug flow is most pronounced in the interstage lines for the aqueous phase. However, slug flow does occur in the organic interstage lines. This is not as well defined and may be less of a problem because organic phase can usually be seen in the bottom of the interstage lines, suggesting a continuous flow of solvent in addition to the occasional slug.

In aqueous interstage lines operating at low flow rates (around $2 \mathrm{~mL} / \mathrm{min}$ ), there can be 20 to $40 \mathrm{~s}$ between slugs. This indicates a slug volume of 0.7 to $1.4 \mathrm{~mL}$. During a previous CSSX test reported elsewhere [LEONARD-1999A], the time between individual slugs ranged from 1 to $25 \mathrm{~s}$, with an average time of $10 \mathrm{~s}$ at an aqueous flow rate of $32 \mathrm{~mL} / \mathrm{min}$. This suggests an average slug volume of $5.3 \mathrm{~mL}$. In the one-phase flow tests reported here, slug flow was observed in the aqueous effluent line at flow rates from 1 to $48 \mathrm{~mL} / \mathrm{min}$. The average slug volume over a one-minute interval was $1.9 \mathrm{~mL} \pm 0.4 \mathrm{~mL}$, with minimum and maximum volumes of 1.2 and $2.6 \mathrm{~mL}$, respectively, based on 14 observations.

To reduce the size of the slugs, we inserted a 304 stainless steel wire rope into the aqueous and organic effluent lines of a one-stage 2-cm contactor (Fig. 9). The wire rope was passed into the contactor housing until it reached the collector ring at the point where the tangential exit port starts to leave the collector ring. Wire ropes with diameters of $1.6 \mathrm{~mm}(1 / 16$ in.) and $2.4 \mathrm{~mm}(3 / 32 \mathrm{in}$.) were tested and found to work about the same. For the aqueous 
effluent line, a droplet volume of $0.8 \mathrm{~mL}$ was reduced to $0.06 \mathrm{~mL}$. Figure 9 shows a droplet forming at the end of the aqueous effluent tube (FEP tubing with 9.5-mm inside diameter and $0.8-\mathrm{mm}$-thick wall) with a wire rope (1.6- $\mathrm{mm}$ diameter) in place. For the organic effluent line, the droplet volume was $0.06 \mathrm{~mL}$ with or without the wire rope. However, an aqueous slug that formed at the exit of the lower (organic) collector was eliminated. For our flowsheet tests, we used a 304 stainless-steel wire rope that had a diameter of $1.6 \mathrm{~mm}$. Each rope consisted of 7 strands with 7 wires in each strand (McMaster-Carr catalog number: 3461T44). When the wire rope was placed in each interstage line, the upper end was at the point where the tangential exit port met the collector ring while the lower end entered the inlet port and extended $1.6 \mathrm{~mm}(1 / 16$ in.) into the mixing zone so that it just touched the rotor surface.

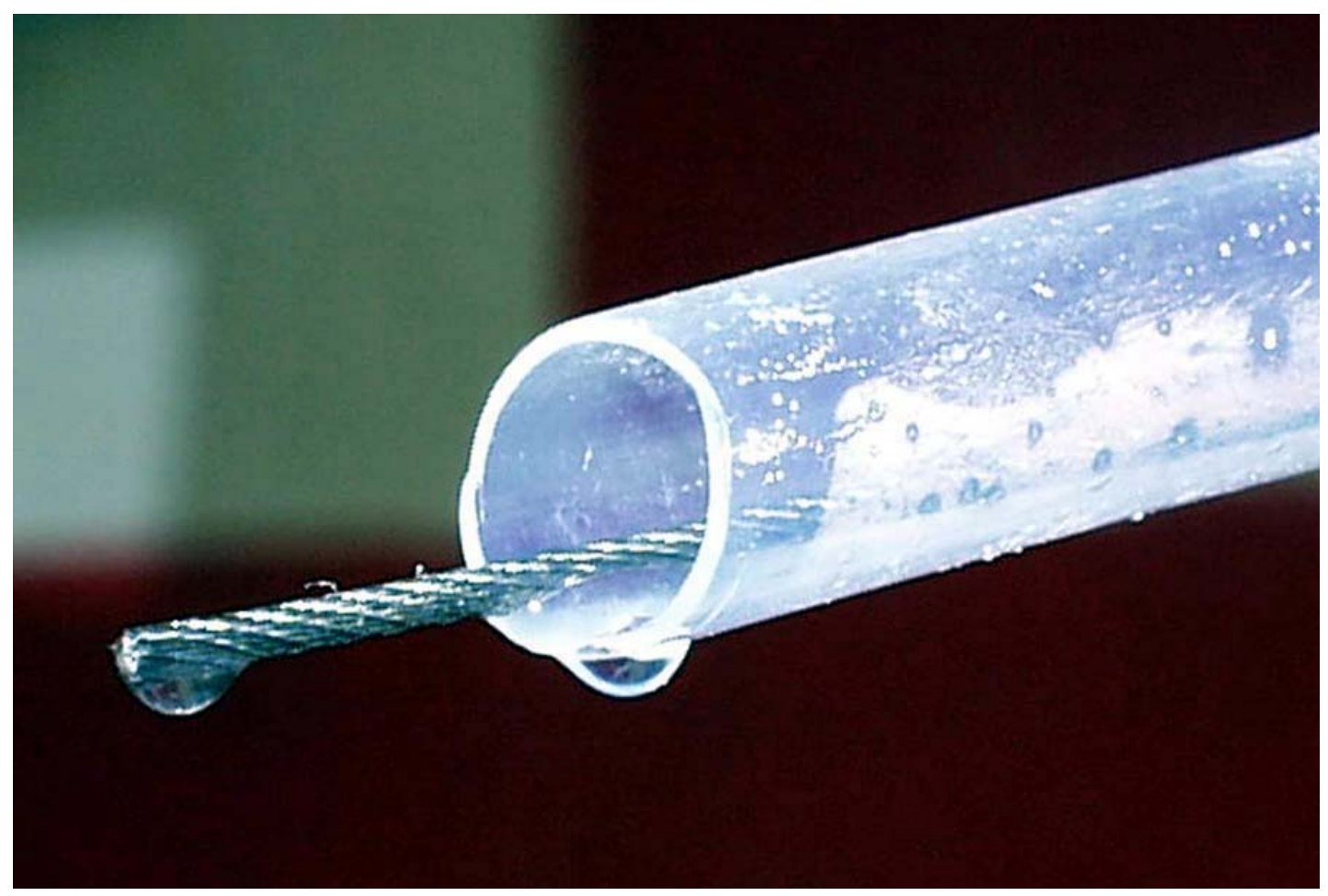

Fig. 9. Wire Rope in Effluent Line

Since the inside diameter of the interstage line is $9.5 \mathrm{~mm} \mathrm{(3/8} \mathrm{in.),} \mathrm{the} \mathrm{diameter} \mathrm{of} \mathrm{the}$ wire rope is only a small fraction of the cross-sectional area of the line and does not pose any flow restrictions. To keep the wire rope lying in the bottom of the interstage lines, we crimped the rope using a Multiform Bender (hand brake). Little kinks were placed about every $3.2 \mathrm{~mm}$ ( $1 / 8$ in.) in the bend region. Further crimping was done until the at-rest shape of the wire rope matched the interstage line. After the wire ropes were crimped, they worked as planned, lying at the bottom of the interstage lines, wicking liquid around from stage to stage, and eliminating slug flow.

After forming the bend, the wire ropes were cut to length and cleaned. After the ends were cut using a grinding wheel, the wire rope was immediately put into soapy water to rinse off the grinding fluid. Later, the wire ropes were cleaned by soaking in a chlorinated solvent (either 
trichloroethylene or tetrachloroethylene) and dried. Finally, they were cleaned in ethanol and allowed to air dry.

\section{STAGE EFFICIENCY}

The above-mentioned three ways to improve stage efficiency were tested together to determine if their combined effect could increase efficiency from $60 \%$ to $80 \%$ or greater. First, the contactor stages were cleaned so that data would not be compromised by earlier contactor tests. Then, stage-efficiency measurements were made for the extraction, scrub, and strip sections. Finally, the results were evaluated using the SASSE worksheet [LEONARD-1994].

\section{A. Multistage Tests}

The contactor stages were cleaned as described in Appendix B. Then, the multistage efficiency tests in the 2-cm contactor were carried out as follows. Each process section was tested separately. The four-stage extraction test, designated CS20, was done in stages 1-4 on June 22, 2000. The two-stage scrub test, CS21, was done in stages 5-6 on June 23, 2000. The four-stage strip test, CS22, was done in stages 7-10 on June 26, 2000. By conducting the tests in separate stages, we did not have to stop and clean them up between tests. The flow rates for the three tests were determined from the flow rates given in Fig. 8. The flow rates in Fig. 8 are proportional to the baseline flow rates for a plant, which are $20.1 \mathrm{gpm}(76.1 \mathrm{~L} / \mathrm{min})$ for the DF feed and $1.33 \mathrm{gpm}(5.0 \mathrm{~L} / \mathrm{min})$ for the aqueous strip $(\mathrm{EF})$ feed. At the present time, the baseline feed rate for the solvent (DX) in a plant is $6.6 \mathrm{gpm}(25.0 \mathrm{~L} / \mathrm{min})$, and the scrub (DS) feed rate is $20 \%$ of the DX feed rate.

For the extraction-section test (CS20), the flowsheet is shown in Fig. 10. For this test, the aqueous (DF) feed was alkaline simulant III along with the appropriate amount of scrub $(0.05 \underline{\mathrm{M}}$ $\mathrm{HNO}_{3}$ ) feed. This made the cesium concentration in the waste (DF) feed $1.314 \times 10^{-4} \underline{\mathrm{M}}$. The solvent volume, which was $1.5 \mathrm{~L}$, fixed the length of the extraction-section tests. Based on this volume of solvent, a stage volume of $10 \mathrm{~mL}$ for the organic phase, and a stage volume of $16 \mathrm{~mL}$ for the aqueous phase, the dimensionless residence time for this test would be 68 with respect to the aqueous flow rate and 33 with respect to the organic flow rate. Enough DF feed was prepared to process the entire solvent volume. The DF feed was spiked with $0.01 \mathrm{mCi} / \mathrm{L}$ of Cs137 so that we could measure decontamination factors up to 1000, the highest value expected for these tests. 


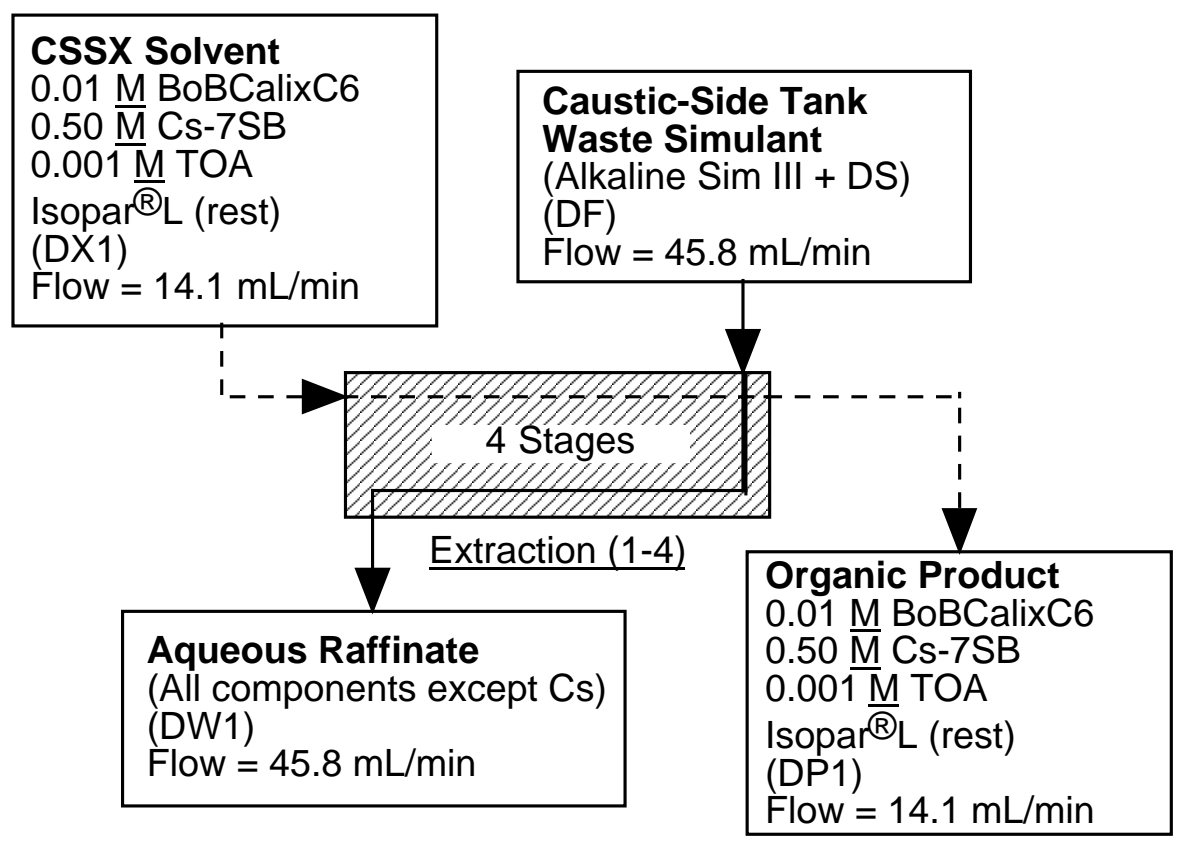

Fig. 10. Flowsheet for Stage Efficiency Test of the Extraction Section (Test CS20)

For the scrub-section test (CS21), the flowsheet is shown in Fig. 11. For this test, the organic feed was all the solvent that was loaded with Cs during test CS20. Enough DS feed was prepared to process the entire solvent volume. Based on the $1.5 \mathrm{~L}$ of solvent for CS20, the dimensionless residence time for the test CS21 is 7.1 with respect to the aqueous flow rate and 57 with respect to the organic flow rate.

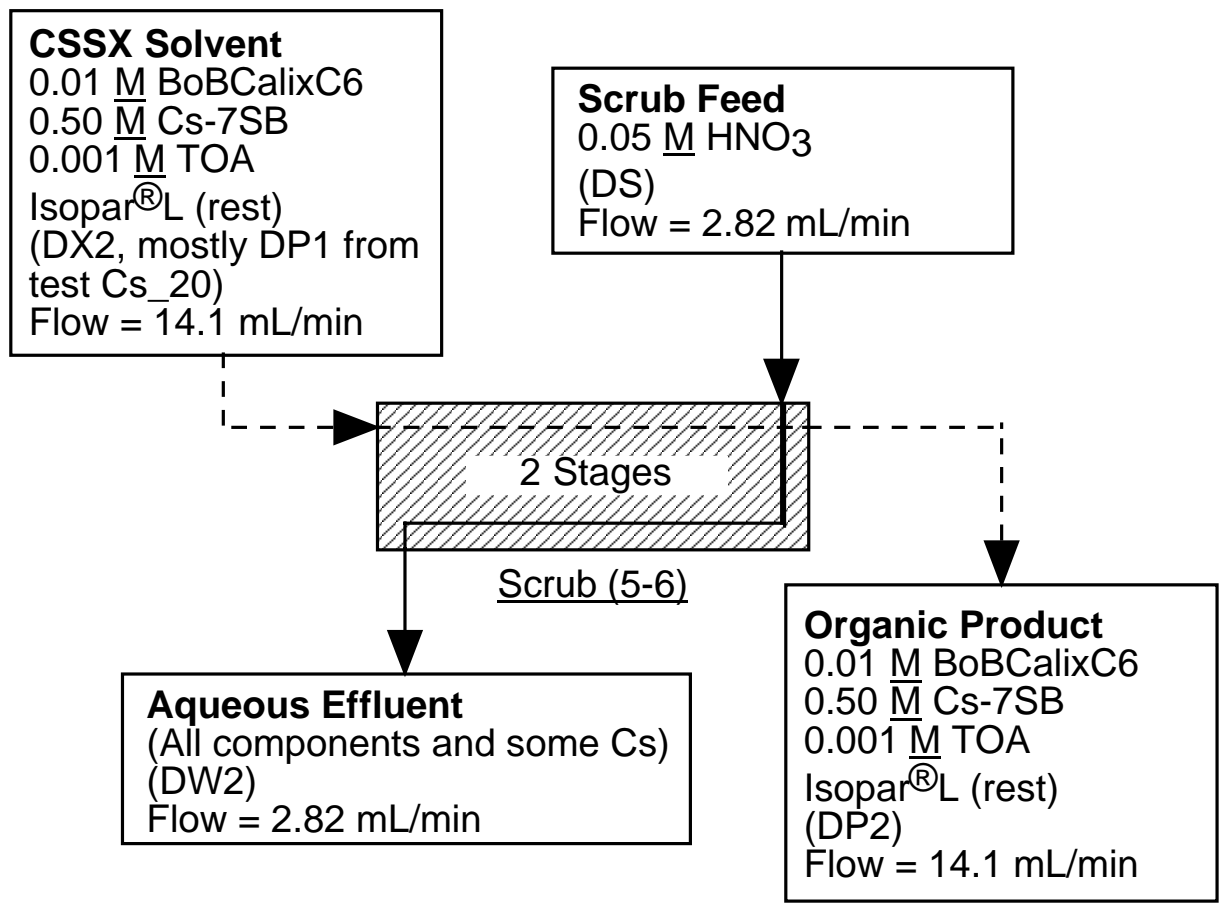

Fig. 11. Flowsheet for Stage Efficiency Test of the Scrub Section (Test CS21) 
For the strip-section test (CS22), the flowsheet is shown in Fig. 12. For this test, the organic feed was all the solvent that was scrubbed during test CS21. Enough EF feed was prepared to process the entire solvent volume. Based on the $1.5 \mathrm{~L}$ of solvent for CS20, the dimensionless residence time for the test CS22 would be 2.8 with respect to the aqueous flow rate and 22 with respect to the organic flow rate. Since a process is typically close to steady state after three dimensionless residence times, the $1.5 \mathrm{~L}$ of solvent chosen for the extraction test ensures that the results for the scrub and strip tests will be at, or close to, steady state by the end of the tests.

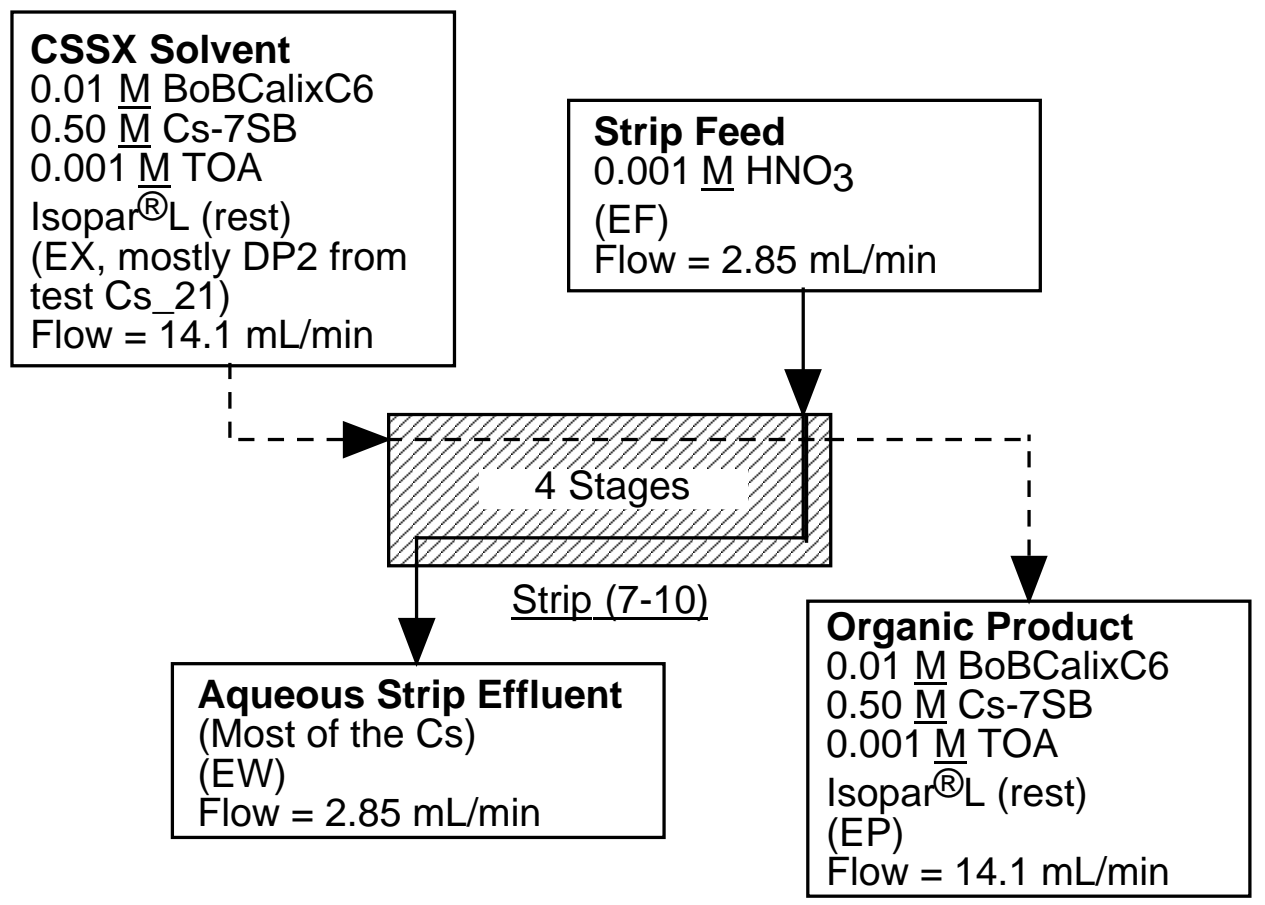

Fig. 12. Flowsheet for Stage Efficiency Test of the Strip Section (Test CS22)

During the three tests, the flow in the interstage lines was free of liquid slugs because of the wire rope at the bottom of each line. In Fig. 13, the wire rope can be seen in the aqueous interstage line between stages 2 and 1. Effluent samples were taken every 15 min starting 5 min after the radioactive (hot) feed was introduced into the contactor. In addition to measuring the Cs-137 concentration, the sample was collected so that we could check the effluent flow rate, its appearance, and the presence of any other-phase carryover. For the scrub and strip tests, we also measured the $\mathrm{pH}$ of the aqueous effluent. After each test, the two immiscible liquids in each stage were drained, and their volumes were equilibrated at a known temperature. The two phases were separated, and each phase was analyzed for its cesium concentration. These measurements yield a cesium distribution ratio $\left(\mathrm{D}_{\mathrm{Cs}}\right)$ at a known temperature for each process stage. All experimental data are given in Appendix B. 


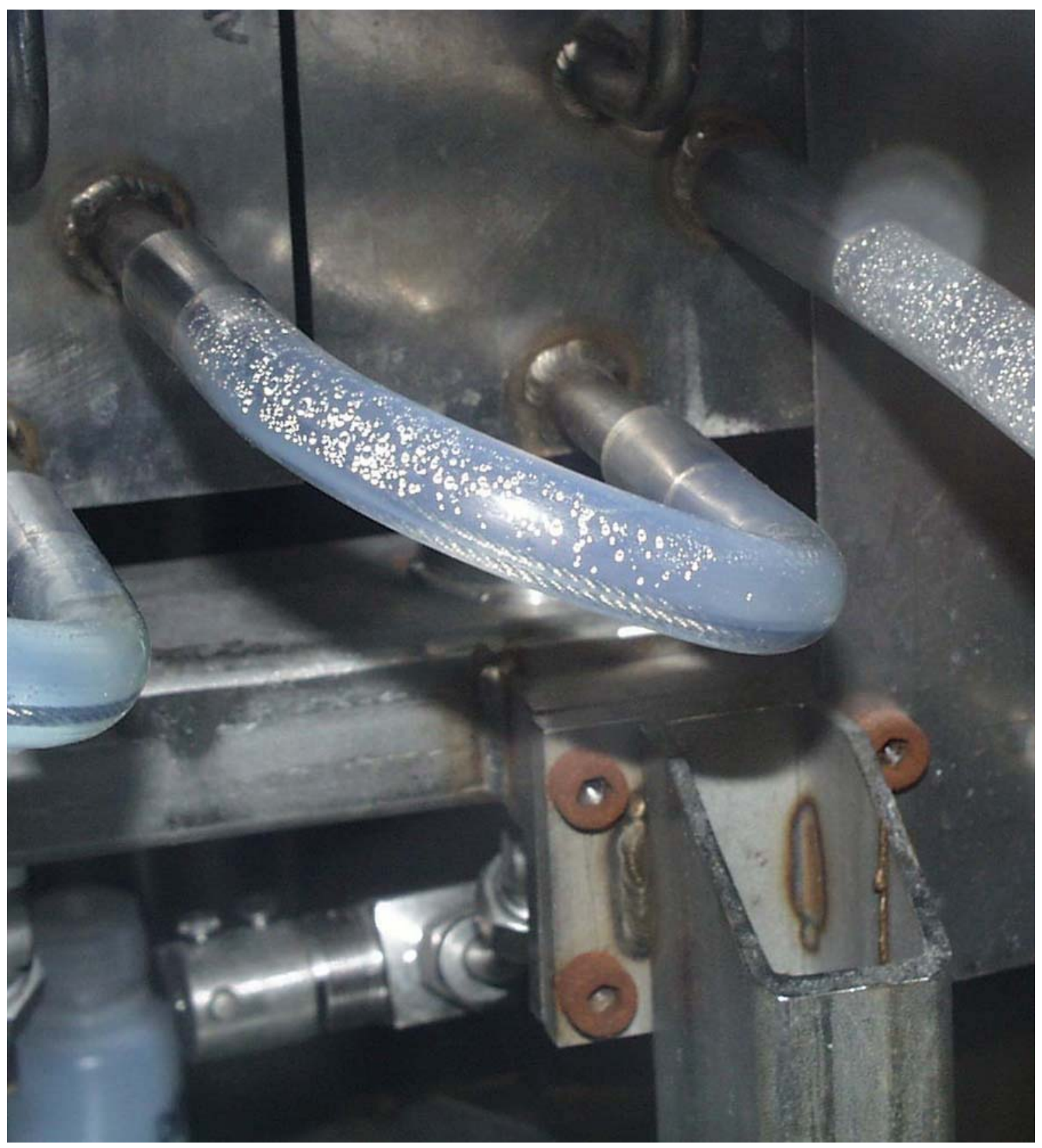

Fig. 13. Aqueous Interstage Line during Test CS20

\section{B. Equilibrium Distribution Ratios for Cs}

Batch-equilibrium $\mathrm{D}_{\mathrm{Cs}}$ values were measured using the solutions and the volume ratios for the stage-efficiency tests. The $\mathrm{D}_{\mathrm{Cs}}$ results, given in Table 2 , are in reasonable agreement with earlier data for a similar alkaline-waste simulant [BONNESEN-2000].

Using the batch $\mathrm{D}_{\mathrm{Cs}}$ values, the cesium concentration in each feed, the feed flow rates, the estimated temperature in each stage, and the SASSE model [LEONARD-1994], we calculated 
the average stage efficiency for each test. The batch $\mathrm{D}_{\mathrm{Cs}}$ values, which were obtained at $25^{\circ} \mathrm{C}$, were corrected to the stage temperature by using

$$
D_{1}=D_{0} e\left\{(H / R)\left[\left(1 / T_{1}\right)-\left(1 / T_{0}\right)\right]\right\}
$$

where $\mathrm{D}_{0}$ is the $\mathrm{D}_{\mathrm{Cs}}$ ratio at a known absolute temperature, $\mathrm{T}_{0}$, in $\mathrm{K} ; \mathrm{D}_{1}$ is the $\mathrm{D}_{\mathrm{Cs}}$ ratio required at absolute temperature, $\mathrm{T}_{1}$, in $\mathrm{K} ; \mathrm{H}$ is the enthalpy for this cesium extraction reaction in $\mathrm{kJ} / \mathrm{mol}$; and $\mathrm{R}$ is $0.0083144 \mathrm{~kJ} /(\mathrm{mol} \cdot \mathrm{K})$. The enthalpies for the cesium extraction reactions were obtained from the slope of the appropriate curve in Fig. 5 of [BONNESEN-2000]. They are 42.8 $\mathrm{kJ} / \mathrm{mol}$ for the extraction section, $61.8 \mathrm{~kJ} / \mathrm{mol}$ for the scrub section, and $62.5 \mathrm{~kJ} / \mathrm{mol}$ for the strip section. These data signify that, going from 20 to $30^{\circ} \mathrm{C}, \mathrm{D}_{\mathrm{Cs}}$ will drop by 1.78 times in the extraction section, 2.31 times in the scrub section, and 2.33 times in the strip section.

Table 2. Cesium Distribution Ratios from Batch-Equilibrium Measurements for Stage Efficiency Tests

\begin{tabular}{|c|c|c|c|c|}
\hline Section & $\begin{array}{c}\text { Batch Test } \\
\text { Number }\end{array}$ & O/A Volume Ratio & $\mathrm{D}_{\mathrm{Cs}}$ at $25^{\circ} \mathrm{C}$ & Notes \\
\hline Extraction & 1 & 0.31 & 14.6 & $\mathrm{a}$ \\
\hline Extraction & 2 & 0.31 & 15.1 & $\mathrm{a}$ \\
\hline Scrub & 1 & 5.0 & 1.08 & $\mathrm{~b}$ \\
\hline Scrub & 2 & 5.0 & 1.15 & $\mathrm{~b}$ \\
\hline Strip & 1 & 5.0 & 0.125 & $\mathrm{c}$ \\
\hline Strip & 2 & 5.0 & 0.085 & $\mathrm{c}$ \\
\hline Strip & 3 & 5.0 & 0.053 & $\mathrm{c}$ \\
\hline Strip & 4 & 5.0 & 0.054 & $\mathrm{c}$ \\
\hline
\end{tabular}

${ }^{a}$ Using those data, the no-load $\mathrm{D}_{\mathrm{Cs}}$ value for the extraction section is $15.6 \pm 0.8$.

${ }^{\mathrm{b}}$ Using those data, the no-load $\mathrm{D}_{\mathrm{Cs}}$ value for the scrub section is $1.17 \pm 0.05$.

${ }^{c}$ These values were used unchanged, except for temperature correction, in SASSE calculations for this strip stage. Analysis of these four strip $\mathrm{D}_{\mathrm{Cs}}$ values indicates that at very low $\mathrm{Cs}$ concentrations with $0.001 \underline{\mathrm{M}} \mathrm{HNO}_{3}, \mathrm{D}_{\mathrm{Cs}}$ will be $0.050 \pm 0.004$.

\section{Model for Cs Loading}

To model the effect that the Cs loading of the BOBCalixC6 in the solvent has on the $\mathrm{D}_{\mathrm{Cs}}$ value for the extraction and scrub sections, the following equation was used:

$$
D_{C s}=D_{C s, n l} \bullet\left(\frac{y_{e x}-y_{C s}}{y_{e x}}\right)
$$

where $\mathrm{D}_{\mathrm{Cs}}$ is the distribution ratio for $\mathrm{Cs}, \mathrm{D}_{\mathrm{Cs}, \mathrm{nl}}$ is the no-load $\mathrm{D}_{\mathrm{Cs}}$ value, $\mathrm{y}_{\mathrm{ex}}$ is the concentration of the BOBCalixC6 extractant in the organic phase, and $\mathrm{y}_{\mathrm{Cs}}$ is the Cs concentration in the organic phase. Using Eq. 5 and the data in Table 2, we determined that the average no-load $\mathrm{D}_{\mathrm{Cs}}$ values are $15.6 \pm 0.8$ for the extraction section and $1.17 \pm 0.05$ for the scrub section. Equation 5 was then used in the SASSE model to calculate the effect of the organic-phase Cs concentration (Cs 
loading of the extractant in the solvent) on $\mathrm{D}_{\mathrm{Cs}}$ for the extraction and scrub sections. The temperature correction given by Eq. 4 was applied to the no-load $\mathrm{D}_{\mathrm{Cs}}$ values.

\section{Calculation of Stage Efficiency}

We calculated the stage efficiencies for the three multistage tests using the data in Appendix $\mathrm{B}$ along with the batch $\mathrm{D}_{\mathrm{Cs}}$ values, Eq. 4, and Eq. 5. The results are summarized in Table 3. For the extraction section, the measured ratio of the cesium concentration in the aqueous feed to that in the aqueous effluent was 166.2. Also, the measured ratio for the cesium concentration in the solvent feed to that in the aqueous effluent was 1.162 for the scrub section and the measured ratio for the cesium concentration in the solvent feed to that in the solvent effluent was 84.3 for the strip section. Inputting these three ratios into the SASSE model yielded the stage efficiencies of $91.8 \%, 89.0 \%$, and $90.5 \%$, respectively. The stage efficiencies are plotted in Fig. 4 as "Multistage (Improved, Meas)." Note they are on the line for the single-stage correlation. For the three sections of the CSSX flowsheet, the average stage efficiency is $90.4 \pm$ $1.4 \%$. Thus, the changes we made to the $2-\mathrm{cm}$ contactor increased its mass transfer efficiency in multistage operation from $60 \%$ to above the goal of $80 \%$.

Table 3. Stage Efficiency for Multistage Operation

\begin{tabular}{|c|c|c|c|}
\hline & Stages & $\begin{array}{c}\text { Organic-to-Aqueous } \\
\text { Flow Ratio }\end{array}$ & Efficiency $^{\mathrm{a}}, \%$ \\
\hline Extraction & 4 & 0.31 & 91.8 \\
\hline Scrub & 2 & 5.4 & 89.0 \\
\hline Strip & 4 & 5.5 & 90.5 \\
\hline
\end{tabular}

${ }^{a}$ These stage efficiency values are slightly different from those reported earlier [LEONARD-2001A]. This is because the enthalpy $(\mathrm{H})$ for this cesium extraction reaction was revised using the slope of the appropriate curves in Fig. 5 of [BONNESEN-2000]. The revised $\mathrm{H}$ values are $42.8 \mathrm{~kJ} / \mathrm{mol}$ for the extraction section, $61.8 \mathrm{~kJ} / \mathrm{mol}$ for the scrub section, and $62.5 \mathrm{~kJ} / \mathrm{mol}$ for the strip section. The earlier $\mathrm{H}$ values were $45.4 \mathrm{~kJ} / \mathrm{mol}$ for the extraction section, $62.5 \mathrm{~kJ} / \mathrm{mol}$ for the scrub section, $79.0 \mathrm{~kJ} / \mathrm{mol}$ for the first three strip stages, and $67.1 \mathrm{~kJ} / \mathrm{mol}$ for subsequent strip stages. With these revised $\mathrm{H}$ values, the extraction section efficiency was unchanged at $91.8 \%$. The scrub section efficiency increased from 88.8 to $89.0 \%$; the strip section efficiency, from 88.0 to $90.5 \%$; and the overall stage efficiency, from $89.5 \pm$ $2.0 \%$ to $90.4 \pm 1.4 \%$.

\section{E. Metal Ions in the Aqueous Strip Effluent}

While the CSSX solvent extracts Cs very strongly, it extracts K weakly and the other metal ions not at all. This can be seen in Table 4, which gives the composition of metal ions in the aqueous (EW) strip effluent. On the basis of molar concentration, the EW effluent contains mostly $\mathrm{Cs}$ with some $\mathrm{Na}, \mathrm{K}$, and $\mathrm{Al}$. Considering the large concentration of $\mathrm{Na}$ and $\mathrm{Al}$ in the waste (DF) feed relative to the $\mathrm{Cs}$ and the small concentration of $\mathrm{Na}$ and $\mathrm{Al}$ relative to the $\mathrm{Cs}$ in the EW effluent, it appears that they are not extracted. For the K ion, Table 4 shows that $0.1 \%$ remains with the $\mathrm{Cs}$, which is not unexpected as $\mathrm{K}$ is weakly extracted by the solvent. 
Table 4. Composition of the Aqueous Strip Effluent during Stage Efficiency Test CS22

\begin{tabular}{|c|c|c|c|}
\hline Component & $\begin{array}{c}\text { Conc. in Extraction } \\
\text { (DF) Feed, } \mathrm{mM}\end{array}$ & $\begin{array}{c}\text { Conc. in Aqueous } \\
\text { (EW) Strip Effluent, } \\
\mathrm{mM}\end{array}$ & $\begin{array}{c}\text { Amt. that Component in DF } \\
\text { Extracted into EW Effluent } \\
\text { Relative to Cs, \% }\end{array}$ \\
\hline $\mathrm{Cs}$ & 0.14 & 1.59 & Not Applicable \\
\hline $\mathrm{Na}$ & 5,600 & 0.38 & 0.0006 \\
\hline $\mathrm{Al}$ & 280 & 0.16 & 0.005 \\
\hline $\mathrm{K}$ & 15 & 0.17 & 0.10 \\
\hline
\end{tabular}

\section{FLOWSHEET TESTS}

With the successful completion of the stage efficiency tests, we proceeded to the proofof-principle flowsheet tests for caustic-side solvent extraction of cesium from tank waste. The CSSX flowsheet shown in Fig. 8 was used in these tests. As reported earlier [LEONARD-2000], the first CSSX flowsheet test (CS23) was done on September 19, 2000, without solvent recycle. It initially reached both key process goals: (1) a cesium decontamination factor of 40,000 and (2) a cesium concentration factor of 15 . However, as the test progressed, the extraction section temperature rose steadily. At the same time period, the decontamination factor fell steadily and soon was less than the required value. The second test (CS24) was done on September 28, 2000, without solvent recycle and with the revised temperature control plan. As a result of this change, we were able to maintain both key process goals. The third test (CS25) was done on October 11, 2000 , with the solvent being recycled four times. Using the revised temperature control plan, we maintained both process goals throughout the testing period.

The flowsheet test with solvent recycle (CS25) was the final test required to prove that the CSSX process could be used to remove Cs from SRS tank waste. The decontamination factor (the Cs in the DF feed divided by the Cs in the DW raffinate) for this test is given as a function of time in Fig. 14. Near the beginning of the test, the decontamination factor dropped below the desired value of 40,000 because one motor/rotor assembly in the extraction section was not working well. We stopped the test and replaced the motor/rotor assembly. The decontamination factors for the rest of the test were excellent. The concentration factor (the Cs in the aqueous strip effluent divided by the Cs in the DF feed) for test CS25 is given as a function of time in Fig. 15. Its value stayed close to the desired value throughout the test. The stripping factor (the Cs in the DF feed divided by the Cs in the organic strip effluent) is given as a function of time in Fig. 16. It stayed above the required value throughout the test. These results demonstrate that the CSSX flowsheet can be operated with solvent recycle while maintaining both process goals. These tests completed the proof-of-principle for the CSSX process. 


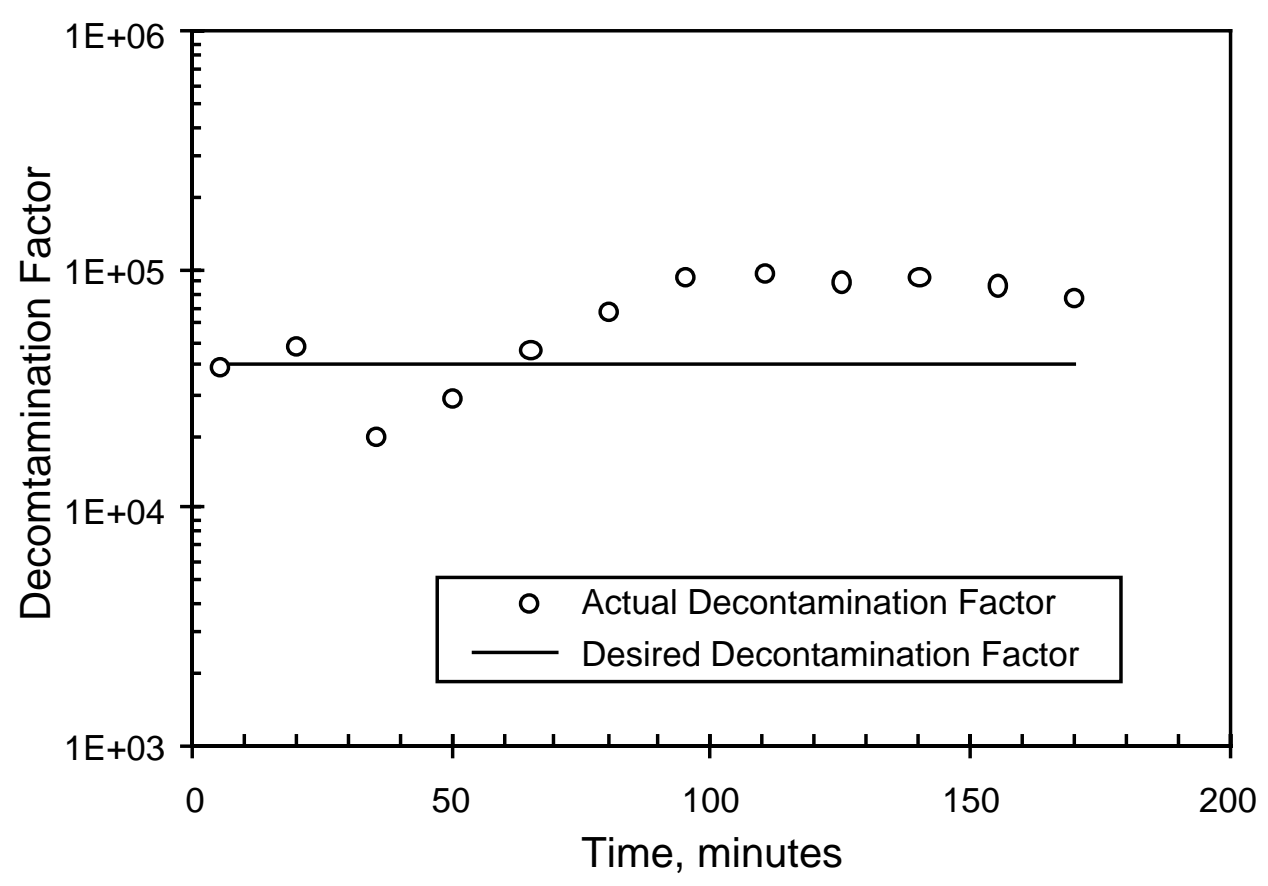

Fig. 14. Decontamination Factor vs. Time for CSSX Flowsheet Test with Solvent Recycle (CS25)

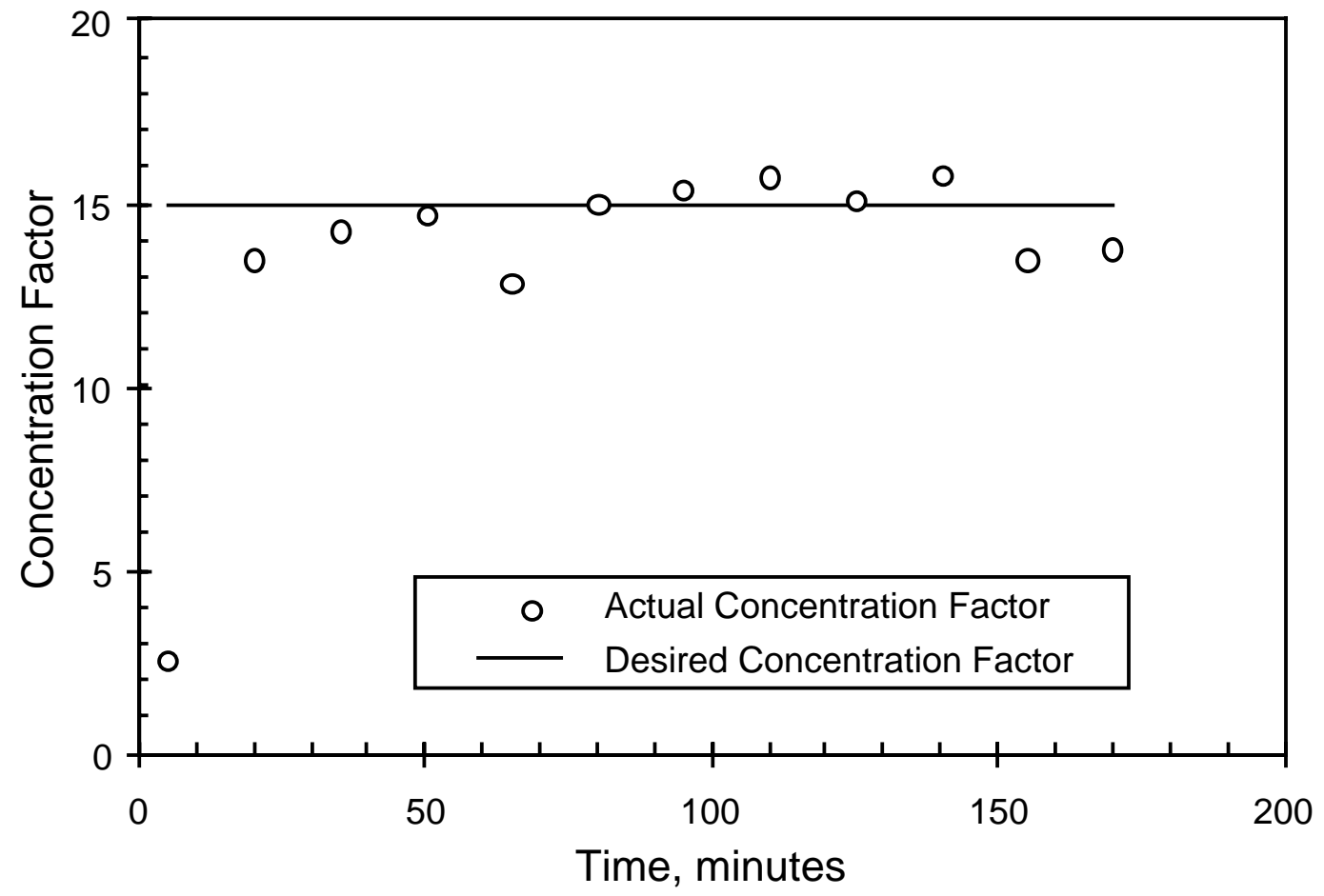

Fig. 15. Concentration Factor vs. Time for CSSX Flowsheet Test with Solvent Recycle (CS25) 


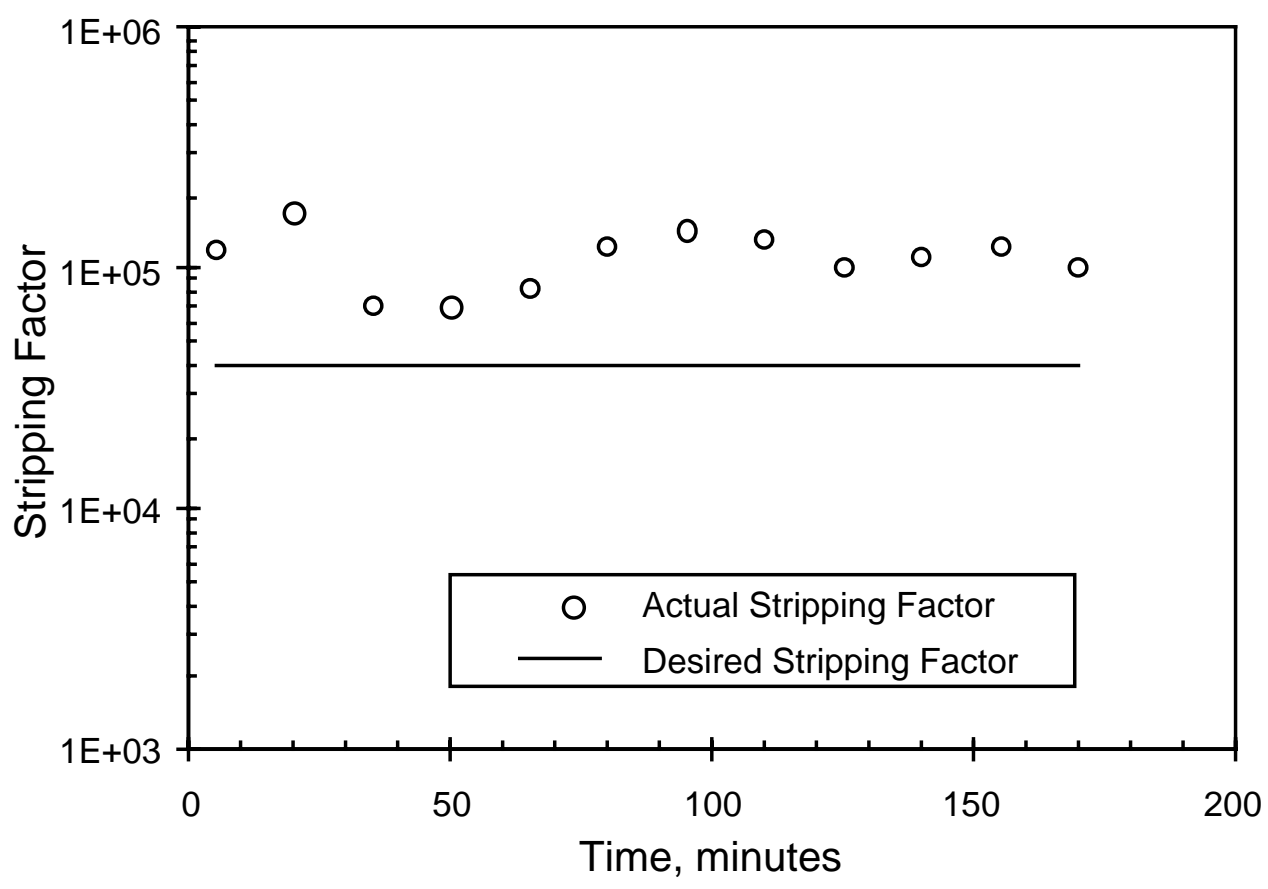

Fig. 16. Stripping Factor vs. Time for CSSX Flowsheet Test with Solvent Recycle (CS25)

Preparations for the CSSX flowsheet tests are discussed in Appendix C along with detailed test measurements and observations.

\section{DISCUSSION}

Three methods were used to improve stage efficiency in a multistage 2-cm contactor: use of a wire rope in the interstage lines, increased liquid volume in the annular mixing zone, and use of the maximum possible flow rate. Because of the lack of time, these methods could not be evaluated individually. Instead, they were all implemented and tested together. In the future, it would be desirable to measure each separately to determine its true contribution.

To estimate the contributions of these three changes, we analyzed the experimental data for the 2-cm contactor tests. When the multistage mass transfer efficiencies for the improved 2$\mathrm{cm}$ contactor are plotted in Fig. 4, they fall on the model curve for single-stage operation. Thus, it appears the change making the greatest contribution is associated with multistage operation, that is, the wire rope in the interstage lines. Although we eliminated slugs in interstage flow, when the liquid enters the stage in single-stage operation, it probably enters as small droplets, as illustrated in Fig. 9. The changes we made here do not affect this part of the liquid flow. When the second change (the increased liquid volume in the annular mixing zone) is compared to the volume of the slugs that occurs in interstage lines, it appears to be the same order of magnitude. Thus, increasing the liquid volume in the annular mixing zone should have only a small effect on the stage efficiency. For the third change (the increased flow), the flow rate becomes important in improving stage efficiency at high flow rates (about $100 \mathrm{~mL} / \mathrm{min}$ and greater). Thus, the 
increased flow at the flow rates in our tests $(<60 \mathrm{~mL} / \mathrm{min})$ will probably have only a minor effect. From this analysis of the data, our estimate of the probable contribution of each factor to the improved $\mathrm{E}_{\mathrm{a}}$ value is as follows: wire rope, $\sim 70$ to $80 \%$; increased liquid volume, $\sim 10$ to $30 \%$; increased flow rate, $\sim 0$ to $10 \%$.

The $\mathrm{E}_{\mathrm{a}}$ data in Fig 4 show significant scatter. This suggests that other factors affect $\mathrm{E}_{\mathrm{a}}$ besides the two used there, O/A flow ratio and single- vs. multi-stage operation. One of these factors could be the gap at the bottom of the rotor and the top of the bottom vanes. Since our units were made over a period of time and drawing specifications allow for a gap variation of 1.6 $\mathrm{mm} \pm 0.8 \mathrm{~mm}(1 / 16 \pm 1 / 32 \mathrm{in}$.), significant variations can occur in the liquid height in the annular mixing zone. To the extent that this liquid height affects $E_{a}$, this gap could be one of the variables contributing to the scatter in the $\mathrm{E}_{\mathrm{a}}$ data.

Slug flow in the interstage lines of the 2-cm contactor appears to decrease $E_{a}$ values. In larger contactors with interstage flows greater than $100 \mathrm{~mL} / \mathrm{min}$, fluid momentum rather than surface tension controls this flow. The slugs disappear and expected $E_{a}$ values are measured. Another hydraulic problem that we observed in the old 2-cm contactor was phase inversion [LEONARD-1988]. In this unit, the organic phase remained the continuous phase even though the O/A flow ratio was very low, that is, phase inversion to an aqueous-continuous system did not occur. Instead, the dispersion in the mixing zone became very viscous and would not flow into the inlet at the bottom of the rotor. As a result, the dispersion rose in the mixing zone and flowed out the less-dense-phase exit. This phase-inversion problem has never been observed with 4-cm and larger contactors. Thus, we expect that hydraulic performance and stage efficiency will improve for larger centrifugal contactors.

As was seen for earlier CSSX tests [LEONARD-1999A], the $\mathrm{D}_{\mathrm{Cs}}$ values determined from stage samples in the strip section are high when compared with the $\mathrm{D}_{\mathrm{Cs}}$ values from batch tests. As before, they were determined to be high because the stage efficiencies calculated from them were greater than $100 \%$. Based on the definition of stage efficiency, values cannot be greater than $100 \%$. We suspect that the low acid level in the strip section makes it easy to change the chemistry of the draining liquids, probably because of impurities in the drain line. The drain lines have an outside diameter of $6.4 \mathrm{~mm}$ (1/4 in.) and an inside diameter of $4.8 \mathrm{~mm}$ (3/16 in.), so that it is physically difficult to clean out these lines.

For the stage efficiency tests, the material balance and the $\mathrm{E}_{\mathrm{a}}$ for the scrub section were not as accurate as for the extraction and strip sections. This was not surprising as the mass transfer of cesium in the strip section is low. As a result, small errors in the cesium analysis and the flow rate measurements are magnified. However, for the scrub section, the $E_{a}$ values are not as important as for the other two sections. The chief functions of the scrub section are to (1) back extract other metal ions so that the aqueous strip effluent is mainly Cs and (2) ensure that entrained waste feed cannot reach the strip section where its high concentration of anions, especially nitrate, would impair stripping. The solvent is made slightly acidic before it leaves the scrub section. In this way, the strip section, which is only slightly acidic, stays acidic. Based on the metal ions in the aqueous strip effluent and the $\mathrm{pH}$ measurements of the aqueous strip effluent, the scrub section worked very well. 
The rotors between the extraction and scrub tests were cleaned of the alkaline aqueous solution by dipping them in a beaker with $0.05 \mathrm{M} \mathrm{HNO}_{3}$. We also had to turn the rotor on so that the acid was flushed through the rotor. Only by these steps could we ensure that the alkaline aqueous phase was completely removed. After cleaning, the acid solution was checked with $\mathrm{pH}$ paper to be sure it was still acidic. If it was not, the cleaning was repeated with fresh acid solution.

Since the final temperatures in the aqueous raffinate for tests CS24 and CS25 had risen close to the point where the decontamination factor drops below 40,000, we need to design a better system for controlling the temperature of the liquid in the extraction section. This potential problem will be considered in any future tests of the CSSX flowsheet.

\section{ACKNOWLEDGMENTS}

This work was supported by the Office of Environment Management of the U.S. Department of Energy through (1) the Office of Project Completion and (2) the Tank Focus Area of the Office of Science and Technology under Contract W-31-109-Eng-38 with Argonne National Laboratory, managed by the University of Chicago.

The authors wish to acknowledge the help of Greg Dolnak, ANL Waste Management Operations, in setting up and running the tests reported here and the help of Frank Markun, Del Bowers, and Lillian Ruscic, all of the ANL Chemical Technology Division, in preparing the test solutions. Tests CS23, CS24, and CS25 were observed by Reid Peterson and Paul Rutland, both of Westinghouse Savannah River Company (WSRC). Tests CS23 and CS24 were observed by Ken Rueter of WSRC. Tests CS23 and CS25 were observed by Joe Carter of WSRC. 


\section{REFERENCES}

[ARAFAT-2001]

[BERNSTEIN-1973]

[BONNESEN-2000]

[CAMPBELL-2001]

[LEONARD-1980]

[LEONARD-1988]

[LEONARD-1994]

[LEONARD-1997]

[LEONARD-1999A]

[LEONARD-1999B]
H. A. Arafat and R. A. Leonard, Temperature Management of Centrifugal Contactor for Caustic-Side Solvent Extraction of Cesium from Tank Waste, Argonne National Laboratory Report ANL-00/31 (2001).

G. J. Bernstein, D. E. Grosvenor, J. F. Lenc, and N. M. Levitz, "A High-Capacity Annular Centrifugal Contactor," Nucl. Technol. 20, 200-202 (1973).

P. V. Bonnesen, L. H. Delmau, B. A. Moyer, and R. A. Leonard, "A Robust Alkaline-Side CSEX Solvent Suitable for Removing Cesium from Savannah River High Level Waste," Solvent Extr. Ion Exch. 18(6), 1079-1108 (2000).

S. G. Campbell, M. W. Geeting, C. W. Kennell, J. D. Law, R. A. Leonard, M. A. Norato, R. A. Pierce, T. A. Todd, D. D. Walker, and W. R. Wilmarth, Demonstration of Caustic-Side Solvent Extraction with Savannah River Site High Level Waste, Westinghouse Savannah River Corporation Technical Report WSRC-TR-2001-00223 (April 2001).

R. A. Leonard, G. J. Bernstein, A. A. Ziegler, and R. H. Pelto, "Annular Centrifugal Contactors for Solvent Extraction," Sep. Sci. Technol. 15, 925-943 (1980).

R. A. Leonard, "Recent Advances in Centrifugal Contactor Design," Sep. Sci. Technol. 23, 1473-1487 (1988).

R. A. Leonard and M. C. Regalbuto, "A Spreadsheet Algorithm for Stagewise Solvent Extraction," Solvent Extr. Ion Exch. 12(5), 909-930 (1994).

R. A. Leonard, D. B. Chamberlain, and C. Conner, "Centrifugal Contactors for Laboratory-Scale Solvent Extraction Tests," Sep. Sci. Technol. 32(1-4), 193-210 (1997).

R. A. Leonard, C. Conner, M. W. Liberatore, J. Sedlet, S. B. Aase, and G. F. Vandegrift, Evaluation of an Alkaline-Side Solvent Extraction Process for Cesium Removal from SRS Tank Waste Using Laboratory-Scale Centrifugal Contactors, Argonne National Laboratory Report ANL-99/14 (1999).

R. A. Leonard, "Design Rules for Solvent Extraction," Sol. Extr. Ion Exch. 17(3), 597-612 (1999). 
[LEONARD-2000]

R. A. Leonard, S. B. Aase, H. A. Arafat, C. Conner, J. R. Falkenberg, and G. F. Vandegrift, Proof-of-Concept Flowsheet Tests for Caustic-Side Solvent Extraction of Cesium from Tank Waste, Argonne National Laboratory Report ANL-00/30 (2000).

[LEONARD-2001A] R. A. Leonard, C. Conner, M. W. Liberatore, J. Sedlet, S. B. Aase, G. F. Vandegrift, L. H. Delmau, P. V. Bonnesen, and B. A. Moyer, "Development of a Solvent Extraction Process for Cesium Removal from SRS Tank Waste," Sep. Sci. Technol. 36(5\&6), 743-766 (2001).

[LEONARD-2001B] R. A. Leonard, S. B. Aase, H. A. Arafat, D. B. Chamberlain, C. Conner, M. C. Regalbuto, and G. F. Vandegrift, Interim Report on a Multi-Day Test of the Caustic-Side Solvent Extraction Flowsheet for Cesium Removal from a Simulated SRS Tank Waste, Argonne National Laboratory Report ANL-01/10 (2001).

[LEVENSON-2000]

M. Levenson et al., Alternatives for High-Level Waste Salt Processing at the Savannah River Site, National Research Council, National Academy Press, Washington, DC (2000).

[PETERSON-2000]

R. A. Peterson, Preparation of Simulated Waste Solutions for Solvent Extraction Testing, Westinghouse Savannah River Co. Report WSRC-RP-2000-361 (May 1, 2000). 


\section{APPENDIX A}

\section{FURTHER DETAILS OF HYDRAULIC TESTS USING THE 2-CM CONTACTOR}

The effect of water flow rate and contactor geometry on liquid height in the annular mixing zone was measured in a single-stage $2-\mathrm{cm}$ contactor. The results are given in Table 5. Both the larger diameter for the rotor inlet and the larger gap between the rotor and the bottom vanes were found to have an effect. As shown in the table, the increased diameter for the rotor inlet had the larger effect. The contactor housing for these tests was a transparent acrylic so that we could measure the increase in liquid height in the mixing zone.

Table 5. Effect of Water Flow Rate and Contactor Geometry on Liquid Height in the Annular Mixing Zone

\begin{tabular}{|c|c|c|c|c|c|}
\hline $\begin{array}{c}\text { Dia. of Rotor } \\
\text { Inlet, mm (in.) }\end{array}$ & $\begin{array}{c}\text { Gap below Rotor, } \\
\mathrm{mm}(\mathrm{in} .)\end{array}$ & $\begin{array}{c}\text { Liquid Height in } \\
\text { Mixing Zone, } \\
\mathrm{mm}\end{array}$ & $\begin{array}{c}\text { Flow Rate, } \\
\mathrm{mL} / \mathrm{min}\end{array}$ & $\begin{array}{c}\text { Increase in } \\
\text { Lid Height, } \\
\%\end{array}$ & Notes \\
\hline $7.92(0.312)$ & $1.19(0.047)$ & 12.2 & 0 & - & Base case \\
\hline $7.92(0.312)$ & $1.19(0.047)$ & 14.2 & 10 & - & Base case \\
\hline $7.92(0.312)$ & $1.19(0.047)$ & 18 & 50 & - & Base case \\
\hline $7.92(0.312)$ & $1.98(0.078)$ & 17.3 & 0 & 42 & \\
\hline $7.92(0.312)$ & $1.98(0.078)$ & 20.9 & 10 & 47 & \\
\hline $7.92(0.312)$ & $1.98(0.078)$ & 22.2 & 50 & 23 & \\
\hline $10.72(0.422)$ & $1.19(0.047)$ & 17.7 & 0 & 45 & \\
\hline $10.72(0.422)$ & $1.19(0.047)$ & 23.9 & 10 & 68 & \\
\hline $10.72(0.422)$ & $1.19(0.047)$ & 34.5 & 50 & 92 & $\mathrm{~d}$ \\
\hline $10.72(0.422)$ & $1.98(0.078)$ & 18.5 & 0 & 52 & \\
\hline $10.72(0.422)$ & $1.98(0.078)$ & 22.5 & 10 & 58 & \\
\hline $10.72(0.422)$ & $1.98(0.078)$ & 33 & 50 & 83 & \\
\hline
\end{tabular}

${ }^{\text {a }}$ Smaller gap of $1.19 \mathrm{~mm}$ is the normal gap size.

${ }^{\mathrm{b}}$ The liquid height is measured up from the bottom edge of the rotor.

${ }^{c}$ This height increase is relative to the rotor with the $7.92 \mathrm{~mm}$ inlet dia. and the normal (1.19 $\mathrm{mm}$ ) gap between the bottom of the rotor and the top of the bottom vanes.

${ }^{\mathrm{d}}$ Photos taken during this measurement with automatic flash and available light are shown in Figs 6 and 7, respectively. Photos were taken with an Olympus D-600L digital camera.

We carried out a series of single-stage, two-phase hydraulic performance tests to determine the maximum throughput for each section of the CSSX process. The contactor housing was made of an acrylic resin so that it was transparent. Thus, if flooding of the mixing zone occurred, it could be observed directly. The results of the two-phase flow tests are given in Table 6. 
Table 6. Results of Two-Phase Flow Tests in Single-Stage 2-cm Contactor

\begin{tabular}{|c|c|c|c|c|c|c|c|}
\hline $\begin{array}{c}\text { O/A Flow } \\
\text { Ratio }\end{array}$ & $\begin{array}{c}\text { Total Flow, } \\
\mathrm{mL} / \mathrm{min}\end{array}$ & $\begin{array}{l}\text { Initial Cont. } \\
\text { Phase }^{\mathrm{a}}\end{array}$ & $\mathrm{O}$ in $\mathrm{A}, \%$ & $\begin{array}{c}\text { Appearance of A } \\
\text { Phase }^{\mathrm{b}}\end{array}$ & $\mathrm{A}$ in $\mathrm{O}, \%$ & $\begin{array}{c}\text { Appearance of O } \\
\text { Phase }^{\mathrm{b}}\end{array}$ & Notes \\
\hline \multicolumn{8}{|c|}{$0.001 \mathrm{M} \mathrm{HNO}_{3}$ (Strip Section) } \\
\hline 0.2 & 45 & A & $\operatorname{tr}$ & hazy & 0.12 & clr & \\
\hline 0.2 & 45 & $\mathrm{O}$ & - & - & - & - & $\mathrm{c}$ \\
\hline 1 & 10 & A & 0.0 & clr & 10 & sl cldy & \\
\hline 1 & 10 & $\mathrm{O}$ & 0.0 & clr & 8 & sl cldy & \\
\hline 1 & 45 & A & 0.0 & clr & $\operatorname{tr}$ & hazy & \\
\hline 1 & 45 & $\mathrm{O}$ & 0.0 & clr & $\operatorname{tr}$ & hazy & \\
\hline 1 & 72 & A & $\operatorname{tr}$ & cldy & 0.0 & hazy & \\
\hline 1 & 72 & $\mathrm{O}$ & 50 & cldy & 12 & hazy & \\
\hline 5 & 45 & A & 0.0 & clr & 0.03 & hazy & \\
\hline 5 & 45 & $\mathrm{O}$ & 0.0 & clr & 0.05 & hazy & \\
\hline \multicolumn{8}{|c|}{$0.05 \mathrm{M} \mathrm{HNO}_{3}$ (Scrub Section) } \\
\hline 0.2 & 45 & A & 0.0 & hazy & 0.0 & hazy & \\
\hline 0.2 & 45 & $\mathrm{O}$ & 1.3 & sl cldy & 7 & hazy & $\mathrm{d}$ \\
\hline 0.2 & 72 & $\mathrm{~A}$ & - & - & - & - & $\mathrm{e}$ \\
\hline 1 & 10 & A & 0.0 & crys clr & $\operatorname{tr}$ & clr & \\
\hline 1 & 10 & $\mathrm{O}$ & 0.0 & crys clr & 0.0 & $\mathrm{clr}$ & \\
\hline 1 & 45 & $\mathrm{~A}$ & 0.0 & crys clr & 0.0 & cldy & \\
\hline 1 & 45 & $\mathrm{O}$ & 0.0 & crys clr & $\operatorname{tr}$ & sl cldy & \\
\hline 1 & 72 & A & $\operatorname{tr}$ & crys clr & 2 & sl cldy & \\
\hline 1 & 72 & $\mathrm{O}$ & - & - & - & - & $\mathrm{f}$ \\
\hline 5 & 45 & A & 0.0 & crys clr & 0.0 & hazy & \\
\hline 5 & 45 & $\mathrm{O}$ & 0.0 & hazy & 0.0 & sl cldy & \\
\hline \multicolumn{8}{|c|}{$1 \mathrm{M}$ NaOH (Alkaline Simulant I for Extraction Section) } \\
\hline 0.2 & 72 & A & 0.0 & hazy & 1.4 & cldy & \\
\hline 0.2 & 72 & $\mathrm{O}$ & 0.0 & hazy & 2.4 & cldy & \\
\hline 1 & 72 & $\mathrm{~A}$ & 0.0 & crys clr & 0.0 & cldy & \\
\hline 1 & 72 & $\mathrm{O}$ & 0.0 & $\mathrm{clr}$ & $\operatorname{tr}$ & cldy & \\
\hline \multicolumn{8}{|c|}{ Alkaline Simulant II (Extraction Section) } \\
\hline 0.2 & 45 & A & $\operatorname{tr}$ & hazy & $\operatorname{tr}$ & $\mathrm{clr}$ & \\
\hline 0.2 & 45 & $\mathrm{O}$ & 0.0 & clr & 0.0 & clr & \\
\hline 0.2 & 72 & A & $\operatorname{tr}$ & cldy & 1.5 & hazy & \\
\hline 0.2 & 72 & $\mathrm{O}$ & 0.0 & cldy & 1.9 & hazy & \\
\hline 0.2 & 90 & $\mathrm{~A}$ & $\operatorname{tr}$ & hazy & $\operatorname{tr}$ & hazy & \\
\hline 0.2 & 90 & $\mathrm{O}$ & - & - & - & - & $\mathrm{g}$ \\
\hline 1 & 10 & $\mathrm{~A}$ & 0.0 & crys clr & $\operatorname{tr}$ & sl cldy & \\
\hline 1 & 10 & $\mathrm{O}$ & 0.0 & crys clr & 0.0 & sl cldy & \\
\hline 1 & 45 & $\mathrm{~A}$ & 0.0 & crys clr & $\operatorname{tr}$ & hazy & \\
\hline 1 & 45 & $\mathrm{O}$ & 0.0 & crys clr & $\operatorname{tr}$ & hazy & \\
\hline 1 & 72 & $\mathrm{~A}$ & 0.0 & clr & 0.8 & sl cldy & \\
\hline 1 & 72 & $\mathrm{O}$ & 0.0 & crys clr & $\operatorname{tr}$ & sl cldy & \\
\hline 1 & 90 & $\mathrm{~A}$ & 0.0 & $\mathrm{clr}$ & 2 & hazy & \\
\hline 1 & 90 & $\mathrm{O}$ & 0.0 & $\mathrm{clr}$ & 2 & hazy & \\
\hline 5 & 45 & $\mathrm{~A}$ & 0.0 & clr & $\operatorname{tr}$ & hazy & \\
\hline 5 & 45 & $\mathrm{O}$ & 0.0 & $\mathrm{clr}$ & $\operatorname{tr}$ & hazy & \\
\hline
\end{tabular}

${ }^{a}$ Phase that is in the mixing zone before the other phase is introduced.

b Appearance is defined as follows: "crys clr" is crystal clear; "clr" is clear; "hazy" is hazy; "sl cldy" is slightly cloudy such that one can still see fairly well through a 40-mL centrifuge tube; "cldy" is cloudy such that one can still see through a 40-mL centrifuge tube, but not well; and "v cldy" is very cloudy such that one cannot see through a 40-mL centrifuge tube.

${ }^{c}$ Inoperable. Liquid level in mixing zone rose quickly after started A flow.

${ }^{\mathrm{d}}$ Inoperable. Had to work hard to get results this good.

${ }^{\mathrm{e}}$ Inoperable. Liquid level in mixing zone rose quickly and flooded rotor. Both phases out both exit ports.

${ }^{\mathrm{f}}$ Inoperable. Foam and high liquid level were seen in mixing zone when second phase was introduced. All $\mathrm{O}$ was in A effluent.

${ }^{g}$ Inoperable. Noted other phase carryover of O into A effluent. Also, had liquid level in mixing zone go all the way up the rotor. 
For the strip section (aqueous feed is $0.001 \underline{\mathrm{M}} \mathrm{HNO}_{3}$ ), the hydraulic performance was acceptable at the high O/A flow ratios (around 5.0) needed for the CSSX flowsheet. This means that other-phase carryover was less than $1 \%$ for both effluents. At the low O/A flow ratios (around 0.2), problems developed if the two-phase flow was established with the mixing zone initially filled with the organic phase, that is, initially organic continuous. Thus, operation at low $\mathrm{O} / \mathrm{A}$ flow ratios should be avoided. At an O/A flow ratio of 1.0, hydraulic performance was mixed. At low flow rates $(10 \mathrm{~mL} / \mathrm{min}$ total flow $)$, hydraulic performance was unsatisfactory, since 8 to $10 \% \mathrm{~A}$ in $\mathrm{O}$ was observed. At $45 \mathrm{~mL} / \mathrm{min}$ total flow, hydraulic performance was fine. At $72 \mathrm{~mL} / \mathrm{min}$ total flow, we had exceeded the maximum throughput of the contactor. When operation was started as initially aqueous continuous, hydraulic performance was acceptable. However, when started as initially organic continuous, hydraulic performance was unacceptable, with $12 \% \mathrm{~A}$ in $\mathrm{O}$ and $50 \% \mathrm{O}$ in $\mathrm{A}$. While the hydraulic performance in the strip section is mixed, it works at the high O/A flow ratios needed for the CSSX flowsheet.

The hydraulic performance for the scrub section (aqueous feed is $0.05 \underline{\mathrm{M}} \mathrm{HNO}_{3}$ ) was similar to that for the strip section. At the high O/A flow ratios (around 5.0) needed for the CSSX flowsheet, hydraulic performance was okay. At the low O/A flow ratios (around 0.2), problems developed at $45 \mathrm{~mL} / \mathrm{min}$ total flow if the two-phase flow was initially organic continuous. These problems were not as severe as for the strip section. However, at $72 \mathrm{~mL} / \mathrm{min}$ total flow, the contactor was inoperable even when the two-phase flow was initially organic continuous. Thus, operation at low O/A flow ratios should be avoided. At an O/A flow ratio of 1.0, hydraulic performance was good at flow rates up to $45 \mathrm{~mL} / \mathrm{min}$ total flow. However, at 72 $\mathrm{mL} / \mathrm{min}$ total flow, we exceeded the maximum throughput. The contactor became inoperable when we tried to start it up as initially organic continuous. When operation was started as initially aqueous continuous, hydraulic performance was acceptable except for $2 \% \mathrm{~A}$ in $\mathrm{O}$. While the hydraulic performance in the scrub section is mixed, it works at the high O/A flow ratios needed for the CSSX flowsheet.

For the extraction section (see the results for $1.0 \mathrm{M} \mathrm{NaOH}$ and, especially, alkaline simulant II), hydraulic performance is good at all O/A flow ratios up to $45 \mathrm{~mL} / \mathrm{min}$ total flow. Since we want to operate at an O/A flow ratio around 0.3, the flow rates for O/A flow ratios of 0.2 and 1.0 were increased up to $90 \mathrm{~mL} / \mathrm{min}$. At $72 \mathrm{~mL} / \mathrm{min}$, we obtained 0.8 to $1.9 \% \mathrm{~A}$ in $\mathrm{O}$. Based on this, we concluded that $60 \mathrm{~mL} / \mathrm{min}$ total flow could be used as shown in the CSSX flowsheet (Fig. 8). At $90 \mathrm{~mL} / \mathrm{min}$, an O/A flow ratio of 0.2 , and initially organic continuous, the contactor becomes inoperable. Thus, while hydraulic performance in the extraction section is good for the flow rates and O/A flow ratios needed for the CSSX flowsheet, $60 \mathrm{~mL} / \mathrm{min}$ must be considered the maximum throughput. 


\section{APPENDIX B}

\section{FURTHER DETAILS OF THE STAGE EFFICIENCY TESTS}

Discussed here are preparations for tests CS20, CS21, and CS22, as well as detailed measurements and observations made during the tests. These details supplement the test summary given in the body of this report.

The contactor stages were cleaned as follows. Fill the stages with deionized (DI) water by removing the motor/rotor assembly from one stage and adding water to the empty contactor housing. Water will flow to adjacent stages. Replace the motor/rotor assembly. Allow the contactors to soak in the DI water (in some cases overnight). Repeat for all stages to be cleaned. (The rotors may be turned on and run for 1-2 min.) Drain the stages. Allow the stages to sit with the drains open overnight to dry. Close all stage drains. Disconnect all interstage lines from the stage to be cleaned. Put $90^{\circ}$ elbows made of plastic tubing over the inlet ports on both sides of the stage with the arm of each elbow pointing upward. Fill the stage with an organic solvent, such as trichloroethylene, and allow it to run out of the outlet ports. Collect the solvent as it runs out, then place a beaker under the stage drain and open it. Dip a bottle brush in the solvent and clean the inlet and outlet ports. Also clean the collector rings with a narrow bottle brush in the same manner. Pour solvent into the standpipe and use the narrow brush to clean inside each one. Fill the stage with solvent once again, and collect the rinsate through the stage drain. The solvent may be reused for other stages.

During the three tests, effluent samples were taken every 15 min starting 5 min after the radioactive (hot) feed was introduced into the contactor. For flow rates above $10 \mathrm{~mL} / \mathrm{min}$, a sample collection time of 1 min was used. For lower flow rates, a sample collection time of 5 min was used. In addition to measuring the Cs-137 concentration, this collection procedure allowed us to check the effluent flow rate, its appearance, and the presence of any other-phase carryover. For the scrub and strip tests, we also measured the $\mathrm{pH}$ of the aqueous effluent. Test CS20 ran for $92 \mathrm{~min}, \mathrm{CS} 21$ ran for $88 \mathrm{~min}$, and CS22 ran for $74 \mathrm{~min}$. In each case, the test continued until we ran out of solvent. The data from these effluent samples are summarized in Table 7. During each test, the liquid backup in the interstage lines was observed and recorded for various times, as reported in Table 8. If the interstage line is listed as "open," the amount of liquid is less than $10 \%$. After each test, the two immiscible liquids in each stage were drained, and their volumes and temperature measured. They were equilibrated by shaking for 15-20 s in 60-mL collection bottles. After equilibration, the temperature was measured again. The two phases were separated, and each phase was analyzed for its cesium concentration. This gives a $\mathrm{D}_{\mathrm{Cs}}$ value at a known temperature for each process stage. The stage-sample results are summarized in Table 9. Average flow rates for the feeds and effluents are listed in Table 10 along with their cesium concentrations. Using these data, we did a cesium material balance for each test, which is also shown in Table 10. The material balances were very good for the extraction and strip tests and not as good for the scrub test. Thus, the scrub results should be used with caution. 
Table 7. Effluent Samples Taken during Stage Efficiency Tests

\begin{tabular}{|c|c|c|c|c|c|c|c|}
\hline Test & $\begin{array}{c}\text { Time, } \\
\text { min }\end{array}$ & $\begin{array}{c}\text { Effluent } \\
\text { Flow Rate, } \\
\text { mL/min }\end{array}$ & $\begin{array}{c}\text { Effluent } \\
\text { Temp, }{ }^{\circ} \mathrm{C}\end{array}$ & Appearance & $\begin{array}{c}\text { Other- } \\
\text { Phase } \\
\text { Carryover, } \\
\%\end{array}$ & $\begin{array}{c}\text { Cs Conc, } \\
\underline{\mathrm{M}}\end{array}$ & $\mathrm{pH}$ \\
\hline \multicolumn{8}{|c|}{ Aqueous Effluent } \\
\hline CS20 & 5 & 46.8 & 24.1 & sl cldy & 0 & $3.52 \mathrm{E}-07$ & - \\
\hline CS20 & 20 & 44.0 & 25.4 & sl cldy & 0 & $4.28 \mathrm{E}-07$ & - \\
\hline $\mathrm{CS} 20$ & 35 & 46.7 & 26.4 & sl cldy & 0 & $5.25 \mathrm{E}-07$ & - \\
\hline CS20 & 50 & 46.0 & 27.1 & cldy & 0 & 7.04E-07 & - \\
\hline CS20 & 65 & 46.5 & 27.6 & sl cldy & 0 & 7.01E-07 & - \\
\hline CS20 & 80 & 45.0 & 27.8 & sl cldy & 0 & 7.91E-07 & - \\
\hline CS21 & 5 & 2.64 & 25.8 & hazy & 0 & $3.45 \mathrm{E}-04$ & 2 \\
\hline CS21 & 20 & 2.40 & 25.8 & $\mathrm{clr}$ & 0 & $4.61 \mathrm{E}-04$ & 1.5 \\
\hline CS21 & 35 & 2.84 & 26.2 & $\mathrm{clr}$ & 0 & 4.91E-04 & 1.5 \\
\hline $\mathrm{CS} 21$ & 50 & 2.72 & 26.5 & clr & 0 & $5.04 \mathrm{E}-04$ & 1.5 \\
\hline CS21 & 65 & 2.71 & 25.9 & $\mathrm{clr}$ & 0 & $5.10 \mathrm{E}-04$ & 1.5 \\
\hline CS21 & 80 & 2.74 & 26.2 & $\mathrm{clr}$ & 0 & 5.33E-04 & 1.5 \\
\hline $\mathrm{CS} 22$ & 5 & 2.26 & 26.2 & $\mathrm{clr}$ & 0 & $9.70 \mathrm{E}-04$ & 4 \\
\hline $\mathrm{CS} 22$ & 20 & 2.68 & 25.5 & clr & 0 & $1.50 \mathrm{E}-03$ & 4.5 \\
\hline CS22 & 35 & 2.00 & 27.5 & hazy & 0 & $1.46 \mathrm{E}-03$ & 4 \\
\hline CS22 & 50 & 2.72 & 27.1 & hazy & 0 & $1.58 \mathrm{E}-03$ & 4.5 \\
\hline $\mathrm{CS} 22$ & 65 & 2.60 & 26.7 & hazy & 0 & $1.60 \mathrm{E}-03$ & 5 \\
\hline \multicolumn{8}{|c|}{ Organic Effluent } \\
\hline CS20 & 5 & 16.0 & 24.2 & $\mathrm{clr}$ & 0 & $4.00 \mathrm{E}-04$ & Not Appl \\
\hline CS20 & 20 & 14.5 & 23.9 & clr & 0 & 4.38E-04 & Not Appl \\
\hline CS20 & 35 & 14.0 & 24.0 & clr & 0 & 4.07E-04 & Not Appl \\
\hline CS20 & 50 & 14.0 & 25.4 & $\mathrm{clr}$ & 0 & 3.98E-04 & Not Appl \\
\hline CS20 & 65 & 14.0 & 24.6 & clr & 0 & 4.60E-04 & Not Appl \\
\hline CS20 & 80 & 14.0 & 24.2 & clr & 0 & \begin{tabular}{|l|}
$3.95 \mathrm{E}-04$ \\
\end{tabular} & Not Appl \\
\hline CS21 & 5 & 16.0 & 25.9 & hazy & 0 & $2.85 \mathrm{E}-04$ & Not Appl \\
\hline CS21 & 20 & 15.0 & 27.3 & hazy & 0 & \begin{tabular}{|l|}
$3.37 \mathrm{E}-04$ \\
\end{tabular} & Not Appl \\
\hline CS21 & 35 & 14.5 & 27.4 & hazy & 0 & $2.74 \mathrm{E}-04$ & Not Appl \\
\hline CS21 & 50 & 14.0 & 27.4 & hazy & 0 & $2.73 \mathrm{E}-04$ & Not Appl \\
\hline CS21 & 65 & 14.0 & 27.4 & clr & 0 & $2.82 \mathrm{E}-04$ & Not Appl \\
\hline CS21 & 80 & 14.0 & 28.0 & clr & 0 & $2.70 \mathrm{E}-04$ & Not Appl \\
\hline $\mathrm{CS} 22$ & 5 & 15.0 & 26.9 & clr & 0 & $2.69 \mathrm{E}-06$ & Not Appl \\
\hline CS22 & 20 & 13.0 & 27.8 & $\mathrm{clr}$ & 0 & 5.88E-06 & Not Appl \\
\hline CS22 & 35 & 6.5 & 27.1 & clr & 0 & \begin{tabular}{|l|}
$5.67 \mathrm{E}-06$ \\
\end{tabular} & Not Appl \\
\hline $\mathrm{CS} 22^{\mathrm{a}}$ & 44 & 16.0 & Not Meas & Not Meas & Not Meas & Not Meas & Not Appl \\
\hline CS22 & 50 & 13.0 & 27.7 & clr & 0 & 3.52E-06 & Not Appl \\
\hline $\mathrm{CS} 22$ & 65 & 14.0 & 29.1 & clr & 0 & 3.61E-06 & Not Appl \\
\hline
\end{tabular}

\footnotetext{
${ }^{a}$ Special sample taken just to check flow rate.
} 
Table 8. Amount of Liquid in Interstage Lines during Stage Efficiency Tests

\begin{tabular}{|c|c|c|c|c|c|c|c|c|}
\hline & & & \multicolumn{5}{|c|}{ Amount of Liquid in Interstage Line during Test, $\%$} \\
\cline { 4 - 9 } Test & Phase & Line $^{\text {a }}$ & 5 min & 20 min & 35 min & 50 min & 65 min & 80 min \\
\hline CS20 & A & 2 to 1 & open & open & & open & open & \\
\hline CS20 & A & 3 to 2 & 50 & 50 & & 50 & open & \\
\hline CS20 & A & 4 to 3 & 30 & 25 & & 25 & 25 & \\
\hline CS20 & O & 1 to 2 & 70 & 80 & & 60 & 70 & \\
\hline CS20 & O & 2 to 3 & 60 & 60 & & 45 & 50 & \\
\hline CS20 & O & 3 to 4 & 30 & 45 & & 50 & 60 & \\
\hline CS21 & A & 6 to 5 & 25 & 30 & 25 & 25 & 25 & 25 \\
\hline CS21 & O & 5 to 6 & open & open & open & open & open & open \\
\hline CS22 & A & 8 to 7 & open & open & open & & & \\
\hline CS22 & A & 9 to 8 & 15 & open & open & & & \\
\hline CS22 & A & 10 to 9 & 40 & 30 & 40 & & & \\
\hline CS22 & O & 7 to 8 & 50 & 55 & 10 & & open & \\
\hline CS22 & O & 8 to 9 & 50 & 50 & 50 & & 50 & \\
\hline CS22 & O & 9 to 10 & open & open & open & & open & \\
\hline
\end{tabular}

${ }^{\text {a }}$ Shows stage where flow enters interstage line and stage where it exits.

$\mathrm{b}$ "Open" means that the amount of liquid is less than $10 \%$.

Table 9. Stage Samples Taken after Stage Efficiency Tests

\begin{tabular}{|c|c|c|c|c|c|c|c|c|c|c|}
\hline Test & Stage & $\begin{array}{c}\text { Aq } \\
\text { Vol in } \\
\text { Stage } \\
\text { after } \\
\text { Test, } \\
\text { mL } \\
\end{array}$ & $\begin{array}{c}\text { Org } \\
\text { Vol in } \\
\text { Stage } \\
\text { after } \\
\text { Test, } \\
\text { mL }\end{array}$ & \begin{tabular}{|c|} 
Temp \\
when \\
Drain \\
Stage \\
Liquid, \\
${ }^{\circ} \mathrm{C}$
\end{tabular} & $\begin{array}{c}\text { Time } \\
\text { when } \\
\text { Meas'd } \\
\text { Temp, }{ }^{\text {a }} \\
\text { min }\end{array}$ & $\begin{array}{c}\text { Est'd } \\
\text { Temp }^{\mathrm{b}} \text { in } \\
\text { Stage } \\
\text { during } \\
\text { Test, }^{\circ} \mathrm{C}\end{array}$ & $\begin{array}{c}\text { [Cs] in A } \\
\text { after } \\
\text { Equili- } \\
\text { brated } \\
\text { Phases, M }\end{array}$ & $\begin{array}{c}\text { [Cs] in } \mathrm{O} \\
\text { after Equili- } \\
\text { brated } \\
\text { Phases, } \mathrm{M}\end{array}$ & $\begin{array}{c}\text { Temp of } \\
\text { Equili- } \\
\text { bration, } \\
{ }^{\circ} \mathrm{C}\end{array}$ & $\begin{array}{c}\mathrm{D}_{\mathrm{Cs}} \text { at } \\
\text { Temp of } \\
\text { Equili- } \\
\text { bration }\end{array}$ \\
\hline CS20 & 1 & - & - & 26.2 & 4 & 27.8 & $6.95 \mathrm{E}-07$ & $8.15 \mathrm{E}-06$ & 25.6 & 11.73 \\
\hline CS20 & 2 & 21 & 19 & 26.1 & 5 & 26.6 & $2.00 \mathrm{E}-06$ & $2.44 \mathrm{E}-05$ & 25.6 & 12.19 \\
\hline CS20 & 3 & 24 & 12 & 25.0 & 5 & 25.5 & $6.33 \mathrm{E}-06$ & $9.36 \mathrm{E}-05$ & 24.6 & 14.79 \\
\hline CS20 & 4 & 14 & 10 & 23.6 & 5 & 24.4 & $1.40 \mathrm{E}-05$ & $2.20 \mathrm{E}-04$ & 23.3 & 15.73 \\
\hline CS21 & 5 & 8 & 14 & 27.2 & 5 & 26.2 & $2.31 \mathrm{E}-04$ & $4.42 \mathrm{E}-04$ & 27.2 & 1.92 \\
\hline CS21 & 6 & 8 & 12 & 27.4 & 3 & 28.0 & $1.74 \mathrm{E}-04$ & $3.35 \mathrm{E}-04$ & 26.9 & 1.92 \\
\hline CS22 & 7 & 10 & 9 & 27.5 & 9 & 29.2 & $1.14 \mathrm{E}-03$ & $2.26 \mathrm{E}-04$ & 27.3 & 0.198 \\
\hline CS22 & 8 & 10 & 9 & 27.4 & 8 & 29.1 & 7.17E-04 & 7.39E-05 & 28.1 & 0.103 \\
\hline CS22 & 9 & 9 & 17 & 28.1 & 8 & 30.0 & $1.95 \mathrm{E}-04$ & $1.27 \mathrm{E}-05$ & 27.4 & 0.065 \\
\hline CS22 & 10 & 10 & 12 & 27.3 & 6 & 28.6 & $5.43 \mathrm{E}-05$ & $3.58 \mathrm{E}-06$ & 27.5 & 0.066 \\
\hline
\end{tabular}

${ }^{a}$ This gives the time between when the test was stopped and the temperature of the drained stage samples was measured.

$\mathrm{b}$ This estimate of stage temperature takes into account the effluent temperatures, the room temperature, the temperature of the stage samples, and the time the samples had to cool off before their temperature was measured. More weight was given to the effluent temperatures than to the stage temperatures. 
Table 10. Feed and Effluent Streams during Stage Efficiency Tests

\begin{tabular}{|c|c|c|c|c|c|c|c|}
\hline Test & Phase & $\begin{array}{c}\text { Feed } \\
\text { Temp, } \\
{ }^{\circ} \mathrm{C}\end{array}$ & $\begin{array}{c}\text { Cs Conc. } \\
\text { in Feed, } \\
\underline{\mathrm{M}}\end{array}$ & $\begin{array}{c}\text { Average } \\
\text { Effluent } \\
\text { Temp, }{ }^{\circ} \mathrm{C}\end{array}$ & $\begin{array}{c}\text { Average Flow } \\
\text { Rate, mL/min }\end{array}$ & $\begin{array}{c}\text { Cs Conc. in } \\
\text { Effluent, } \underline{\mathrm{M}}\end{array}$ & $\begin{array}{c}\text { Material } \\
\text { Balance, \% } \\
\text { Cs Recovered }\end{array}$ \\
\hline CS20 & A & 22 & $1.314 \mathrm{E}-04$ & 26.4 & $45.8 \pm 1.1$ & $7.91 \mathrm{E}-07^{\mathrm{a}}$ & 100.3 \\
\hline CS20 & $\mathrm{O}$ & 22 & 0 & 24.4 & $14.4 \pm 0.8$ & $4.16 \mathrm{E}-04^{\mathrm{b}}$ & \\
\hline CS21 & A & 22 & 0 & 26.1 & $2.68 \pm 0.15$ & $3.45 \mathrm{E}-04^{\mathrm{c}}$ & 87.4 \\
\hline CS21 & O & 23 & $4.01 \mathrm{E}-04$ & 27.2 & $14.6 \pm 0.8$ & $2.87 \mathrm{E}-04^{\mathrm{b}}$ & \\
\hline CS22 & A & 23 & 0 & 26.6 & $2.59 \pm 0.55$ & $1.59 \mathrm{E}-03^{\mathrm{d}}$ & 97.4 \\
\hline CS22 & O & 24 & $3.01 \mathrm{E}-04$ & 27.7 & $14.2 \pm 3.4$ & $3.57 \mathrm{E}-06^{\mathrm{d}}$ & \\
\hline
\end{tabular}

${ }^{\mathrm{a}}$ Used value for longest time (last point) from Table 7.

${ }^{\mathrm{b}}$ Used all points from Table 7.

${ }^{c}$ Used first point from Table 7. This value gives $89.0 \%$ stage efficiency. The other points give Cs material balance recoveries closer to $100 \%$, but they were rejected because they give stage efficiencies greater than $100 \%$.

${ }^{\mathrm{d}}$ Take average of last two values from Table 7.

Only four rotors were used in these tests. The rotors were washed carefully between tests to ensure that highly alkaline aqueous phase in the extraction section was not carried into the scrub or strip sections. All feed pumps were metering pumps (FMI pumps were used for the aqueous scrub and strip feeds, Masterflex pumps were used for the DF feed and the solvent feeds) that were set before the test. During the test, flow rates were measured each time a sample was taken. Flow rates were also obtained by measuring the rate at which each feed was pumped out of its feed vessel. 


\section{APPENDIX C \\ FURTHER DETAILS OF THE CSSX FLOWSHEET TESTS}

Further details of the three CSSX flowsheet tests (CS23, CS24, and CS25) are given here. These details include preparations for the tests as well as detailed measurements and observations made during the tests. These details supplement the test summary given in the body of this report and the full set of test results given in [LEONARD-2000].

\section{Test Preparations}

In preparation for the CSSX flowsheet tests, the 24-stage 2-cm contactor in the glovebox was upgraded so that all stages had the larger rotor inlet diameter and all interstage lines had the wire rope insert. In addition, an 8 -stage 2 -cm contactor with the same modifications was added to the unit. After the 8 additional stages along with parts required for the contactor table were bagged into the glovebox through the 56- $\mathrm{cm}$ (22-in.) diameter port, the table and contactor stages were put into the space used by the 56-cm (22-in.) port. All subsequent bag-in and bag-out operations were done using the $20-\mathrm{cm}(8$-in.) diameter port. After all 32 stages were in place, they were cleaned following the same procedure used to prepare for the stage efficiency tests. Since the rotors were being modified in the hot machine shop, the cleaning procedure for the contactor stages included the use of deionized water that stayed in the stages overnight. Since stages 11-24 had not been used since they were cleaned before the stage efficiency tests, they were not re-cleaned with deionized water. However, the cleaning with an organic solvent (trichloroethylene) was repeated. After the 8 additional stages were added, they became stages 1-8. The other 24 stages became stages 9-32.

Before the three CSSX flowsheet tests were carried out, batch-equilibrium $\mathrm{D}_{\mathrm{Cs}}$ values were measured using the solutions and the volume ratios specified for the tests. The $\mathrm{D}_{\mathrm{Cs}}$ results, given in Table 11, are in reasonable agreement with earlier data for a similar alkaline-waste simulant [BONNESEN-2000].

Table 11. $D_{\mathrm{Cs}}$ Values from Batch-Equilibrium Measurements for Flowsheet Tests

\begin{tabular}{|c|c|c|c|c|}
\hline Section & $\begin{array}{c}\text { Batch Test } \\
\text { Number }\end{array}$ & O/A Volume Ratio & $\mathrm{D}_{\mathrm{Cs}}$ at $25^{\circ} \mathrm{C}$ & Notes \\
\hline Extraction & 1 & 0.31 & 16.7 & $\mathrm{a}$ \\
\hline Extraction & 2 & 0.31 & 17.9 & $\mathrm{a}$ \\
\hline Scrub & 1 & 5.0 & 1.27 & $\mathrm{~b}$ \\
\hline Scrub & 2 & 5.0 & 1.38 & $\mathrm{~b}$ \\
\hline Strip & 1 & 5.0 & 0.136 & $\mathrm{c}$ \\
\hline Strip & 2 & 5.0 & 0.090 & $\mathrm{c}$ \\
\hline Strip & 3 & 5.0 & 0.078 & $\mathrm{c}$ \\
\hline Strip & 4 & 5.0 & 0.059 & $\mathrm{c}$ \\
\hline
\end{tabular}

${ }^{a}$ Using these data, the no-load $\mathrm{D}_{\mathrm{Cs}}$ value for the extraction section is $18.3 \pm 1.4$.

${ }^{\mathrm{b}}$ Using these data, the no-load $\mathrm{D}_{\mathrm{Cs}}$ value for the scrub section is $1.40 \pm 0.08$.

${ }^{c}$ Based on the strip section data, the $\mathrm{D}_{\mathrm{Cs}}$ value at low Cs concentrations in the strip section is $0.056 \pm 0.005$. 
In the past, the low flow rates to the scrub and strip sections, that is, the DS and EF flow rates, were measured during the test by timing the rate at which the solution level dropped in the 1-L feed bottles. For the CSSX flowsheet tests, a new method was developed to measure these two flow rates. The 1-L feed bottles were put on electronic balances with a feed pick-up tube that was held in place so that it did not touch the bottom of the feed bottles. This setup, which is shown in Fig. 17, was implemented for the DS and EF feeds. With this setup, accurate flow rates could be measured over short time intervals of 1 to $4 \mathrm{~min}$. The pumps for the DS and EF feeds were FMI rotary piston pumps. The pumps for the DF and DX feeds were Masterflex peristaltic pumps with polytetrafluoroethylene (PTFE) tubing in the pump head. The PTFE tubing, which had a 4-mm ID and a 6-mm OD, had been previously operated for several days so that the change in flow rate with time during the CSSX flowsheet tests would be minimized.

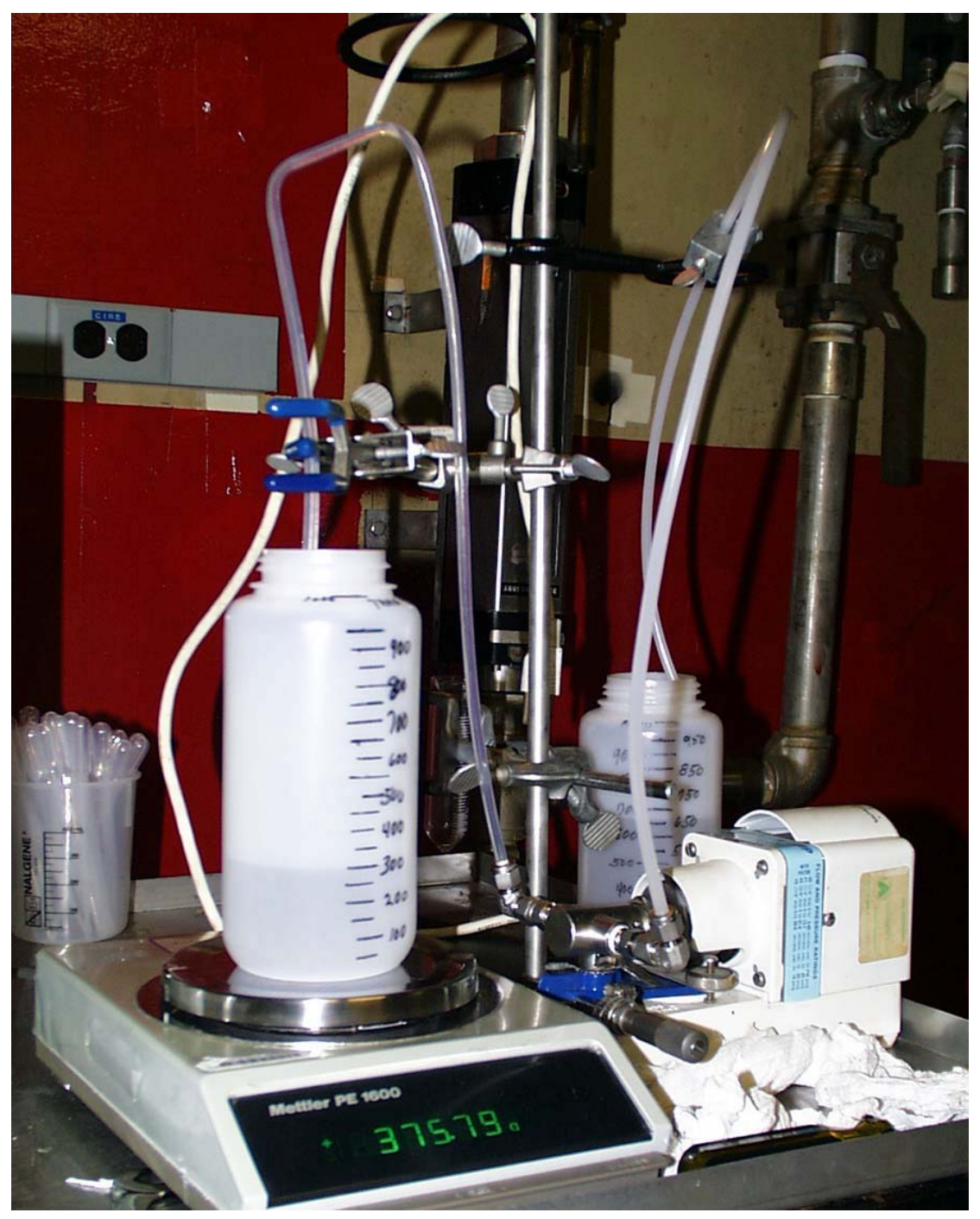

Fig. 17. Electronic Balance Being Used for Measurement of Feed Flow Rates 


\section{Measurements and Observations during the Tests}

During the three flowsheet tests, effluent flow rates were measured by taking timed effluent samples every $15 \mathrm{~min}$ starting $5 \mathrm{~min}$ after the radioactive (hot) feed was introduced into the contactor. The time when the hot feed was started was called time zero (0). For flow rates above $10 \mathrm{~mL} / \mathrm{min}$, the collection time for an effluent sample was $1 \mathrm{~min}$. For lower flow rates, the collection time was $5 \mathrm{~min}$. In addition to measuring the effluent flow rate, this procedure allowed us to check effluent appearance, determine the amount of any other-phase carryover, and take a sample of the liquid for determination of its Cs-137 concentration. We also measured the $\mathrm{pH}$ of the aqueous effluent from the strip section. After time zero $(\mathrm{t}=0)$, test CS23 ran for 114 min, test CS24 ran for $100 \mathrm{~min}$, and test CS25 ran for $177 \mathrm{~min}$. For CS23 and CS24, the tests continued until we ran out of solvent. For CS25, the test continued until we ran out of the SRS simulant.

In the flowsheet tests, time zero is defined as follows. First the stages are filled with aqueous phase flowing at the flow rate shown on the flowsheet. The aqueous strip feed is used to fill the strip stages. The aqueous scrub feed is used to fill the scrub stages. A cold (nonradioactive) waste feed is used to fill the extraction stages. When these stages are filled and aqueous phase is coming out the aqueous (DW) raffinate and the aqueous strip (EW) effluent, the solvent flow is started. When the solvent is coming out of the organic strip (EP) effluent, the hot (radioactive) waste feed is started. The start of the hot waste feed is time zero.

The data from the effluent samples are summarized for the aqueous (DW) raffinate, the aqueous strip (EW) effluent, and the organic strip (EP) effluent in Tables 12, 13, and 14, respectively. Liquid volume balances for the feed and effluent flows are given in Table 15 . Cesium material balances appear in Table 16.

For the stage efficiency tests no temperature control was needed since we measured the $\mathrm{D}_{\mathrm{Cs}}$ value at each stage and used it to calculate the stage efficiency. However, the full CSSX process tests using the flowsheet shown in Fig. 8 are different in that a certain range of $\mathrm{D}_{\mathrm{Cs}}$ values is required in each section for successful process operation. As the enthalpy values for this cesium extraction reaction show, $\mathrm{D}_{\mathrm{Cs}}$ is strongly dependent on temperature. Before the first CSSX flowsheet test, we were concerned that the lab temperature, which was at $18^{\circ} \mathrm{C}$, would make the $\mathrm{D}_{\mathrm{Cs}}$ value in the strip section too high and prevent the start of stripping. For significant stripping to occur, the extraction factor, that is, $\mathrm{D}_{\mathrm{Cs}}$ times the $\mathrm{O} / \mathrm{A}$ flow ratio, must be less than 1.0 [LEONARD-1999B]. When the $\mathrm{D}_{\mathrm{Cs}}$ value is high, the Cs loaded in the solvent cannot be stripped. Such a high $\mathrm{D}_{\mathrm{Cs}}$ value could occur if the laboratory temperature were too low. To prevent this from happening, the lab temperature was raised to $25^{\circ} \mathrm{C}$ for the first CSSX flowsheet test (CS23). At this lab temperature, the stripping section worked well. However, the extraction section became so warm that it could not give the desired decontamination factor after the first few minutes of the test. As the temperature of the aqueous raffinate climbed steadily from 32 to $37^{\circ} \mathrm{C}$ over the two-hour test, the decontamination factor dropped from 66,000 after $10 \mathrm{~min}$ to 680 by the end of the test (see Table 12).

An analysis of test CS23 indicated that the high temperatures in the extraction section and the aqueous raffinate were the result of heat that came from the rotor motors [ARAFAT-2001]. To minimize the effect of this motor heat, the temperature control plan was revised for the 
second CSSX flowsheet test (CS24) as follows. First, the laboratory temperature was lowered to $18^{\circ} \mathrm{C}$. Second, the rotor motors for the strip section were started an hour before the test to warm up that section. Third, the rotor motors for the extraction section were not turned on until the waste (DF) feed was started. Finally, the waste (DF) feed was run through an ice bath between the DF pump and the DF feed point at stage 15. This procedure gave us the temperature control that we needed. The room temperature during the flowsheet tests is given in Table 17. The temperature of the contactor stages was not measured during flowsheet test CS23. The temperature for selected contactor stages was measured during flowsheet tests CS24 and CS25. The results are given in Tables 18 and 19, respectively. These temperatures were measured by taping digital thermometers to the housing face of the selected contactor stages. As shown in Table 12, the temperature of the aqueous (DW) raffinate for test CS24 rose as it did for test CS23, but it leveled out at $29^{\circ} \mathrm{C}$. The revised temperature control plan was used for the third flowsheet test (CS25) as well, the first flowsheet test with solvent recycle. Again, as shown in Table 12 , the temperature of the aqueous (DW) raffinate leveled out before it exceeded $32^{\circ} \mathrm{C}$, this time at $31^{\circ} \mathrm{C}$. 
Table 12. Aqueous (DW) Raffinate for the CSSX Flowsheet Tests

\begin{tabular}{|c|c|c|c|c|c|c|c|c|}
\hline Test & $\begin{array}{l}\text { Time, } \\
\min \end{array}$ & $\begin{array}{c}\text { Effluent } \\
\text { Flow } \\
\text { Rate, } \\
\text { mL/min }\end{array}$ & $\begin{array}{c}\text { Effluent } \\
\text { Temp, } \\
{ }^{\circ} \mathrm{C}\end{array}$ & Appearance & $\begin{array}{c}\text { Other- } \\
\text { Phase } \\
\text { Carryover, } \\
\%\end{array}$ & Cs Conc, $\underline{\mathrm{M}}$ & $\begin{array}{c}\text { Decontamination } \\
\text { Factor }\end{array}$ & Notes \\
\hline CS23 & -15 & & 30.1 & & & & & \\
\hline CS23 & 10 & 44.0 & 32.4 & sl cldy & 0 & $2.10 \mathrm{E}-09$ & 66,535 & \\
\hline CS23 & 20 & 45.0 & 33.3 & $\mathrm{clr}$ & 0 & 4.98E-09 & 28,134 & \\
\hline CS23 & 35 & 47.5 & 34.1 & clr & 0 & $9.72 \mathrm{E}-09$ & 14,407 & \\
\hline CS23 & 50 & 46.0 & 34.8 & clr & 0 & $1.61 \mathrm{E}-08$ & 8,682 & \\
\hline CS23 & 65 & 42.5 & 35.2 & $\mathrm{clr}$ & 0 & $2.01 \mathrm{E}-08$ & 6,970 & \\
\hline CS23 & 80 & 52.0 & 35.9 & $\mathrm{clr}$ & 0 & $4.61 \mathrm{E}-08$ & 3,034 & \\
\hline CS23 & 95 & 52.0 & 36.3 & clr & 0 & $1.29 \mathrm{E}-07$ & 1,083 & \\
\hline CS23 & 105 & 49.5 & 36.9 & $\mathrm{clr}$ & 0 & $2.07 \mathrm{E}-07$ & 676 & \\
\hline CS24 & 5 & 42.5 & 22.5 & clr & 0 & $1.23 \mathrm{E}-09$ & 113,881 & \\
\hline CS24 & 20 & 44.0 & 24.1 & $\mathrm{clr}$ & 0 & $2.44 \mathrm{E}-09$ & 57,286 & \\
\hline CS24 & 35 & 44.0 & 25.6 & clr & 0 & $1.92 \mathrm{E}-09$ & 73,033 & \\
\hline CS24 & 50 & 44.0 & 27.0 & clr & 0 & $2.40 \mathrm{E}-09$ & 58,434 & \\
\hline CS24 & 65 & 46.0 & 28.0 & clr & 0 & $1.65 \mathrm{E}-09$ & 84,899 & $\mathrm{a}$ \\
\hline CS24 & 80 & 45.0 & 28.6 & clr & 0 & $1.71 \mathrm{E}-09$ & 81,925 & \\
\hline CS24 & 95 & 44.0 & 29.4 & clr & 0 & $1.60 \mathrm{E}-09$ & 87,770 & \\
\hline $\mathrm{CS} 25$ & 5 & 47.0 & 23.4 & $\mathrm{clr}$ & 0 & $3.56 \mathrm{E}-09$ & 39,299 & \\
\hline CS25 & 20 & 33.0 & 25.0 & clr & 0 & $2.85 \mathrm{E}-09$ & 49,087 & $\mathrm{~b}$ \\
\hline CS25 & 35 & 31.0 & 26.7 & clr & 0 & $6.94 \mathrm{E}-09$ & 20,172 & $\mathrm{~b}$ \\
\hline CS25 & 50 & 49.5 & 28.2 & $\mathrm{clr}$ & 0 & $4.83 \mathrm{E}-09$ & 28,997 & $\mathrm{~b}$ \\
\hline CS25 & 65 & 44.0 & 28.0 & $\mathrm{clr}$ & 1.1 & $2.98 \mathrm{E}-09$ & 46,918 & $\mathrm{c}$ \\
\hline CS25 & 80 & 46.0 & 28.6 & $\mathrm{clr}$ & 5.4 & $2.08 \mathrm{E}-09$ & 67,155 & \\
\hline CS25 & 95 & 44.0 & 29.5 & clr & 4.5 & $1.47 \mathrm{E}-09$ & 95,002 & \\
\hline CS25 & 110 & 47.0 & 30.1 & clr & 7.4 & $1.44 \mathrm{E}-09$ & 97,146 & \\
\hline CS25 & 125 & 46.0 & 30.5 & clr & 8.7 & $1.55 \mathrm{E}-09$ & 90,473 & \\
\hline CS25 & 140 & 47.5 & 31.4 & $\mathrm{clr}$ & 8.4 & $1.49 \mathrm{E}-09$ & 94,148 & \\
\hline CS25 & 155 & 46.5 & 30.8 & clr & 7.5 & $1.61 \mathrm{E}-09$ & 87,168 & \\
\hline CS25 & 170 & 43.0 & 30.9 & clr & 4.7 & 1.79E-09 & 78,329 & \\
\hline
\end{tabular}

${ }^{\text {a }}$ Start ice bath chiller at $56 \mathrm{~min}$.

${ }^{\mathrm{b}}$ Omit from flow rate average as process upset.

${ }^{\mathrm{c}}$ Start ice bath chiller at $28 \mathrm{~min}$. 
Table 13. Aqueous Strip (EW) Effluent for the CSSX Flowsheet Tests

\begin{tabular}{|c|c|c|c|c|c|c|c|c|c|}
\hline Test & $\begin{array}{c}\text { Time, } \\
\text { min }\end{array}$ & $\begin{array}{l}\text { Effluent } \\
\text { Flow } \\
\text { Rate, } \\
\mathrm{mL} / \mathrm{min}\end{array}$ & $\begin{array}{c}\text { Effluent } \\
\text { Temp, } \\
{ }^{\circ} \mathrm{C}\end{array}$ & Appearance & $\begin{array}{c}\text { Other- } \\
\text { Phase } \\
\text { Carryover } \\
\%\end{array}$ & $\begin{array}{c}\text { Cs Conc, } \\
\underline{\mathrm{M}}\end{array}$ & $\begin{array}{c}\text { Concentration } \\
\text { Factor }\end{array}$ & $\mathrm{pH}$ & Notes \\
\hline CS23 & -7 & & 31 & & & & & & \\
\hline CS23 & 10 & 6.10 & 26 & hazy & 0 & $1.25 \mathrm{E}-03$ & 8.9 & 4 & \\
\hline CS23 & 20 & 2.80 & 31 & hazy & 0 & $1.81 \mathrm{E}-03$ & 13.0 & 4 & \\
\hline CS23 & 35 & 3.46 & 31.6 & hazy & 0 & $1.99 \mathrm{E}-03$ & 14.2 & 3.5 & \\
\hline CS23 & 50 & 2.96 & 31.6 & hazy & 0 & $2.21 \mathrm{E}-03$ & 15.8 & 3.5 & \\
\hline CS23 & 65 & 2.24 & 31.5 & hazy & 0 & $2.49 \mathrm{E}-03$ & 17.8 & 3 & \\
\hline CS23 & 80 & 2.70 & 31.9 & hazy & 0 & $2.37 \mathrm{E}-03$ & 16.9 & 3 & \\
\hline CS23 & 95 & 2.84 & 32.6 & hazy & 0 & $2.33 \mathrm{E}-03$ & 16.7 & 3 & \\
\hline CS23 & 105 & 2.70 & 32.6 & hazy & 0 & $2.34 \mathrm{E}-03$ & 16.7 & 3 & \\
\hline $\mathrm{CS} 24$ & 5 & 3.30 & 22.2 & hazy & 0 & $6.17 \mathrm{E}-04$ & 4.4 & 4 & \\
\hline CS24 & 20 & 3.04 & 23.3 & hazy & 0 & $2.03 \mathrm{E}-03$ & 14.5 & 4 & \\
\hline CS24 & 35 & 3.40 & 23.9 & clr & 0 & $2.23 \mathrm{E}-03$ & 16.0 & 3.5 & \\
\hline CS24 & 50 & 2.40 & 24 & hazy & 0 & $2.18 \mathrm{E}-03$ & 15.6 & 3 & \\
\hline CS24 & 65 & 3.20 & 22.6 & hazy & 0 & $2.37 \mathrm{E}-03$ & 17.0 & 3 & $\mathrm{a}$ \\
\hline CS24 & 80 & 3.00 & 22.9 & hazy & 0 & $2.34 \mathrm{E}-03$ & 16.7 & 3 & \\
\hline $\mathrm{CS} 24$ & 95 & 2.00 & 22.5 & hazy & 0 & $2.31 \mathrm{E}-03$ & 16.5 & 3 & \\
\hline $\mathrm{CS} 25$ & 5 & 2.40 & 23.1 & hazy & 0 & $3.59 \mathrm{E}-04$ & 2.6 & 4 & \\
\hline $\mathrm{CS} 25$ & 20 & 3.30 & 24.0 & hazy & 0 & $1.89 \mathrm{E}-03$ & 13.5 & 4 & \\
\hline CS25 & 35 & 2.40 & 23.3 & hazy & 0 & $2.00 \mathrm{E}-03$ & 14.3 & 4 & $\mathrm{~b}$ \\
\hline $\mathrm{CS} 25$ & 50 & 2.60 & 24.0 & hazy & 0 & $2.06 \mathrm{E}-03$ & 14.7 & 4 & \\
\hline CS25 & 65 & 3.10 & 24.0 & hazy & 0 & $1.80 \mathrm{E}-03$ & 12.9 & 4 & \\
\hline CS25 & 80 & 2.90 & 24.4 & hazy & 0 & $2.10 \mathrm{E}-03$ & 15.0 & 4 & \\
\hline $\mathrm{CS} 25$ & 95 & 2.70 & 25.1 & hazy & 0 & $2.15 \mathrm{E}-03$ & 15.4 & 3.5 & \\
\hline $\mathrm{CS} 25$ & 110 & 2.80 & 25.3 & hazy & 0 & $2.20 \mathrm{E}-03$ & 15.7 & 3.5 & \\
\hline $\mathrm{CS} 25$ & 125 & 2.70 & 25.3 & hazy & 0 & $2.12 \mathrm{E}-03$ & 15.1 & 3.5 & \\
\hline $\mathrm{CS} 25$ & 140 & 2.90 & 25.1 & hazy & 0 & $2.21 \mathrm{E}-03$ & 15.8 & 3.5 & \\
\hline $\mathrm{CS} 25$ & 155 & 2.70 & 25.5 & hazy & 0 & $1.89 \mathrm{E}-03$ & 13.5 & 3 & \\
\hline $\mathrm{CS} 25$ & 170 & 2.20 & 24.5 & hazy & 0 & $1.93 \mathrm{E}-03$ & 13.8 & 3 & \\
\hline
\end{tabular}

${ }^{\mathrm{a}}$ Start ice bath chiller at $56 \mathrm{~min}$.

${ }^{\mathrm{b}}$ Start ice bath chiller at $28 \mathrm{~min}$. 
Table 14. Organic Strip (EP) Effluent for the CSSX Flowsheet Tests

\begin{tabular}{|c|c|c|c|c|c|c|c|c|}
\hline Test & $\begin{array}{c}\text { Time, } \\
\text { min }\end{array}$ & $\begin{array}{c}\text { Effluent } \\
\text { Rate, } \\
\text { mL/min }\end{array}$ & $\begin{array}{c}\text { Effluent } \\
\text { Temp, } \\
{ }^{\circ} \text { C }\end{array}$ & Appearance & $\begin{array}{c}\text { Other-Phase } \\
\text { Carryover, } \\
\%\end{array}$ & $\begin{array}{c}\text { Cs Conc, } \\
\text { M }\end{array}$ & $\begin{array}{c}\text { Solvent } \\
\text { Decon } \\
\text { Factor }\end{array}$ & Notes \\
\hline CS23 & -2 & & 27.8 & & & & & \\
\hline CS23 & 10 & 18.5 & 29.8 & hazy & 0 & $3.10 \mathrm{E}-09$ & 45,207 & a \\
\hline CS23 & 20 & 16.0 & 31.0 & hazy & 0 & $2.25 \mathrm{E}-09$ & 62,137 & \\
\hline CS23 & 35 & 15.5 & 30.9 & hazy & 0 & $3.37 \mathrm{E}-09$ & 41,595 & \\
\hline CS23 & 50 & 18.0 & 31.2 & hazy & 1.0 & $1.74 \mathrm{E}-09$ & 80,653 & \\
\hline CS23 & 65 & 14.0 & 31.4 & hazy & 0.8 & $1.43 \mathrm{E}-09$ & 97,878 & \\
\hline CS23 & 80 & 15.5 & 31.8 & hazy & 0.1 & $1.16 \mathrm{E}-09$ & 120,652 & \\
\hline CS23 & 95 & 16.0 & 32.0 & hazy & 0.1 & $1.61 \mathrm{E}-09$ & 86,898 & \\
\hline CS23 & 105 & 15.5 & 32.9 & hazy & 0.2 & $1.87 \mathrm{E}-09$ & 74,889 & \\
\hline CS24 & 5 & 11.0 & 21.2 & clr & 0 & $4.12 \mathrm{E}-09$ & 33,977 & $\mathrm{a}$ \\
\hline CS24 & 20 & 15.0 & 23.8 & hazy & 0.03 & $2.52 \mathrm{E}-09$ & 55,516 & \\
\hline CS24 & 35 & 14.5 & 25.3 & clr & 0.10 & $2.03 \mathrm{E}-09$ & 69,015 & \\
\hline CS24 & 50 & 15.5 & 24.6 & clr & 0.03 & $1.96 \mathrm{E}-09$ & 71,482 & \\
\hline CS24 & 65 & 16.0 & 25.7 & clr & 0.03 & $1.95 \mathrm{E}-09$ & 71,673 & $\mathrm{~b}$ \\
\hline CS24 & 80 & 15.0 & 25.4 & clr & 0.03 & $2.63 \mathrm{E}-09$ & 53,244 & \\
\hline CS24 & 95 & 14.5 & 25.7 & clr & 0 & $1.50 \mathrm{E}-09$ & 93,478 & \\
\hline CS25 & 5 & 8.5 & 23.2 & clr & 0.01 & $1.17 \mathrm{E}-09$ & 120,066 & $\mathrm{a}$ \\
\hline CS25 & 20 & 13.0 & 24.6 & clr & 0 & $8.13 \mathrm{E}-10$ & 172,247 & \\
\hline CS25 & 35 & 12.0 & 26.4 & clr & 0.12 & $1.96 \mathrm{E}-09$ & 71,446 & c \\
\hline CS25 & 50 & 11.0 & 25.3 & clr & 0.6 & $1.99 \mathrm{E}-09$ & 70,296 & \\
\hline CS25 & 65 & 17.0 & 26.7 & clr & 0.02 & $1.67 \mathrm{E}-09$ & 83,828 & \\
\hline CS25 & 80 & 14.5 & 26.0 & clr & 0.004 & $1.13 \mathrm{E}-09$ & 124,391 & \\
\hline CS25 & 95 & 13.5 & 26.5 & clr & 0.03 & $9.57 \mathrm{E}-10$ & 146,321 & \\
\hline CS25 & 110 & 14.0 & 26.2 & clr & 0.004 & $1.03 \mathrm{E}-09$ & 136,155 & \\
\hline CS25 & 125 & 13.5 & 26.9 & clr & 0.03 & $1.34 \mathrm{E}-09$ & 104,250 & \\
\hline CS25 & 140 & 14.5 & 26.6 & clr & 0.03 & $1.24 \mathrm{E}-09$ & 112,876 & \\
\hline CS25 & 155 & 13.5 & 26.5 & clr & 0.03 & $1.12 \mathrm{E}-09$ & 124,674 & \\
\hline CS25 & 170 & 11.0 & 26.6 & clr & 0.005 & $1.35 \mathrm{E}-09$ & 103,943 & \\
\hline Do & & & & & & \\
\hline
\end{tabular}

${ }^{\mathrm{a}}$ Do not include in flow rate calculation.

${ }^{\mathrm{b}}$ Start ice bath chiller at $56 \mathrm{~min}$.

${ }^{\mathrm{c}}$ Start ice bath chiller at $28 \mathrm{~min}$. 
Table 15. Summary of the Aqueous and Organic Flow Rates for the CSSX Flowsheet Tests

\begin{tabular}{|c|c|c|c|c|c|c|c|}
\hline \multirow[b]{2}{*}{ Test } & \multirow[b]{2}{*}{$\begin{array}{l}\text { Stream } \\
\text { ID }\end{array}$} & \multicolumn{3}{|c|}{ Flow Rate, $\mathrm{mL} / \mathrm{min}$} & \multirow[b]{2}{*}{$\begin{array}{c}\text { Volume } \\
\text { Recovered, } \\
\%\end{array}$} & \multirow{2}{*}{$\begin{array}{c}\text { Expected } \\
\text { Conc. Factor } \\
\text { based on DF } \\
\text { and EF Flow } \\
\text { Rates }\end{array}$} & \multirow[b]{2}{*}{ Notes } \\
\hline & & Before Test & During Test & Best & & & \\
\hline \multirow[t]{7}{*}{23} & DF & $43.8 \pm 0.3$ & $43.1 \pm 0.8$ & 43.8 & & 15.8 & $\mathrm{a}$ \\
\hline & DS & $2.75 \pm 0.06$ & $2.70 \pm 0.02$ & 2.70 & & & b \\
\hline & DW & N/A & $47.3 \pm 3.6$ & 47.3 & 101.7 & & \\
\hline & $\mathrm{EF}$ & $2.85 \pm 0.01$ & $2.77 \pm 0.06$ & 2.77 & & & $\mathrm{~b}$ \\
\hline & EW & N/A & $2.81 \pm 0.36$ & 2.81 & 101.4 & & \\
\hline & DX & $14.1 \pm 0.1$ & $12.8 \pm 1.7$ & 14.1 & & & $\mathrm{a}$ \\
\hline & EP & N/A & $13.5 \pm 1.1$ & 13.5 & 95.7 & & \\
\hline \multirow[t]{7}{*}{24} & DF & $44.8 \pm 0.3$ & $42.0 \pm 3.5$ & 44.8 & & 15.9 & $\mathrm{a}$ \\
\hline & DS & $2.79 \pm 0.02$ & $2.85 \pm 0.01$ & 2.85 & & & $\mathrm{~b}$ \\
\hline & DW & N/A & $44.2 \pm 1.1$ & 44.2 & 92.8 & & \\
\hline & $\mathrm{EF}$ & $2.83 \pm 0.01$ & $2.81 \pm 0.05$ & 2.81 & & & $\mathrm{~b}$ \\
\hline & EW & N/A & $2.91 \pm 0.51$ & 2.91 & 103.6 & & \\
\hline & DX & $14.0 \pm 0.2$ & $14.8 \pm 1.6$ & 14.0 & & & $\mathrm{a}$ \\
\hline & EP & N/A & $15.1 \pm 0.6$ & 15.1 & 107.9 & & \\
\hline \multirow[t]{7}{*}{25} & DF & $42.9 \pm 0.1$ & $40.7 \pm 3.8$ & 42.9 & & 15.2 & $\mathrm{a}$ \\
\hline & DS & $2.83 \pm 0.03$ & $2.90 \pm 0.04$ & 2.90 & & & $\mathrm{~b}$ \\
\hline & DW & N/A & $45.7 \pm 1.6$ & 45.7 & 99.8 & & \\
\hline & $\mathrm{EF}$ & $2.80 \pm 0.01$ & $2.82 \pm 0.09$ & 2.82 & & & $\mathrm{~b}$ \\
\hline & EW & N/A & $2.73 \pm 0.31$ & 2.73 & 96.8 & & \\
\hline & DX & $14.0 \pm 0.2$ & N/A & 14.0 & & & \\
\hline & EP & N/A & $13.4 \pm 1.7$ & 13.4 & 95.7 & & \\
\hline
\end{tabular}

a Chose "Before" as "Best" value since it is a more accurate measurement than the "During" value.

b Chose "During" as "Best" value since it was measured in the same way as "Before" and liquid height has slight effect. 
Table 16. Summary of the Cesium Concentrations for the CSSX Flowsheet Tests

\begin{tabular}{|c|c|c|c|c|c|c|}
\hline Test & $\begin{array}{c}\text { Stream } \\
\text { ID }\end{array}$ & $\begin{array}{c}\text { Flow Rate, } \\
\text { mL/min }\end{array}$ & Cs Conc, $\underline{\text { M }}$ & $\begin{array}{c}\text { Cs } \\
\text { Recovered, } \\
\%\end{array}$ & $\begin{array}{c}\text { Measured Cs } \\
\text { Conc. Factor }\end{array}$ & Notes \\
\hline 23 & DF & 43.8 & $1.40 \mathrm{E}-04$ & 105.1 & 16.4 & \\
\hline & DS & 2.70 & 0 & & & \\
\hline & DW & 47.3 & $2.07 \mathrm{E}-07$ & & & \\
\hline & EF & 2.77 & 0 & & & \\
\hline & EW & 2.81 & $2.29 \mathrm{E}-03$ & & & a \\
\hline & DX & 14.1 & 0 & & & \\
\hline & EP & 13.5 & $1.87 \mathrm{E}-09$ & & & \\
\hline 24 & DF & 44.8 & $1.40 \mathrm{E}-04$ & 104.2 & 16.0 & \\
\hline & DS & 2.85 & 0 & & & \\
\hline & DW & 44.2 & $1.60 \mathrm{E}-09$ & & & \\
\hline & EF & 2.81 & 0 & & & \\
\hline & EW & 2.91 & $2.25 \mathrm{E}-03$ & & & a \\
\hline & DX & 14.0 & 0 & & & \\
\hline & EP & 15.1 & $1.50 \mathrm{E}-09$ & & & \\
\hline 25 & DF & 42.9 & $1.40 \mathrm{E}-04$ & 94.8 & 14.9 & \\
\hline & DS & 2.90 & 0 & & & \\
\hline & DW & 45.7 & $1.79 \mathrm{E}-09$ & & & \\
\hline & EF & 2.82 & 0 & & & \\
\hline & EW & 2.73 & $2.09 \mathrm{E}-03$ & & & b \\
\hline & DX & 14.0 & $3.51 \mathrm{E}-09$ & & & \\
\hline & EP & 13.4 & $1.35 \mathrm{E}-09$ & & & \\
\hline
\end{tabular}

${ }^{a}$ Average of EW concentrations from 20 min to end of test.

${ }^{\mathrm{b}}$ Average of EW concentrations from 80 min to end of test.

${ }^{c}$ Cs concentration in solvent tank (DX) was higher than that in organic effluent (EP) since some solvent was added from test CS24 solvent tank. This solvent has a Cs concentration of $9.68 \mathrm{E}-09 \underline{\mathrm{M}}$. 
Table 17. Room Temperature during CSSX Flowsheet Tests

\begin{tabular}{|c|c|c|c|c|}
\hline Date & Test & $\begin{array}{c}\text { Set Point for } \\
\text { Laboratory } \\
\text { Temperature, }{ }^{\circ} \mathrm{C}\end{array}$ & $\begin{array}{c}\text { Temperature at } \\
\text { Start of the Test, } \\
{ }^{\circ} \mathrm{C}\end{array}$ & $\begin{array}{c}\text { Temperature at End } \\
\text { of the Test, }{ }^{\circ} \mathrm{C}\end{array}$ \\
\hline $9 / 19 / 00$ & $\mathrm{CS} 23$ & 25 & $23.8 \pm 0.9$ & $25.2 \pm 0.2$ \\
\hline $9 / 28 / 00$ & $\mathrm{CS} 24$ & 18 & $17.0 \pm 0.5$ & $18.7 \pm 0.1$ \\
\hline $10 / 11 / 00$ & $\mathrm{CS} 25$ & 18 & $17.5 \pm 0.5$ & $19.3 \pm 0.7$ \\
\hline
\end{tabular}

Table 18. Stage Temperatures during CSSX Flowsheet Test CS24

\begin{tabular}{|c|c|c|c|c|c|}
\hline $\begin{array}{c}\text { Time into test, } \\
\text { min }\end{array}$ & \multicolumn{6}{|c|}{ Stage (Contactor Block) Temperature, ${ }^{\circ} \mathrm{C}$} & \multirow{2}{*}{ Notes } \\
\hline Stage Number & 1 & 15 & 18 & 32 & \\
\hline 5 & 22.1 & 21 & 29.5 & N/M & \\
\hline 20 & 23 & 25.4 & 29.3 & 29.3 & \\
\hline 35 & 23.8 & 24 & 29.8 & 31 & \\
\hline 50 & 29 & 22.8 & 26.4 & 31.5 & $\mathrm{a}$ \\
\hline 65 & 30.4 & 20.5 & 32 & 30.6 & \\
\hline 80 & 31 & 20.4 & 31.6 & 31.2 & \\
\hline 95 & 31.4 & 20.1 & 32.3 & 31.7 & $\mathrm{~b}$ \\
\hline
\end{tabular}

${ }^{\mathrm{a}}$ Start using the ice bath to cool the DF feed at 45 min into the test.

${ }^{\mathrm{b}}$ Test ends at $100 \mathrm{~min}$. 
Table 19. Stage Temperatures during CSSX Flowsheet Test CS25

\begin{tabular}{|c|c|c|c|c|c|c|c|c|c|c|c|c|c|c|c|c|}
\hline $\begin{array}{l}\text { Time } \\
\text { into } \\
\text { Test, } \\
\text { min }\end{array}$ & & & & & & & Temp & eratur & $\mathrm{e},{ }^{\circ} \mathrm{C}$ & & & & & & & \\
\hline & $1^{\mathrm{a}}$ & 3 & 8 & 10 & 13 & 15 & 16 & 17 & 18 & 20 & 22 & 25 & 27 & 30 & 32 & Notes \\
\hline-110 & 18.8 & 17.9 & 17.8 & N/M & 17.8 & 16.4 & 18.8 & 18.8 & 19.1 & 19.6 & 18.2 & 18.1 & 18.5 & 18.5 & 17.9 & $\mathrm{~b}$ \\
\hline-95 & 18.0 & 17.9 & 17.9 & 18.9 & 17.8 & 16.5 & 19.7 & 19.7 & 20.0 & 20.6 & 18.2 & 19.8 & 20.0 & 20.7 & 19.7 & \\
\hline-80 & 18.0 & 17.9 & 17.9 & 18.2 & N/M & 17.6 & 22.5 & 22.2 & 23.1 & 23.7 & 22.4 & 22.6 & 22.5 & 22.9 & 21.9 & \\
\hline-65 & 18.1 & 18.0 & \begin{tabular}{|l|}
17.9 \\
\end{tabular} & 18.3 & 17.8 & 18.3 & 24.8 & 24.5 & 25.7 & 26.6 & 24.5 & 24.8 & 24.9 & 25.6 & 24.5 & \\
\hline-50 & 18.1 & 18.0 & 18.0 & 18.4 & 17.9 & 18.5 & 26.4 & 26.3 & 27.7 & 28.4 & 25.9 & 25.9 & 25.9 & 26.9 & 22.9 & \\
\hline-35 & 18.4 & 18.3 & 18.3 & 19.1 & 18.5 & 19.6 & 26.8 & 27.8 & 29.4 & 30.6 & 28.2 & 27.7 & 28.0 & 29.1 & 25.1 & $\mathrm{c}$ \\
\hline-20 & 20.7 & 20.6 & 20.6 & 21.9 & 20.8 & 21.5 & 27.6 & 28.5 & 30.8 & 31.6 & 28.9 & 29.0 & 29.6 & 30.7 & 26.4 & \\
\hline-5 & 23.6 & 24.1 & 23.4 & 25.0 & 22.8 & 22.5 & 28.4 & 26.9 & 31.5 & 32.5 & 30.8 & 30.4 & 30.7 & 31.5 & 27.8 & \\
\hline 10 & 25.0 & 25.6 & 24.8 & 26.6 & 23.7 & 23.1 & 29.2 & 30.2 & 32.2 & 33.3 & 31.7 & 31.3 & 31.7 & 32.4 & 28.8 & \\
\hline 25 & 27.7 & 28.2 & 26.7 & 28.5 & 24.8 & 23.5 & 29.4 & 30.6 & 32.6 & 33.8 & 32.0 & 31.6 & 32.0 & 32.9 & 29.5 & \\
\hline 40 & 29.5 & 30.5 & 28.1 & 29.6 & 24.8 & 21.9 & 29.9 & 31.0 & 33.1 & 34.2 & 32.5 & 32.0 & 32.5 & 33.3 & 30.0 & $\mathrm{~d}$ \\
\hline 55 & 30.3 & 30.4 & 29.2 & 30.4 & 24.2 & 21.0 & 29.9 & 31.2 & 33.6 & 34.1 & 32.4 & 32.6 & 33.0 & 33.8 & 30.5 & \\
\hline 70 & 30.6 & 29.5 & 29.0 & 30.7 & 24.0 & 20.7 & 28.8 & 31.2 & 33.7 & 34.9 & 33.0 & 32.8 & 33.3 & 34.1 & 30.9 & \\
\hline 85 & 31.0 & 31.2 & 29.9 & 30.7 & 23.7 & 20.4 & 28.9 & 31.3 & 34.0 & 34.5 & 32.7 & 33.5 & 33.4 & 34.4 & 31.3 & \\
\hline 100 & 31.5 & 32.1 & 28.8 & 30.4 & 23.6 & 20.8 & 28.9 & 31.5 & \begin{tabular}{|l|}
34.1 \\
\end{tabular} & 34.9 & 32.8 & 33.8 & 33.8 & 34.8 & 31.5 & \\
\hline 115 & 31.9 & 32.8 & 28.8 & 29.3 & 23.5 & 20.4 & 28.9 & 31.5 & 34.3 & 35.4 & 33.4 & 33.7 & 34.0 & 34.9 & 31.6 & \\
\hline 130 & 32.2 & 33.1 & 29.8 & 29.3 & 23.7 & 20.3 & 28.8 & 31.5 & 34.4 & 35.7 & 33.7 & 33.9 & 34.2 & 35.1 & 31.7 & \\
\hline 145 & 32.5 & 33.4 & 29.8 & 29.5 & 23.7 & 20.6 & 28.8 & 31.5 & 34.6 & 35.8 & 33.8 & 34.1 & 34.5 & 35.0 & 31.9 & \\
\hline 160 & 32.5 & 33.6 & 29.5 & 29.7 & 23.8 & 20.6 & 29.0 & 31.5 & 34.6 & 35.9 & 34.2 & 34.1 & 34.5 & 35.4 & 32.1 & \\
\hline 175 & 32.9 & 33.7 & 29.8 & 29.7 & 23.8 & 20.5 & 29.1 & 31.8 & 34.7 & 35.0 & 34.0 & 34.3 & 34.6 & 35.7 & 32.1 & $\mathrm{e}$ \\
\hline
\end{tabular}

${ }^{\mathrm{a}}$ Numbers in this row identify contactor stage.

${ }^{\mathrm{b}}$ Start the stage 16-32 rotors 5 min before this reading.

${ }^{c}$ Start the stage $1-15$ rotors 10 min before this reading.

${ }^{\mathrm{d}}$ Start using ice bath to cool the DF feed at $28 \mathrm{~min}$ into the test.

e Test ends at $176 \mathrm{~min}$.

During the three CSSX flowsheet tests, the liquid level in the interstage lines was observed. The data are given in Tables 20 and 21 for the aqueous and organic interstage lines, respectively. In some cases, the liquid level could change with time, moving up and then receding or just staying high. As an example, the level of the organic phase in the line from stage 3 to stage 4 in test CS25 is shown for three times in Fig. 18. 
Table 20. Liquid Levels in Aqueous Interstage Lines during CSSX Flowsheet Tests

\begin{tabular}{|c|c|c|c|c|c|c|c|c|}
\hline \multirow[b]{3}{*}{ Line $^{\mathrm{a}}$} & \multicolumn{7}{|c|}{$\begin{array}{c}\text { Amount of Liquid in Aqueous Interstage Lines during Test, } \\
\%\end{array}$} & \multirow[b]{3}{*}{ Notes } \\
\hline & \multicolumn{2}{|c|}{ CS23 } & \multicolumn{2}{|c|}{ CS24 } & \multicolumn{3}{|c|}{ CS25 } & \\
\hline & $43 \mathrm{~min}$ & $92 \mathrm{~min}$ & $33 \min$ & $88 \min$ & $63 \mathrm{~min}$ & $103 \mathrm{~min}$ & $148 \mathrm{~min}$ & \\
\hline 2 to 1 & 10 & 10 & 0 & 0 & 0 & 0 & 0 & Extraction section \\
\hline 3 to 2 & 10 & 10 & 0 & 0 & 0 & 0 & 0 & Extraction section \\
\hline 4 to 3 & 10 & 10 & 0 & 0 & 0 & 0 & 0 & Extraction section \\
\hline 5 to 4 & 10 & 10 & 0 & 10 & 0 & 0 & 0 & Extraction section \\
\hline 6 to 5 & 10 & 10 & 0 & 0 & 0 & 0 & 0 & Extraction section \\
\hline 7 to 6 & 20 & 10 & 0 & 0 & 0 & 0 & 0 & Extraction section \\
\hline 8 to 7 & 10 & 10 & 0 & 0 & 0 & 0 & 0 & Extraction section \\
\hline 9 to 8 & 10 & 10 & 0 & 0 & 0 & 0 & 0 & Extraction section \\
\hline 10 to 9 & 10 & 10 & 0 & 0 & 0 & 0 & 0 & Extraction section \\
\hline 11 to 10 & 10 & 10 & 0 & 0 & 0 & 0 & 0 & Extraction section \\
\hline 12 to 11 & 10 & 10 & 0 & 0 & 0 & 0 & 0 & Extraction section \\
\hline 13 to 12 & 10 & 10 & 0 & 0 & 0 & 0 & 0 & Extraction section \\
\hline 14 to 13 & 20 & 20 & 20 & 30 & 0 & 0 & 0 & Extraction section \\
\hline 15 to 14 & 20 & 20 & 0 & 0 & 10 & 10 & 0 & Extraction section \\
\hline 16 to 15 & - & - & - & - & - & - & - & $\begin{array}{l}\text { Cannot see as metal } \\
\text { interstage line with DF } \\
\text { feed tube }\end{array}$ \\
\hline 17 to 16 & 10 & 10 & 0 & 0 & 0 & 10 & 0 & Scrub section \\
\hline 18 to 17 & - & - & - & - & - & - & - & $\begin{array}{l}\text { Aqueous effluent, no } \\
\text { interstage line }\end{array}$ \\
\hline 19 to 18 & 10 & 10 & 10 & 10 & 0 & 0 & 10 & Strip section \\
\hline 20 to 19 & 10 & 10 & 0 & 0 & 0 & 0 & 0 & Strip section \\
\hline 21 to 20 & 10 & 10 & 0 & 0 & 0 & 0 & 0 & Strip section \\
\hline 22 to 21 & 10 & 10 & 0 & 0 & 0 & 0 & 0 & Strip section \\
\hline 23 to 22 & 10 & 10 & 0 & 0 & 0 & 0 & 0 & Strip section \\
\hline 24 to 23 & 10 & 10 & 0 & 0 & 0 & 0 & 0 & Strip section \\
\hline 25 to 24 & 10 & 10 & 0 & 0 & 0 & 0 & 0 & Strip section \\
\hline 26 to 25 & 10 & 10 & 0 & 10 & 10 & 0 & 10 & Strip section \\
\hline 27 to 26 & $95^{\mathrm{b}}$ & $95^{\mathrm{b}}$ & 0 & 0 & 0 & 0 & 0 & Strip section \\
\hline 28 to 27 & 80 & 70 & 10 & 0 & 0 & 0 & 0 & Strip section \\
\hline 29 to 28 & 75 & 60 & 0 & 0 & 0 & 0 & 0 & Strip section \\
\hline 30 to 29 & 10 & 10 & 10 & 0 & 15 & 10 & 10 & Strip section \\
\hline 31 to 30 & 10 & 10 & 0 & 10 & 10 & 10 & 15 & Strip section \\
\hline 32 to 31 & 10 & 10 & 0 & 0 & 0 & 0 & 0 & Strip section \\
\hline
\end{tabular}

${ }^{\mathrm{a}}$ Shows stage where flow enters interstage line and stage where flows exits.

${ }^{\mathrm{b}}$ White material (emulsion) in interstage line. 
Table 21. Liquid Levels in Organic Interstage Lines during CSSX Flowsheet Tests

\begin{tabular}{|c|c|c|c|c|c|c|c|c|}
\hline \multirow[b]{3}{*}{ Line $^{a}$} & \multicolumn{7}{|c|}{$\begin{array}{l}\text { Amount of Liquid in Organic Interstage Lines during Test, } \\
\%\end{array}$} & \multirow[b]{3}{*}{ Notes } \\
\hline & \multicolumn{2}{|c|}{ CS23 } & \multicolumn{2}{|c|}{ CS24 } & \multicolumn{3}{|c|}{ CS25 } & \\
\hline & $46 \mathrm{~min}$ & $88 \mathrm{~min}$ & $\begin{array}{c}36 \text { to } 47 \\
\min \end{array}$ & $\begin{array}{l}64 \text { to } 92 \\
\min \end{array}$ & $75 \mathrm{~min}$ & $105 \mathrm{~min}$ & $150 \mathrm{~min}$ & \\
\hline 1 to 2 & 10 & 20 & 50 & 30 & 15 & 10 & 0 & Extraction section \\
\hline 2 to 3 & 30 & 10 & 10 & 10 & 10 & 0 & 0 & Extraction section \\
\hline 3 to 4 & 10 & 10 & 10 & 0 & 90 & 90 & 90 & Extraction section \\
\hline 4 to 5 & 10 & 10 & 20 & 0 & 80 & 50 & 50 & Extraction section \\
\hline 5 to 6 & 20 & 30 & 30 & 0 & 10 & 15 & 10 & Extraction section \\
\hline 6 to 7 & 20 & 10 & 20 & 10 & 15 & 0 & 0 & Extraction section \\
\hline 7 to 8 & 30 & 20 & 30 & 20 & 15 & 0 & 0 & Extraction section \\
\hline 8 to 9 & 10 & 15 & 20 & 10 & 60 & 0 & 60 & Extraction section \\
\hline 9 to 10 & 10 & 10 & 0 & 0 & 60 & 60 & 50 & Extraction section \\
\hline 10 to 11 & 60 & 60 & 50 & 50 & 60 & 60 & 60 & Extraction section \\
\hline 11 to 12 & 15 & 15 & 30 & 80 & 0 & 0 & 0 & Extraction section \\
\hline 12 to 13 & 50 & 50 & 80 & 80 & 0 & 0 & 0 & Extraction section \\
\hline 13 to 14 & 60 & 50 & 90 & 80 & 30 & 30 & 25 & Extraction section \\
\hline 14 to 15 & 60 & 60 & 80 & 80 & 30 & 30 & 25 & Extraction section \\
\hline 15 to 16 & 10 & 10 & 0 & 0 & 10 & 0 & 0 & Extraction to scrub \\
\hline 16 to 17 & 10 & 10 & 0 & 0 & 10 & 0 & 0 & Scrub section \\
\hline 17 to 18 & 10 & 10 & 10 & 0 & 0 & 0 & 0 & Scrub to strip \\
\hline 18 to 19 & 10 & 10 & 10 & 0 & 0 & 0 & 0 & Strip section \\
\hline 19 to 20 & 10 & 10 & 0 & 0 & 0 & 0 & 0 & Strip section \\
\hline 20 to 21 & 10 & 10 & 0 & 0 & 0 & 0 & 0 & Strip section \\
\hline 21 to 22 & 10 & 10 & 0 & 0 & 0 & 0 & 0 & Strip section \\
\hline 22 to 23 & 10 & 10 & 0 & 0 & 0 & 0 & 0 & Strip section \\
\hline 23 to 24 & 10 & 10 & 0 & 0 & 0 & 0 & 0 & Strip section \\
\hline 24 to 25 & 20 & 10 & 0 & 0 & 0 & 0 & 0 & Strip section \\
\hline 25 to 26 & 30 & 30 & 0 & 0 & 0 & 0 & 0 & Strip section \\
\hline 26 to 27 & 15 & 30 & 0 & 0 & 0 & 0 & 0 & Strip section \\
\hline 27 to 28 & 50 & 60 & 0 & 10 & 0 & 0 & 0 & Strip section \\
\hline 28 to 29 & 10 & 10 & 0 & 0 & 0 & 0 & 0 & Strip section \\
\hline 29 to 30 & 10 & 10 & 0 & 0 & 0 & 0 & 0 & Strip section \\
\hline 30 to 31 & 10 & 10 & 0 & 0 & 0 & 0 & 0 & Strip section \\
\hline 31 to 32 & 10 & 10 & 0 & 0 & 0 & 0 & 0 & Strip section \\
\hline
\end{tabular}

${ }^{\mathrm{a}}$ Shows stage where flow enters interstage line and stage where flows exits. 


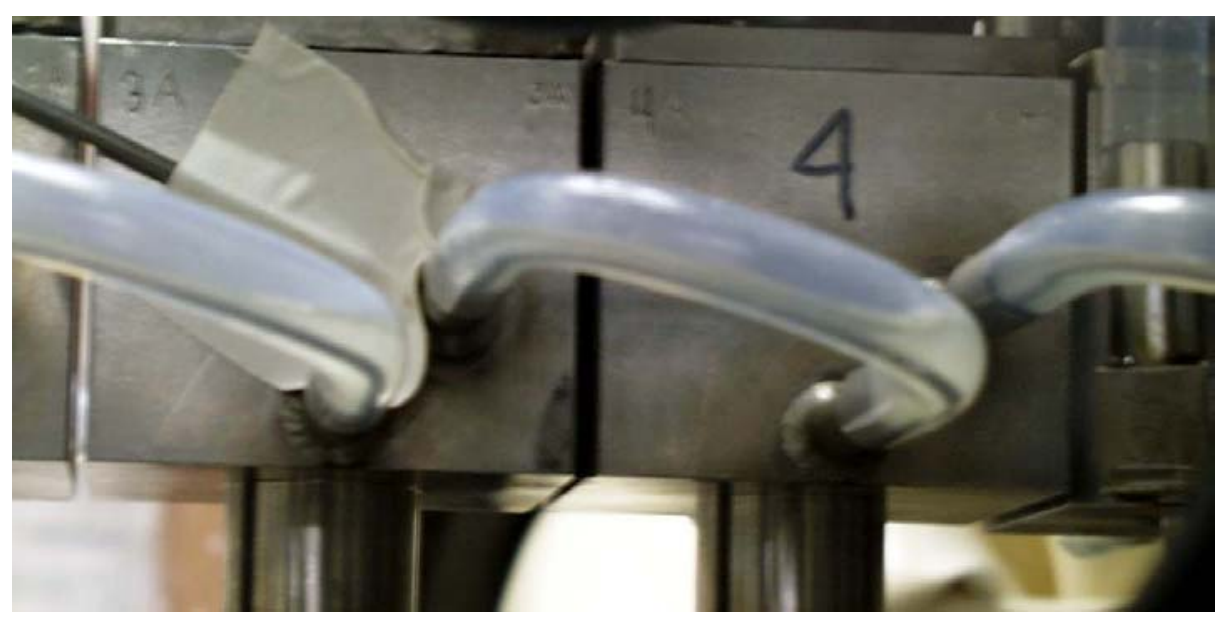

(a) $\mathrm{t}=11 \min 30 \mathrm{~s}$

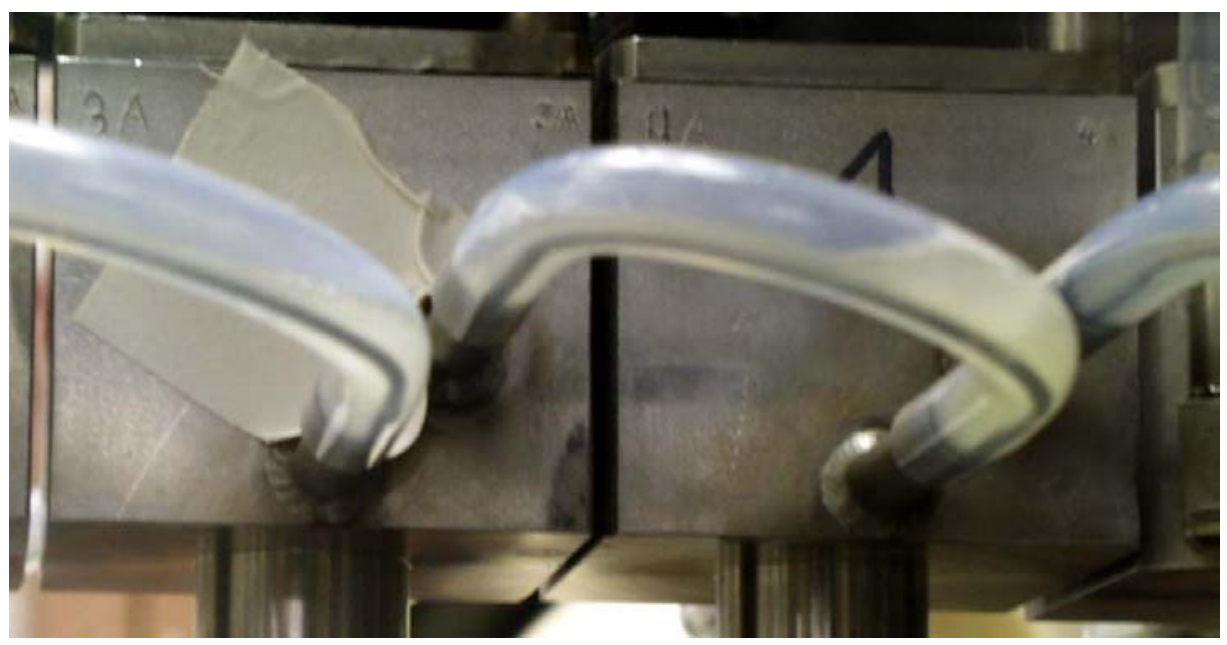

(b) $t=11 \min 46 \mathrm{~s}$

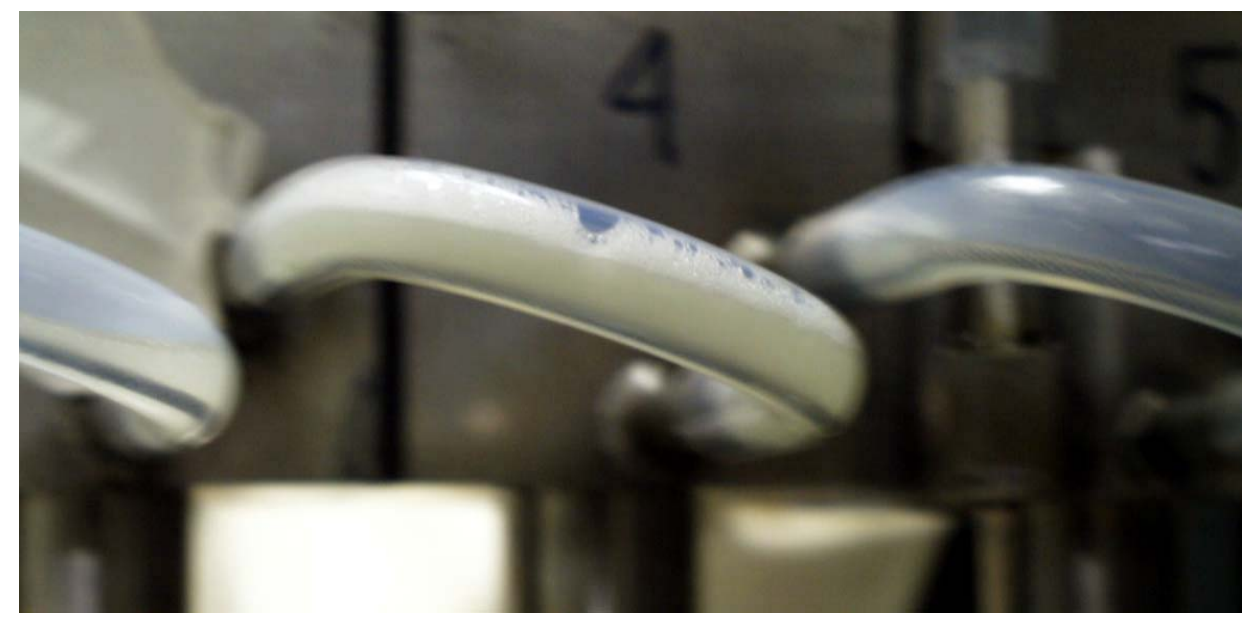

(c) $\mathrm{t}=21 \min 0 \mathrm{~s}$

Fig. 18. Liquid Level Changes in the Organic Interstage Line from Stage 3 to Stage 4 during CSSX Flowsheet Test CS25 


\section{Measurements and Observations after the Tests}

After each test, the two immiscible liquids in each stage were drained, and their volumes and temperature measured. They were equilibrated by shaking for $15-20 \mathrm{~s}$ in the $60-\mathrm{mL}$ collection bottles. After equilibration, the temperature was measured again. The two phases were separated, and each phase was analyzed for its cesium concentration. This gives a $\mathrm{D}_{\mathrm{Cs}}$ value at a known temperature for each process stage. The stage-sample results after the flowsheet tests are summarized in Tables 22, 23, and 24. 
Table 22. Stage Samples Taken after CSSX Flowsheet Test CS23

\begin{tabular}{|c|c|c|c|c|c|c|c|c|c|}
\hline Stage & \begin{tabular}{|c|} 
Aq \\
Vol in \\
Stage \\
after \\
Test, \\
$\mathrm{mL}$ \\
\end{tabular} & $\begin{array}{c}\text { Org } \\
\text { Vol in } \\
\text { Stage } \\
\text { after } \\
\text { Test, } \\
\mathrm{mL} \\
\end{array}$ & $\begin{array}{c}\text { Temp } \\
\text { when } \\
\text { Drain } \\
\text { Stage } \\
\text { Liquid, } \\
{ }^{\circ} \mathrm{C}\end{array}$ & $\begin{array}{c}\text { Time } \\
\text { when } \\
\text { Meas'd } \\
\text { Temp, }{ }^{\text {a }} \\
\text { min } \\
\end{array}$ & $\begin{array}{c}\text { Est'd } \\
\text { Temp }^{\mathrm{b}} \text { in } \\
\text { Stage } \\
\text { during } \\
\text { Test, }^{\circ} \mathrm{C}\end{array}$ & $\begin{array}{c}\text { [Cs] in A } \\
\text { after } \\
\text { Equilibrated } \\
\text { Phases, } \mathrm{M}\end{array}$ & $\begin{array}{c}{[\mathrm{Cs}] \text { in } \mathrm{O}} \\
\text { after } \\
\text { Equilibrated } \\
\text { Phases, } \underline{\mathrm{M}}\end{array}$ & $\begin{array}{c}\text { Temp of } \\
\text { Equilibration, } \\
{ }^{\circ} \mathrm{C}\end{array}$ & $\begin{array}{c}\mathrm{D}_{\mathrm{Cs}} \text { at Temp } \\
\text { of } \\
\text { Equilibration }\end{array}$ \\
\hline 1 & 20 & 5 & 34.9 & 3 & 37 & $1.10 \mathrm{E}-07$ & $1.80 \mathrm{E}-06$ & 26.0 & 16.4 \\
\hline 2 & 17 & 11 & 35.4 & 5.5 & 38 & $2.02 \mathrm{E}-07$ & $3.13 \mathrm{E}-06$ & 26.5 & 15.5 \\
\hline 3 & 27 & 7 & 35.9 & 10 & 39 & $2.70 \mathrm{E}-07$ & $4.25 \mathrm{E}-06$ & 26.4 & 15.7 \\
\hline 4 & 23 & 7 & 34.9 & 14 & 38 & 2.89E-07 & $4.60 \mathrm{E}-06$ & 26.1 & 15.9 \\
\hline 5 & 25 & 9 & 35.6 & 17 & 37 & $3.43 \mathrm{E}-07$ & $5.21 \mathrm{E}-06$ & 26.6 & 15.2 \\
\hline 6 & 29 & 9 & 35.4 & 19 & 36 & 4.69E-07 & $6.98 \mathrm{E}-06$ & 26.9 & 14.9 \\
\hline 7 & 20 & 10 & 34.9 & 22 & 35 & $5.07 \mathrm{E}-07$ & $7.73 \mathrm{E}-06$ & 26.6 & 15.2 \\
\hline 8 & 18 & 6 & 34.3 & 23 & 34 & $7.81 \mathrm{E}-07$ & $1.20 \mathrm{E}-05$ & 26.5 & 15.4 \\
\hline 9 & 18 & 2 & 33.2 & 29 & 33 & 1.19E-06 & $1.93 \mathrm{E}-05$ & 26.6 & 16.2 \\
\hline 10 & N/M & N/M & 33.1 & 32 & 32 & $1.61 \mathrm{E}-06$ & $2.69 \mathrm{E}-05$ & 25.7 & 16.7 \\
\hline 11 & N/M & $\mathrm{N} / \mathrm{M}$ & 32.7 & 35 & 30.5 & $1.92 \mathrm{E}-06$ & $3.25 \mathrm{E}-05$ & 25.5 & 16.9 \\
\hline 12 & N/M & $\mathrm{N} / \mathrm{M}$ & 31.8 & 37 & 29.5 & $3.98 \mathrm{E}-06$ & $6.60 \mathrm{E}-05$ & 25.5 & 16.6 \\
\hline 13 & N/M & $\mathrm{N} / \mathrm{M}$ & 31.6 & 39 & 29 & $6.66 \mathrm{E}-06$ & $1.11 \mathrm{E}-04$ & 25.6 & 16.7 \\
\hline 14 & N/M & $\mathrm{N} / \mathrm{M}$ & 31.3 & 42 & 28 & $1.24 \mathrm{E}-05$ & $2.06 \mathrm{E}-04$ & 25.8 & 16.6 \\
\hline 15 & N/M & $\mathrm{N} / \mathrm{M}$ & 31.0 & 45 & 26 & $2.97 \mathrm{E}-05$ & $4.90 \mathrm{E}-04$ & 24.9 & 16.5 \\
\hline 16 & 10 & 10 & 31.4 & 5 & 28 & $1.76 \mathrm{E}-04$ & $8.85 \mathrm{E}-04$ & 29.6 & 5.0 \\
\hline 17 & 8 & 10 & 32.5 & 8 & 27 & $8.46 \mathrm{E}-04$ & 5.31E-04 & 30.9 & 0.63 \\
\hline 18 & N/M & N/M & 32.8 & 45 & 33 & $1.68 \mathrm{E}-03$ & $2.75 \mathrm{E}-04$ & 26.1 & 0.164 \\
\hline 19 & N/M & $\mathrm{N} / \mathrm{M}$ & 33.4 & 42 & 34 & $3.50 \mathrm{E}-04$ & $4.07 \mathrm{E}-05$ & 25.5 & 0.116 \\
\hline 20 & N/M & $\mathrm{N} / \mathrm{M}$ & 32.7 & 39 & 34 & $7.65 \mathrm{E}-05$ & $6.61 \mathrm{E}-06$ & 25.8 & 0.086 \\
\hline 21 & N/M & $\mathrm{N} / \mathrm{M}$ & 32.6 & 36 & 34 & $1.35 \mathrm{E}-05$ & 1.19E-06 & N/M & 0.088 \\
\hline 22 & 10 & 7 & 32.5 & 34 & 34 & $5.90 \mathrm{E}-06$ & 4.19E-07 & 27.2 & 0.071 \\
\hline 23 & 10 & 7 & 32.3 & 31 & 34 & $1.56 \mathrm{E}-06$ & $1.11 \mathrm{E}-07$ & 26.8 & 0.071 \\
\hline 24 & 11 & 6 & 32.8 & 27 & 34 & $5.76 \mathrm{E}-07$ & $4.08 \mathrm{E}-08$ & 26.9 & 0.071 \\
\hline 25 & 10 & 10 & 33.2 & 23 & 34 & $9.06 \mathrm{E}-08$ & $9.32 \mathrm{E}-09$ & 27.3 & 0.103 \\
\hline 26 & 9 & 22 & 34.1 & 20 & 34 & $3.47 \mathrm{E}-08$ & $3.23 \mathrm{E}-09$ & 27.0 & 0.093 \\
\hline 27 & 9 & 26 & 34.3 & 17 & 34 & $3.95 \mathrm{E}-08$ & $2.97 \mathrm{E}-09$ & 26.9 & 0.075 \\
\hline 28 & 9 & 23 & 34.1 & 15 & 34 & $3.75 \mathrm{E}-08$ & $4.28 \mathrm{E}-09$ & 26.9 & 0.114 \\
\hline 29 & 8 & 14 & 34.8 & 12 & 34 & $4.47 \mathrm{E}-08$ & $5.32 \mathrm{E}-09$ & 26.8 & 0.119 \\
\hline 30 & 10 & 7 & 34.0 & 10 & 34 & 1.09E-08 & $1.75 \mathrm{E}-09$ & 27.1 & 0.161 \\
\hline 31 & 10 & 10 & 33.4 & 7 & 33 & $2.14 \mathrm{E}-08$ & $3.49 \mathrm{E}-09$ & 26.7 & 0.163 \\
\hline 32 & 8 & 12 & 31.8 & 4 & 33 & $4.02 \mathrm{E}-08$ & $2.21 \mathrm{E}-09$ & 26.4 & 0.055 \\
\hline
\end{tabular}

${ }^{\mathrm{a}}$ This gives the time between when the test was stopped and the temperature of the drained stage samples was measured.

${ }^{b}$ This estimate of stage temperature takes into account the effluent temperatures, the room temperature, the temperature of the stage samples, the time the samples had to cool off or heat up before their temperature was measured, and, when available, the contactor block temperature. More weight was given to the effluent temperatures than to the stage temperatures. 
Table 23. Stage Samples Taken after CSSX Flowsheet Test CS24

\begin{tabular}{|c|c|c|c|c|c|c|c|c|c|}
\hline Stage & $\begin{array}{c}\text { Aq Vol } \\
\text { in Stage } \\
\text { after } \\
\text { Test, } \mathrm{mL}\end{array}$ & $\begin{array}{l}\text { Org Vol } \\
\text { in Stage } \\
\text { after } \\
\text { Test, mL }\end{array}$ & $\begin{array}{c}\text { Temp } \\
\text { when } \\
\text { Drain } \\
\text { Stage } \\
\text { Liquid, }{ }^{\circ} \mathrm{C}\end{array}$ & \begin{tabular}{|c|} 
Time \\
when \\
Meas'd \\
Temp, ${ }^{a}$ \\
min \\
\end{tabular} & $\begin{array}{c}\text { Est'd } \\
\text { Temp }^{\mathrm{b}} \\
\text { in Stage } \\
\text { during } \\
\text { Test, }^{\circ} \mathrm{C}\end{array}$ & $\begin{array}{c}\text { [Cs] in A } \\
\text { after } \\
\text { Equilibrated } \\
\text { Phases, } \mathrm{M}\end{array}$ & $\begin{array}{c}{[\mathrm{Cs}] \text { in } \mathrm{O}} \\
\text { after } \\
\text { Equilibrated } \\
\text { Phases, } \underline{\mathrm{M}}\end{array}$ & $\begin{array}{c}\text { Temp of } \\
\text { Equilibration, } \\
{ }^{\circ} \mathrm{C}\end{array}$ & $\begin{array}{c}\mathrm{D}_{\mathrm{Cs}} \text { at Temp } \\
\text { of } \\
\text { Equilibration }\end{array}$ \\
\hline 1 & 19 & 2 & 26.4 & 4 & 31 & $6.02 \mathrm{E}-09$ & $1.22 \mathrm{E}-07$ & 20.0 & 20.2 \\
\hline 2 & 18 & 7 & 28.0 & 6 & 32 & $2.89 \mathrm{E}-09$ & $4.27 \mathrm{E}-08$ & 19.8 & 14.8 \\
\hline 3 & 22 & 8 & 28.2 & 9 & 33 & 3.34E-09 & $5.06 \mathrm{E}-08$ & 19.7 & 15.2 \\
\hline 4 & 20 & 7 & 27.7 & 10 & 32 & $3.12 \mathrm{E}-09$ & $4.20 \mathrm{E}-08$ & 20.0 & 13.5 \\
\hline & 27 & 8 & 27.4 & 13 & 31 & $4.82 \mathrm{E}-09$ & 8.97E-08 & 19.7 & 18.6 \\
\hline 6 & 22 & 13 & 28.0 & 15 & 30 & $5.02 \mathrm{E}-09$ & $1.08 \mathrm{E}-07$ & 19.9 & 21.6 \\
\hline 7 & 21 & 11 & 27.4 & 18 & 29 & $7.95 \mathrm{E}-09$ & $1.77 \mathrm{E}-07$ & 19.9 & 22.3 \\
\hline 8 & 21 & 11 & 26.4 & 20 & 28 & 8.46E-09 & $1.98 \mathrm{E}-07$ & 19.8 & 23.4 \\
\hline 9 & 20 & 10 & 26.1 & 24 & 27 & $1.48 \mathrm{E}-08$ & 3.37E-07 & 19.7 & 22.8 \\
\hline 10 & 18 & 8 & 25.7 & 25 & 26 & $3.10 \mathrm{E}-08$ & 7.94E-07 & 19.7 & 25.6 \\
\hline 11 & 20 & $12^{\mathrm{c}}$ & 24.9 & 27 & 24.5 & $5.39 \mathrm{E}-08$ & $1.40 \mathrm{E}-06$ & 19.7 & 26.0 \\
\hline 12 & 20 & $20^{c}$ & 23.4 & 30 & 23 & $1.47 \mathrm{E}-07$ & $4.06 \mathrm{E}-06$ & 19.6 & 27.7 \\
\hline 13 & 29 & 19 & 22.6 & 32 & 22 & $6.97 \mathrm{E}-07$ & $1.97 \mathrm{E}-05$ & 19.6 & 28.3 \\
\hline 14 & 25 & 17 & 21.7 & 34 & 20 & $2.11 \mathrm{E}-06$ & 5.91E-05 & 19.5 & 28.1 \\
\hline 15 & 21 & 14 & 21.0 & 36 & 17 & $8.50 \mathrm{E}-06$ & $2.13 \mathrm{E}-04$ & 19.5 & 25.1 \\
\hline 16 & 13 & 7 & 22.7 & 11 & 22 & $2.73 \mathrm{E}-05$ & 5.33E-04 & 19.8 & 19.5 \\
\hline 17 & 5 & 15 & 24.3 & 17 & 21 & $1.84 \mathrm{E}-04$ & $4.78 \mathrm{E}-04$ & 19.8 & 2.59 \\
\hline 18 & 10 & 14 & 20.9 & 54 & 23 & $1.50 \mathrm{E}-03$ & $6.48 \mathrm{E}-04$ & 19.1 & 0.431 \\
\hline 19 & 9 & 12 & 26.6 & 51 & 28 & $9.08 \mathrm{E}-04$ & 2.42E-04 & 19.1 & 0.267 \\
\hline 20 & 10 & 10 & 26.1 & 49 & 32 & $4.67 \mathrm{E}-04$ & $9.90 \mathrm{E}-05$ & 19.7 & 0.212 \\
\hline 21 & 9 & 10 & 25.4 & 43 & 34 & $1.56 \mathrm{E}-04$ & $2.85 \mathrm{E}-05$ & 19.2 & 0.182 \\
\hline 22 & 10 & 9 & 25.4 & 39 & 34 & $6.87 \mathrm{E}-05$ & $1.24 \mathrm{E}-05$ & 18.9 & 0.180 \\
\hline 23 & 9 & 11 & 26.7 & 37 & 34 & $3.35 \mathrm{E}-05$ & $5.12 \mathrm{E}-06$ & 19.2 & 0.153 \\
\hline 24 & 10 & 8 & 26.8 & 34 & 34 & $1.24 \mathrm{E}-05$ & $1.84 \mathrm{E}-06$ & 19.7 & 0.149 \\
\hline 25 & 10 & 14 & 28.0 & 27 & 34 & $1.96 \mathrm{E}-06$ & $3.06 \mathrm{E}-07$ & 18.8 & 0.157 \\
\hline 26 & 8 & 11 & 28.7 & 25 & 34 & 4.60E-07 & $6.49 \mathrm{E}-08$ & 19.3 & 0.141 \\
\hline 27 & 10 & 11 & 28.6 & 22 & 34 & $1.93 \mathrm{E}-07$ & $2.29 \mathrm{E}-08$ & 19.5 & 0.119 \\
\hline 28 & 10 & 11 & 27.5 & 20 & 34 & $1.07 \mathrm{E}-07$ & $1.36 \mathrm{E}-08$ & 19.7 & 0.127 \\
\hline 29 & 9 & 12 & 27.4 & 17 & 34 & 4.89E-08 & 5.67E-09 & 19.4 & 0.116 \\
\hline 30 & 9 & $5^{\mathrm{d}}$ & 27.3 & 13 & 34 & 1.09E-07 & $1.45 \mathrm{E}-08$ & 19.7 & 0.133 \\
\hline 31 & 10 & 12 & 28.5 & 10 & 33 & $2.38 \mathrm{E}-08$ & $3.53 \mathrm{E}-09$ & 19.3 & 0.148 \\
\hline 32 & 7 & 15 & 24.9 & 7 & 26 & $1.07 \mathrm{E}-07$ & 7.84E-09 & 19.6 & 0.073 \\
\hline
\end{tabular}

a This gives the time between when the test was stopped and the temperature of the drained stage samples was measured.

b This estimate of stage temperature takes into account the effluent temperatures, the room temperature, the temperature of the stage samples, the time the samples had to cool off or heat up before their temperature was measured, and, when available, the contactor block temperature. More weight was given to the effluent temperatures than to the stage temperatures.

c Some liquid spilt.

d Drains slow. 
Table 24. Stage Samples Taken after CSSX Flowsheet Test CS25

\begin{tabular}{|c|c|c|c|c|c|c|c|c|c|}
\hline Stage & $\begin{array}{l}\text { Aq Vol } \\
\text { in Stage } \\
\text { after } \\
\text { Test, mL }\end{array}$ & $\begin{array}{c}\text { Org Vol } \\
\text { in Stage } \\
\text { after } \\
\text { Test, } \mathrm{mL}\end{array}$ & $\begin{array}{l}\text { Temp } \\
\text { when } \\
\text { Drain } \\
\text { Stage } \\
\text { Liquid, } \\
{ }^{\circ} \mathrm{C}\end{array}$ & $\begin{array}{c}\text { Time } \\
\text { when } \\
\text { Meas'd } \\
\text { Temp, }{ }^{\text {a }} \\
\text { min }\end{array}$ & $\begin{array}{c}\text { Est'd } \\
\text { Temp }^{\mathrm{b}} \\
\text { in Stage } \\
\text { during } \\
\text { Test, }{ }^{\circ} \mathrm{C}\end{array}$ & $\begin{array}{c}\text { [Cs] in A } \\
\text { after } \\
\text { Equilibrated } \\
\text { Phases, } \underline{M}\end{array}$ & $\begin{array}{c}{[\mathrm{Cs}] \text { in } \mathrm{O}} \\
\text { after } \\
\text { Equilibrated } \\
\text { Phases, } \mathrm{M}\end{array}$ & $\begin{array}{c}\text { Temp of } \\
\begin{array}{c}\text { Equilibration, } \\
{ }^{\circ} \mathrm{C}\end{array}\end{array}$ & $\begin{array}{c}\mathrm{D}_{\mathrm{Cs}} \text { at Temp } \\
\text { of } \\
\text { Equilibration }\end{array}$ \\
\hline 1 & 16 & 17 & 29.6 & 6 & 31 & $4.91 \mathrm{E}-09$ & $1.18 \mathrm{E}-07$ & 19.0 & 24.0 \\
\hline 2 & 22 & 20 & 30.1 & 9 & 32 & $3.62 \mathrm{E}-09$ & 7.72E-08 & 19.0 & 21.3 \\
\hline 3 & 26 & 15 & 30.8 & 11 & 33 & $1.82 \mathrm{E}-09$ & $2.89 \mathrm{E}-08$ & 19.1 & 15.9 \\
\hline 4 & 30 & 14 & 30.3 & 14 & 32 & $1.62 \mathrm{E}-09$ & 2.39E-08 & 19.0 & 14.8 \\
\hline 5 & 31 & 15 & 28.8 & 17 & 31 & 2.82E-09 & $6.17 \mathrm{E}-08$ & 19.0 & 21.8 \\
\hline 6 & 20 & 10 & 30.2 & 20 & 30 & $8.86 \mathrm{E}-09$ & $2.03 \mathrm{E}-07$ & 19.4 & 22.9 \\
\hline 7 & 20 & 9 & 29.4 & 22 & 29 & $1.34 \mathrm{E}-08$ & $3.63 \mathrm{E}-07$ & 19.2 & 27.2 \\
\hline 8 & 17 & 9 & 28.2 & 24 & 28 & $1.31 \mathrm{E}-08$ & $3.42 \mathrm{E}-07$ & 19.6 & 26.1 \\
\hline 9 & 20 & 15 & 27.7 & 26 & 27 & $1.84 \mathrm{E}-08$ & $5.02 \mathrm{E}-07$ & 19.4 & 27.2 \\
\hline 10 & 22 & 15 & 26.5 & 29 & 26 & $4.26 \mathrm{E}-08$ & $1.19 \mathrm{E}-06$ & 19.4 & 27.9 \\
\hline 11 & 22 & 10 & 25.8 & 31 & 24.5 & $1.02 \mathrm{E}-07$ & $2.97 \mathrm{E}-06$ & 19.3 & 29.0 \\
\hline 12 & 15 & 11 & 24.6 & 33 & 23 & $3.02 \mathrm{E}-07$ & $8.84 \mathrm{E}-06$ & 19.5 & 29.3 \\
\hline 13 & 20 & 10 & 23.3 & 39 & 22 & $9.75 \mathrm{E}-07$ & $2.82 \mathrm{E}-05$ & 19.5 & 28.9 \\
\hline 14 & 20 & 15 & 22.6 & 41 & 20 & $3.89 \mathrm{E}-06$ & $1.11 \mathrm{E}-04$ & 19.3 & 28.5 \\
\hline 15 & 17 & 12 & 21.9 & 44 & 17 & $1.31 \mathrm{E}-05$ & $3.36 \mathrm{E}-04$ & 19.1 & 25.6 \\
\hline 16 & 10 & 12 & 23.8 & 13 & 22 & $5.87 \mathrm{E}-05$ & $6.90 \mathrm{E}-04$ & 19.7 & 11.8 \\
\hline 17 & 8 & 14 & 26.5 & 15 & 21 & $2.23 \mathrm{E}-04$ & $6.10 \mathrm{E}-04$ & 19.1 & 2.73 \\
\hline 18 & 10 & 9 & 27.5 & 43 & 25 & $1.52 \mathrm{E}-03$ & $6.22 \mathrm{E}-04$ & 20.5 & 0.410 \\
\hline 19 & 10 & 11 & 28.6 & 40 & 30 & $5.18 \mathrm{E}-04$ & $1.35 \mathrm{E}-04$ & 20.3 & 0.261 \\
\hline 20 & 10 & 10 & 27.9 & 38 & 32 & $1.65 \mathrm{E}-04$ & $3.49 \mathrm{E}-05$ & 20.4 & 0.211 \\
\hline 21 & 10 & 9 & 27.0 & 34 & 34 & $3.73 \mathrm{E}-05$ & $8.51 \mathrm{E}-06$ & 20.5 & 0.228 \\
\hline 22 & 10 & 10 & 27.5 & 32 & 34 & $1.85 \mathrm{E}-05$ & $3.26 \mathrm{E}-06$ & 20.6 & 0.176 \\
\hline 23 & 10 & 10 & 27.8 & 30 & 34 & $5.41 \mathrm{E}-06$ & $9.03 \mathrm{E}-07$ & 20.5 & 0.167 \\
\hline 24 & 11 & 8 & 28.0 & 28 & 34 & $1.40 \mathrm{E}-06$ & $2.27 \mathrm{E}-07$ & 20.5 & 0.163 \\
\hline 25 & 10 & 11 & 29.4 & 24 & 34 & $2.40 \mathrm{E}-07$ & $3.85 \mathrm{E}-08$ & 20.7 & 0.160 \\
\hline 26 & 7 & $5^{\mathrm{c}}$ & 28.9 & 22 & 34 & $4.43 \mathrm{E}-08$ & $7.42 \mathrm{E}-09$ & 21.0 & 0.168 \\
\hline 27 & 10 & 10 & 30.5 & 21 & 34 & $3.02 \mathrm{E}-08$ & $4.22 \mathrm{E}-09$ & 21.0 & 0.140 \\
\hline 28 & 10 & 12 & 27.5 & 19 & 34 & $2.59 \mathrm{E}-08$ & $4.15 \mathrm{E}-09$ & 21.0 & 0.160 \\
\hline 29 & 10 & 11 & 29.5 & 15 & 34 & $1.23 \mathrm{E}-08$ & $1.75 \mathrm{E}-09$ & 20.8 & 0.142 \\
\hline 30 & 12 & 11 & 30.9 & 12 & 34 & $1.21 \mathrm{E}-07$ & $1.55 \mathrm{E}-08$ & 21.1 & 0.128 \\
\hline 31 & 12 & 9 & 30.6 & 10 & 30 & $1.20 \mathrm{E}-08$ & $1.94 \mathrm{E}-09$ & 20.6 & 0.162 \\
\hline 32 & 8 & 14 & 27.2 & 8 & 27 & $3.28 \mathrm{E}-08$ & $3.20 \mathrm{E}-09$ & 20.4 & 0.098 \\
\hline
\end{tabular}

a This gives the time between when the test was stopped and the temperature of the drained stage samples was measured.

b This estimate of stage temperature takes into account the effluent temperatures, the room temperature, the temperature of the stage samples, the time the samples had to cool off or heat up before their temperature was measured, and, when available, the contactor block temperature. More weight was given to the effluent temperatures than to the stage temperatures.

c Some liquid spilt. 
The concentrations $\mathrm{Na}, \mathrm{Al}$, and $\mathrm{K}$ in the aqueous strip (EW) effluent with the Cs were measured. The results are given in Table 25. They show that, for all three CSSX flowsheet tests, cesium was the major cation in the EW effluent.

Table 25. Composition of the Aqueous Strip Effluent for the CSSX Flowsheet Tests

\begin{tabular}{|c|c|c|c|c|}
\hline Test & Component & $\begin{array}{c}\text { Conc. in } \\
\text { Extraction } \\
\text { (DF) Feed, } \\
\mathrm{mM}\end{array}$ & $\begin{array}{c}\text { Conc. in } \\
\text { Aqueous (EW) } \\
\text { Strip Effluent, } \\
\mathrm{mM}\end{array}$ & $\begin{array}{c}\text { Amt. that Component in } \\
\text { DF Extracted into EW } \\
\text { Effluent Relative to Cs, \% }\end{array}$ \\
\hline CS23 & $\mathrm{Cs}$ & 0.14 & 2.10 & Not Applicable \\
\hline $\mathrm{CS} 23$ & $\mathrm{Na}$ & 5,600 & 0.65 & 0.0008 \\
\hline $\mathrm{CS} 23$ & $\mathrm{Al}$ & 280 & 0.014 & 0.0003 \\
\hline $\mathrm{CS} 23$ & $\mathrm{~K}$ & 15 & 0.18 & 0.08 \\
\hline $\mathrm{CS} 24$ & $\mathrm{Cs}$ & 0.14 & 2.10 & Not Applicable \\
\hline $\mathrm{CS} 24$ & $\mathrm{Na}$ & 5,600 & 1.16 & 0.0014 \\
\hline $\mathrm{CS} 24$ & $\mathrm{Al}$ & 280 & 0.010 & 0.0002 \\
\hline $\mathrm{CS} 24$ & $\mathrm{~K}$ & 15 & 0.96 & Not Applicable \\
\hline $\mathrm{CS} 25$ & $\mathrm{Cs}$ & 0.14 & 2.10 & 0.0007 \\
\hline $\mathrm{CS} 25$ & $\mathrm{Na}$ & 5,600 & 0.59 & $<0.0002$ \\
\hline $\mathrm{CS} 25$ & $\mathrm{Al}$ & 280 & $<0.007$ & 0.14 \\
\hline $\mathrm{CS} 25$ & $\mathrm{~K}$ & 15 & 0.32 & \\
\hline
\end{tabular}

The concentrations for most of the components in the SRS simulant have been measured and are shown in Table 26. The techniques used were inductively coupled plasma/atomic emission spectrometry (ICP/AES), inductively coupled plasma/mass spectrometry (ICP/MS), ion chromatography (IC), and acid titration. Values are good to $\pm 10 \%$. When a measured concentration is more than expected, it is probably due to the impurities in some of the materials used to make up the SRS simulant. When the measured concentration is less than expected, some of the components may have precipitated out in the white precipitate that forms when the SRS simulant is prepared. 
Table 26. Composition of the SRS Simulant for the CSSX Flowsheet Tests

\begin{tabular}{|c|c|c|c|}
\hline Component & Measured Conc, $\underline{\mathrm{M}}$ & $\begin{array}{l}\text { Measured Conc. } \\
\text { relative to Desired } \\
\text { Conc }\end{array}$ & Measurement Method \\
\hline $\mathrm{Na}$ & 5.22 & 0.93 & ICP/AES \\
\hline $\mathrm{K}$ & 0.024 & 1.59 & ICP/AES \\
\hline $\mathrm{Al}$ & 0.276 & 0.99 & ICP/AES \\
\hline $\mathrm{Cr}$ & 0.00111 & 0.77 & ICP/AES \\
\hline $\mathrm{Fe}$ & $8.06 \mathrm{E}-05$ & 3.13 & ICP/AES \\
\hline $\mathrm{Si}$ & $3.76 \mathrm{E}-03$ & 0.13 & ICP/AES \\
\hline $\mathrm{Cu}$ & $2.74 \mathrm{E}-05$ & 1.21 & $\mathrm{ICP} / \mathrm{MS}$ \\
\hline $\mathrm{Zn}$ & $8.37 \mathrm{E}-05$ & 0.68 & ICP/MS \\
\hline Mo & $8.24 \mathrm{E}-05$ & 1.06 & ICP/MS \\
\hline $\mathrm{Ru}$ & 7.39E-06 & 0.91 & ICP/MS \\
\hline $\mathrm{Rh}$ & $1.94 \mathrm{E}-06$ & 0.95 & ICP/MS \\
\hline $\mathrm{Pd}$ & $3.19 \mathrm{E}-06$ & 0.83 & ICP/MS \\
\hline $\mathrm{Ag}$ & $<9.3 \mathrm{E}-07$ & $\mathrm{a}$ & $\mathrm{ICP} / \mathrm{MS}$ \\
\hline $\mathrm{Sn}$ & $2.07 \mathrm{E}-05$ & 1.02 & ICP/MS \\
\hline Cs & $1.36 \mathrm{E}-04$ & 0.97 & ICP/MS \\
\hline $\mathrm{Pb}$ & $9.27 \mathrm{E}-06$ & 0.91 & ICP/MS \\
\hline Nitrite & 0.45 & 0.90 & IC \\
\hline Nitrate & 1.95 & 0.96 & IC \\
\hline Sulfate & 0.13 & 0.90 & $\mathrm{IC}$ \\
\hline Formate & 0.030 & 0.91 & IC \\
\hline Fluoride & 0.0182 & 0.65 & $\mathrm{IC}$ \\
\hline Phosphate & 0.0076 & 1.09 & $\mathrm{IC}$ \\
\hline Oxalate & 0.0081 & 1.01 & $\mathrm{IC}$ \\
\hline Chloride & 0.0206 & 0.86 & $\mathrm{IC}$ \\
\hline Hydroxide & 2.37 & 1.15 & Titration \\
\hline
\end{tabular}

${ }^{\mathrm{a}}$ Desired concentration is below detection limit. 
Distribution for ANL-01/23

Internal:
S. B. Aase
R. E. Einziger
M. C. Regalbuto
H. A. Arafat
J. E. Helt
D. B. Chamberlain
R. A. Leonard (10)
Y. I. Chang
D. Lewis (2)
J. Sedlet
C. J. Conner
C. J. Mertz
M. L. Dietz
K. L. Nash
G. F. Vandegrift
TIS Files

\section{External:}

\section{DOE-OSTI}

ANL-E- Library

ANL-W-Library

Chemical Technology Division Review Committee Members:

H. U. Anderson, University of Missouri-Rolla, Rolla, MO

A. L. Bement, Jr., Purdue University, West Lafayette, IN

C. L. Hussey, University of Mississippi, University, MS

M. V. Koch, University of Washington, Seattle, WA

V. P. Roan, Jr., University of Florida, Gainesville, FL

J. R. Selman, Illinois Institute of Technology, Chicago, IL

J. S. Tulenko, University of Florida, Gainesville, FL

J. F. Birdwell, Oak Ridge National Laboratory, Oak Ridge, TN

P. V. Bonnesen, Oak Ridge National Laboratory, Oak Ridge, TN

S. Campbell, Westinghouse Savannah River Company, Aiken, SC

J. T. Carter, Westinghouse Savannah River Company, Aiken, SC

J. T. Case, USDOE, Idaho Falls, ID

N. G. Colton, Pacific Northwest National Laboratory, Richland, WA

L. H. Delmau, Oak Ridge National Laboratory, Oak Ridge, TN

S. M. Dinehart, Los Alamos National Laboratory, Los Alamos, NM

S. D. Fink, Westinghouse Savannah River Company, Aiken, SC

M. Geeting, Westinghouse Savannah River Company, Aiken, SC

A. P. Gouge, Westinghouse Savannah River Company, Aiken, SC

H. D. Harmon, Westinghouse Savannah River Company, Aiken, SC

E. P. Horwitz, Naperville, IL

R. T. Jubin, Oak Ridge National Laboratory, Oak Ridge, TN

L. N. Klatt, Oak Ridge National Laboratory, Oak Ridge, TN

D. E. Kurath, Battelle, Pacific Northwest National Laboratory, Richland, WA

K. Lang, USDOE, Washington, DC

J. D. Law, Idaho National Engineering and Environmental Laboratory, Idaho Falls, ID

G. J. Lumetta, Battelle, Pacific Northwest National Laboratory, Richland, WA

J. McCullough, USDOE, Aiken, SC

C. P. McGinnis, Oak Ridge National Laboratory, Oak Ridge, TN 
B. A. Moyer, Oak Ridge National Laboratory, Oak Ridge, TN M. Norato, Westinghouse Savannah River Company, Aiken, SC

A. L. Olson, Idaho National Engineering and Environmental Laboratory, Idaho Falls, ID

M. J. Palmer, Los Alamos National Laboratory, Los Alamos, NM

L. M. Papouchado, Westinghouse Savannah River Company, Aiken, SC

R. A. Peterson, Bechtel-Washington Process Technology, Richland, WA

S. F. Piccolo, Westinghouse Savannah River Company, Aiken, SC

R. A. Pierce, Westinghouse Savannah River Company, Aiken, SC

B. M. Rapko, Battelle, Pacific Northwest National Laboratory, Richland, WA

R. D. Rogers, University of Alabama, Tuscaloosa, AL

K. J. Rueter, Bechtel-Washington Process Technology, Richland, WA

P. Rutland, Bechtel-Washington Process Technology, Richland, WA

S. Schlahta, Battelle, Pacific Northwest National Laboratory, Richland, WA

W. W. Schulz, Albuquerque, NM

M. J. Steindler, Downers Grove, IL

J. L. Swanson, Richland, WA

W. L. Tamosaitis, Westinghouse Savannah River Company, Aiken, SC

I. R. Tasker, Universe Technologies, Frederick, MD

L. L. Tavlarides, Syracuse University, Syracuse, NY

D. W. Tedder, Georgia Institute of Technology, Atlanta, GA

M. C. Thompson, Westinghouse Savannah River Company, Aiken, SC

T. A. Todd, INEEL, Idaho Falls, ID

V. Van Brunt, University of South Carolina, Columbia, SC

D. D. Walker, Westinghouse Savannah River Company, Aiken, SC

J. S. Watson, Oak Ridge National Laboratory, Oak Ridge, TN

R. M. Wham, Oak Ridge National Laboratory, Oak Ridge, TN 
